Rochester Institute of Technology

RIT Scholar Works

Theses

$11-1-2011$

\title{
Environmental impact comparison of distributed and centralized manufacturing scenarios
}

Lionel Senyana

Follow this and additional works at: https://scholarworks.rit.edu/theses

Recommended Citation

Senyana, Lionel, "Environmental impact comparison of distributed and centralized manufacturing scenarios" (2011). Thesis. Rochester Institute of Technology. Accessed from

This Thesis is brought to you for free and open access by RIT Scholar Works. It has been accepted for inclusion in Theses by an authorized administrator of RIT Scholar Works. For more information, please contact ritscholarworks@rit.edu. 


\title{
ENVIRONMENTAL IMPACT COMPARISON OF DISTRIBUTED AND CENTRALIZED MANUFACTURING SCENARIOS
}

\author{
Thesis \\ Submitted in partial fulfillment of the \\ requirements for the degree of \\ Master of Science in Sustainable Engineering \\ in the \\ Department of Industrial \& Systems Engineering \\ Kate Gleason College of Engineering \\ by \\ Lionel Nduwayezu Senyana
}

November, 2011 


\section{DEPARTMENT OF INDUSTRIAL AND SYSTEMS ENGINEERING \\ KATE GLEASON COLLEGE OF ENGINEERING \\ ROCHESTER INSTITUTE OF TECHNOLOGY \\ ROCHESTER, NEW YORK}

CERTIFICATE OF APPROVAL

\section{MASTER OF SCIENCE DEGREE THESIS}

The M.S. Degree Thesis of Lionel Nduwayezu Senyana

has been examined and approved by the

thesis committee as satisfactory for the

thesis requirement for the

Master of Science degree

Approved by:

Dr. Denis R. Cormier (Chair of Committee)

Dr. Andres L. Carrano

Dr. Brian K. Thorn 


\section{Abstract}

Centralized manufacturing and distributed manufacturing are two fundamentally different methods for producing components. This work describes a centralized manufacturing scenario in which parts are produced via forging and finish machining at one central location and are then shipped to the end user. The distributed manufacturing model involves a scenario in which an additive manufacturing process (Electron Beam Melting) is used to produce parts to near net shape with minimal finish machining. Because the process doesn't require molds or dies, production can take place in small production quantities "on demand" at job shops located close to the end user with little transportation. In other words, parts are not produced until they are needed. This is in stark contrast to the centralized model where large quantities of parts are produced and then distributed at a later date when needed from warehouses.

The aim of this thesis is to compare the environmental impact of these two different production approaches under a variety of conditions. The SimaPro software package has been used to model both approaches with input from the user involving part size, amount of finish machining, transportation distances, mode of transportation, production quantities, etc. Results from simulation models indicate that at small production quantities, the environmental impact of forging die production dominates the centralized manufacturing model. As production quantity increases, finish machining begins to dominate the environmental impact. Despite the large transportation distances involved, the transportation distance and mode of transportation actually have relatively little impact on overall environmental impact compared with other factors. Regardless of the production scenario being evaluated, the distributed manufacturing approach had less environmental impact. The production of titanium powder as the raw material contributed the majority of environmental impact for this approach.

Although this work examines environmental impact, it does not consider the cost of producing a part. It should be pointed out, however, that the distributed manufacturing approach could someday have a profound effect on supply chain management for replacement parts by reducing or eliminating the need for warehouses along with associated inventory carrying costs, product obsolescence costs, heating and cooling energy, etc. 


\section{Acknowledgments}

I am grateful to the Rochester Institute of Technology and especially the department of Industrial and Systems Engineering for enhancing my learning and Intellectual experience.

I would like to record my sincere gratitude to Dr. Denis R. Cormier for his supervision, advice, guidance, unflinching encouragement and support from the very early stage of this research. The joy and enthusiasm he has for his research have inspired and enriched my growth as a student. I also express sincere gratitude to Dr. Andres Carrano and Dr. Brian Thorn for serving on my master's committee and providing valuable suggestions.

Thanks to Dr. Robert Parody for providing valuable information regarding design of experiment. Lastly but no means the least, I would like to thank graduate students in the Sustainable Engineering Research Group (SERG) that have greatly supported me with their incentive through the length of this research. 


\section{Table of Contents}

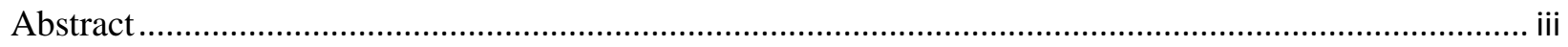

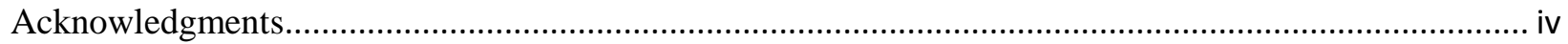

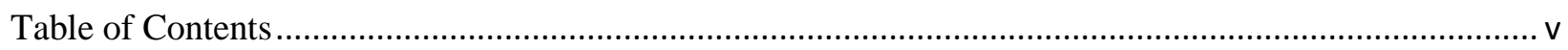

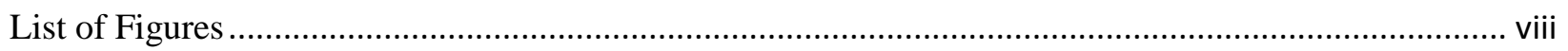

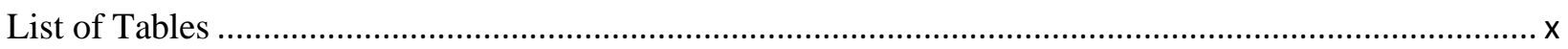

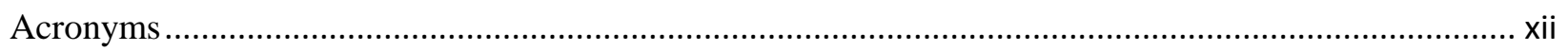

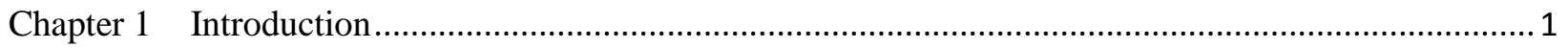

1.1. Distributed Additive Manufacturing (EBM) and Centralized Manufacturing (Forging)............. 2

1.1.1. Traditional Centralized Manufacturing ..................................................................... 2

1.1.2. Distributed Additive Manufacturing …....................................................................... 3

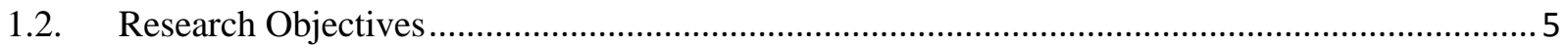

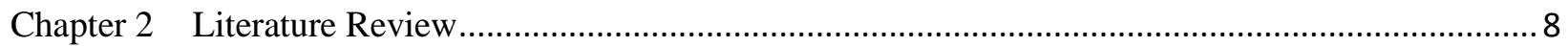

2.1. Environmental Studies Involving Traditional Manufacturing ............................................... 8

2.2. Environmental Studies Involving Rapid Prototyping (RP) .................................................. 12

2.3. Environmental Studies Involving Rapid Manufacturing ................................................. 13

2.3.1. Rapid Manufacturing (RM) Influence On Part Design .............................................. 15

2.3.2. Effect of Rapid Manufacturing on Supply Chains and Logistics.................................... 18

2.3.3. Environmental and Cost Considerations Among RM and Conventional Manufacturing ... 20

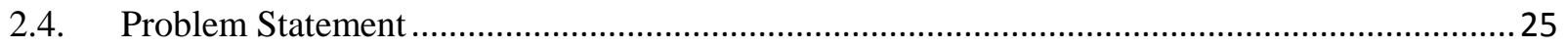

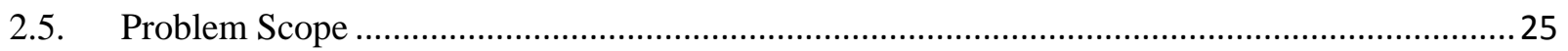

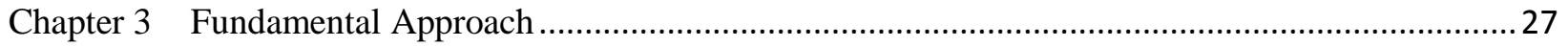

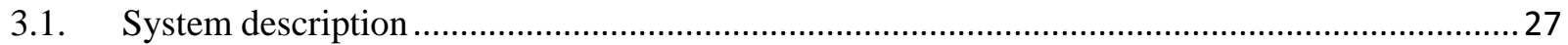

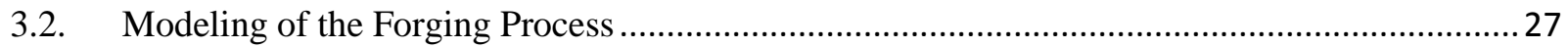

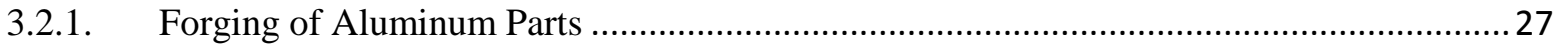

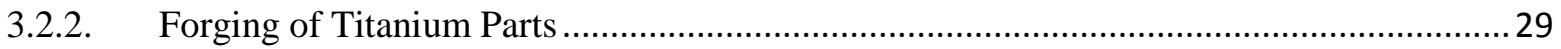




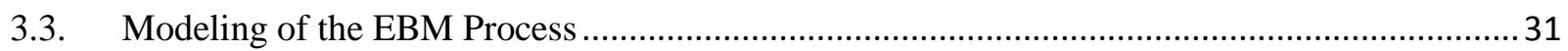

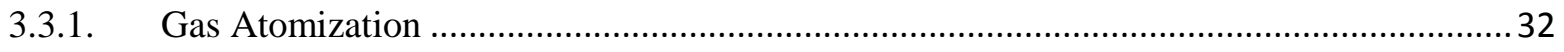

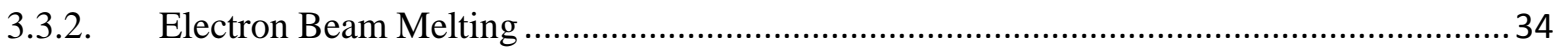

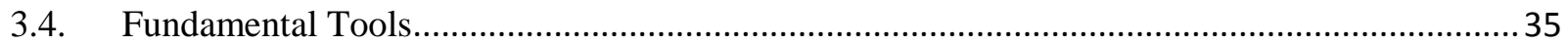

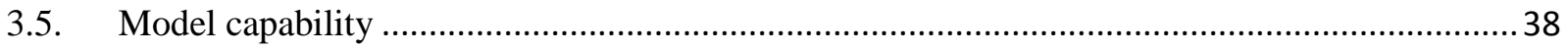

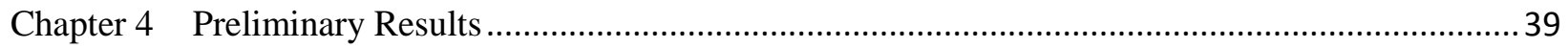

4.1. Environmental Impact Analysis for Forging of a Small Aluminum Part ............................... 42

4.1.1. Environmental Impact of Buy-To-Fly Ratio On Small Aluminum Forgings .................... 45

4.1.2. Environmental Impact of Transportation Distance On Small Aluminum Forgings ...................46

4.1.3. Environmental Impact of Mode of Transportation On Small Aluminum Forgings ............ 47

4.1.4. Environmental Impact of Production Quantity On Small Aluminum Forgings ................ 49

4.2. Environmental Impact Analysis for Forging of a Large Aluminum Part ...............................52

4.2.1. Environmental Impact of Buy-To-Fly Ratio On Large Aluminum Forgings .....................55

4.2.2. Environmental Impact of Transportation Distance On Large Aluminum Forgings ........... 56

4.2.3. Environmental Impact of Mode of Transportation On Large Aluminum Forgings .............57

4.2.4. Environmental Impact of Production Quantity On Large Aluminum Forgings .................58

4.3. Comparison of Part Size In Aluminum Forging …......................................................... 61

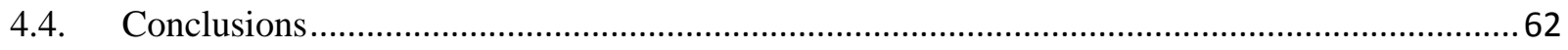

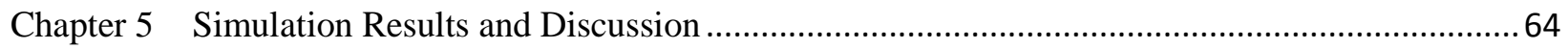

5.1. Simulation Results for a Centralized Manufacturing of Titanium via Forging .......................67

5.1.1. Environmental Impact Analysis for Forging of a Titanium Part ......................................67

5.1.1.1. Environmental Impact of Buy-To-Fly Ratio On Titanium Forgings ........................... 72

5.1.1.2. Environmental Impact of Transportation Distance On Titanium Forgings ................... 73

5.1.1.3. Environmental Impact of Mode of Transportation On Titanium Forgings .................... 75

5.1.1.4. Environmental Impact of Production Quantity On Titanium Forgings ........................ 77

5.1.2. Comparison of Part Size In Titanium Forging ............................................................ 81 
Table 28 Part Size Comparison for a Small and a Large Titanium Forging.....

5.2. Simulation Results for Distributed Manufacturing of Titanium Parts

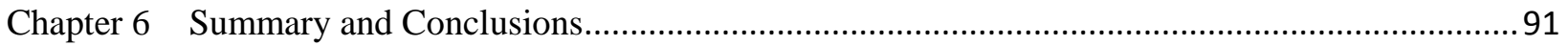

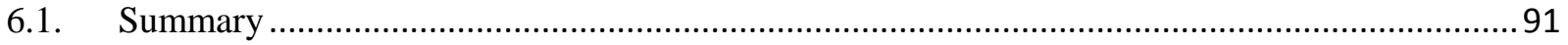

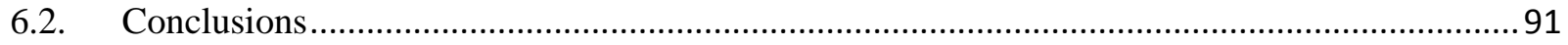

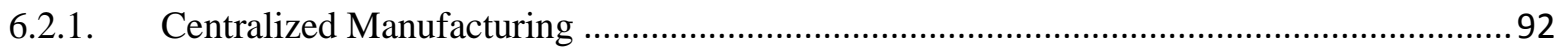

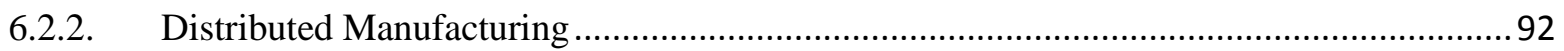

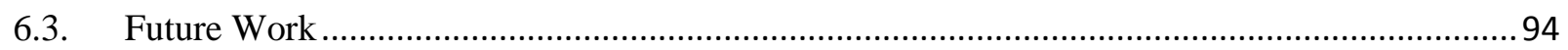

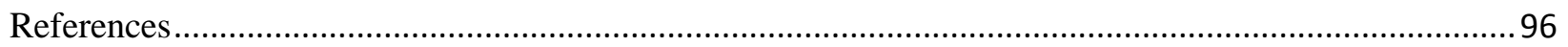

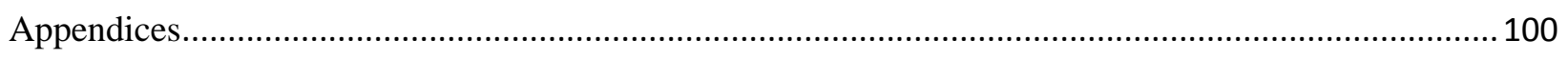




\section{List of Figures}

Figure 1 Example of buy-to-fly ratio of a conventional manufacturing (Taminger, 2008) ........................ 3

Figure 2 Example of buy-to-fly ratio of Electron Beam Free Form Fabrication (Taminger, 2008) ............. 4

Figure 3 Evolution from original design (a) and RM design (b) (Loughborough University, 2007) ......... 16

Figure 4 (a) Re-designed front-plate component; (b) an example manufactured using SLM (Loughborough University, 2007) 16

Figure 5 (a) Manufacturing processes for original front-plate design; (b) Process flow for Rapid Manufacturing. (Loughborough University, 2007).

Figure 6 Total energy consumption for insert production via the DMD process pathway (a), against that for the milling pathway (b) (Morrow et al., 2007) .............................................................................2 20

Figure 7 Example of break-even analysis comparing LS with injection moulding (Ruffo et al., 2006) ....22

Figure 8 (a) lever (the object of study) and (b) Cost comparison between laser sintering and injection

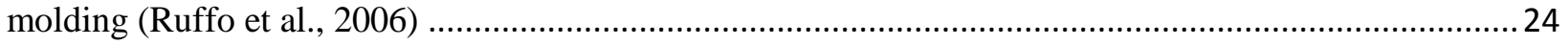

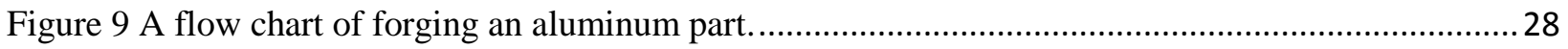

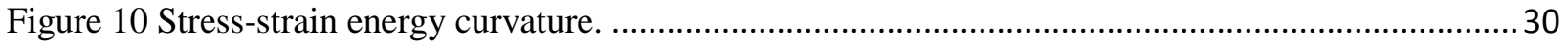

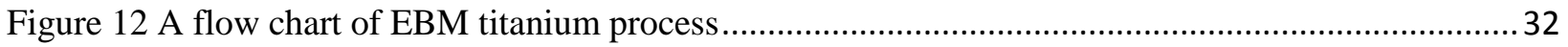

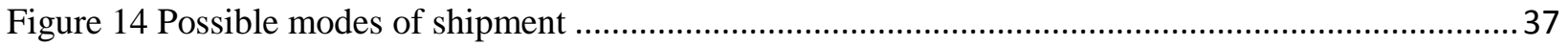

Figure 15 Aluminum forging system model structure in SimaPro .................................................... 38

Figure 17 A polyhedron of extreme points: Eight levels of sensitivity ............................................. 41

Figure 18 Inputs Entered in SimaPro for a Small Part ....................................................................... 43

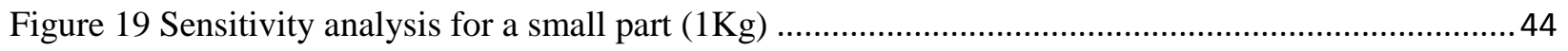

Figure 20 Number of Ecopoints per part for a small part vs. lot size …............................................... 51

Figure 21 Inputs Entered in SimaPro for a Large Part ....................................................................... 52

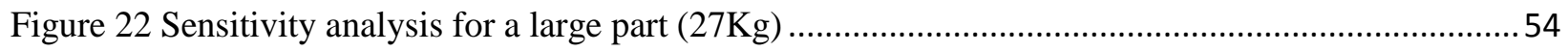

Figure 23 Number of Ecopoints per Part for a Large Part vs. Lot Size ..................................................60 
Figure 24 System structure of centralized titanium manufacture via forging .......................................64

Figure 25 System structure of distributed titanium production via Electron Beam Melting .....................65

Figure 26 A Polyhedron of Extreme Points: Sixteen Levels of Sensitivity ...........................................6 66

Figure 27 Sensitivity analysis for Electron Beam Melting model ...................................................6 66

Figure 28 Inputs Entered in SimaPro for a Small Part.................................................................... 68

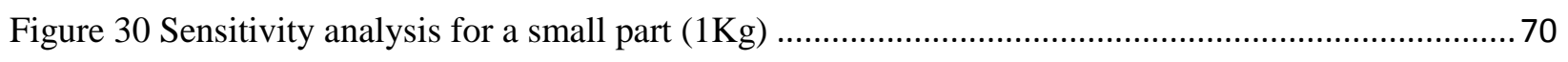

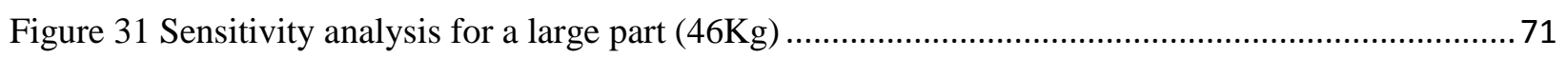

Figure 32 Number of Ecopoints per Part for a Small Part ................................................................ 79

Figure 33 Number of Ecopoints per Part for a large Part (b) ............................................................ 80

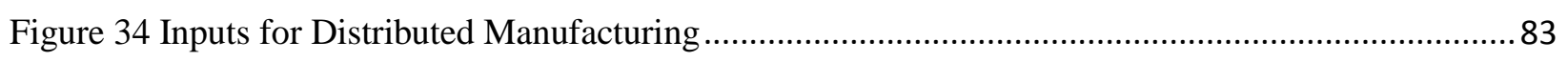

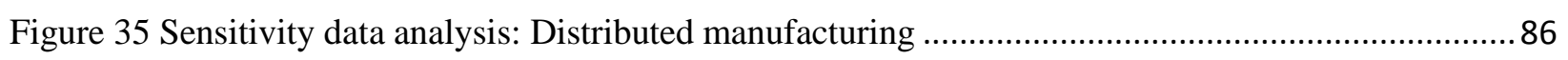

Figure 36 Eco-Points per part for (a) a small part and (b) a large part ................................................. 88

Figure 37 Total Number of Eco-Points for both Centralized and Distributed Manufacturing .................. 89 


\section{List of Tables}

Table 1 Energy Consumption Rate (ECR) for typical SLA, LS and FDM equipment (Loughborough University, 2007)

Table 2 Total energy consumption for Thermojet, FDM 3000 and EOSint M25023 (Loughborough University, 2007)

Table 3 Comparison of optimized RM design and traditional design on part volume and weight

(Loughborough University, 2007)

Table 4 Environmental metric changes for traditional versus rapid manufacturing of original and optimal

Front-plate design. Environmental benefits are highlighted in red. (Loughborough University, 2007)..... 18

Table 5 Buy-to-Fly Comparison for a Small Aluminum Forging....................................................... 45

Table 6 Buy-to-Fly Comparison for Machining Stage .................................................................. 46

Table 7 Transportation Distance Comparison for a Small Aluminum Forging ...................................... 47

Table 8 Transportation Distance Comparison for Transportation Stage ................................................ 47

Table 9 Transportation Mode Comparison for a Small Aluminum Forging.......................................... 48

Table 10 Transportation Mode Comparison for Modes of Transportation ............................................49

Table 11 Production Quantity Comparison for a Small Aluminum Forging ...........................................50

Table 12 Buy-to-Fly Comparison for a Large Aluminum Forging ........................................................ 55

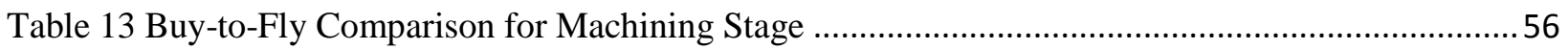

Table 14 Transportation Distance Comparison for a Large Aluminum Forging ....................................56

Table 15 Transportation Distance Comparison for Transportation Stage...............................................57

Table 16 Transportation Mode Comparison for a Large Aluminum Forging .........................................58

Table 17 Transportation Mode Comparison for Modes of Transportation ..............................................58

Table 18 Production Quantity Comparison for a Large Aluminum Forging ...........................................59

Table 19 Part Size Comparison for a Small and a Large Aluminum Forging ........................................62

Table 20 Buy-to-Fly Comparison for a Small Titanium Forging and a Large Titanium Forging .............. 72 
Table 21 Buy-to-Fly Comparison for Machining Stage for Small and Large Parts

Table 22 Transportation Distance Comparison for a Small Titanium Forging and a Large Titanium

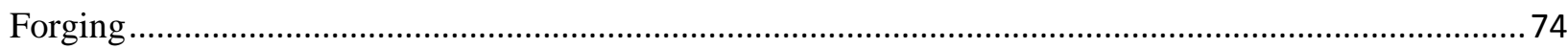

Table 23 Transportation Distance Comparison for Transportation Stage for Small and Large Parts......... 75

Table 24 Transportation Mode Comparison for a Small Titanium Forging and a Large Titanium Forging

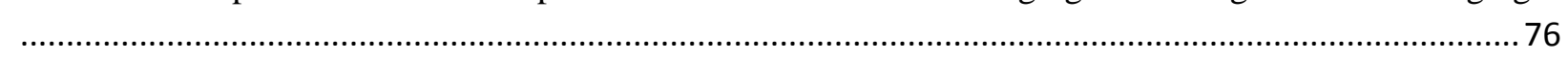

Table 25 Transportation Mode Comparison for Modes of Transportation for Small and Large Parts ....... 76

Table 27 Production Quantity Comparison for a Large Titanium Forging ............................................ 78

Table 28 Part Size Comparison for a Small and a Large Titanium Forging .......................................... 82

Table 29 Sensitivity data analysis results: In case of a small part ................................................... 100

Table 30 Sensitivity data analysis results: In case of a large part ...................................................... 101

Table 31 Sensitivity data analysis results: In case of a small part …................................................. 101

Table 32 Sensitivity data analysis results: In case of a large part ................................................... 102

Table 33 Sensitivity data analysis results: Distributed manufacturing .............................................. 102 


\section{Acronyms}

RERU : Literature Data for Europe (Unit Process Extension)

$\mathrm{CN}$ : Chinese Data

CNU : Chinese Data (Unit Process Extension)

IU : Infrastracture (Unit Process Extension)

RER / IU : Literature Data for Europe/ Infrastracture (Unit Process Extension)

GLOU : Worldwide Production Situation (Unit Process Extension)

SEU : Sweeden (Unit Process Extension)

Pts : Eco-Points 


\section{Chapter 1 Introduction}

This thesis compares the environmental impact of two different methods for producing high quality titanium components. The traditional method involves forging billets and then finish machining them to the final desired shape. The extremely high cost of dies and forging equipment necessitates that production of forged components take place at a very small number of locations. Components are then transported potentially long distances to the end user. This is referred to as "centralized manufacturing". A newer alternative involves the use of near net shape metal additive manufacturing processes such as Electron Beam Melting. These processes eliminate the need for forging dies and require very little finish machining. Due to the fact that expensive forging dies are not needed, these components can be fabricated at any location in which a metal additive machine is available. This approach to production is therefore referred to as "distributed manufacturing" since it can take place much closer to the end user.

To date, there has not been a systematic study of the differences in environmental impact between these two very different approaches. The aim of this thesis is therefore to study inputs and outputs associated with these methods in terms of their environmental impact.

In order to study the overall environmental impact, it is necessary to consider far more than just energy consumption. Human toxicity, abiotic depletion, global warming, solid waste production, acidification, terrestrial ecotoxicity, photochemical ozone formation and aquatic toxicity as all pose significant threats to the environment and should therefore be taken into consideration in an analysis comparing centralized and distributed manufacturing.

The transportation sector, including road and rail vehicles, ships and aircrafts, contributes significantly to global energy consumption and greenhouse gas emissions. One way of reducing transportation energy consumption is through optimal design of vehicle components such that strength-to-weight ratio is maximized. It is often the case, however, that the optimal geometry is not manufacturable via conventional techniques. Additive manufacturing techniques do not require molds or dies, however, hence they represent a promising tool in efforts to reduce energy consumption in the transportation sector.

Based on the above discussion, distributed manufacturing shows promise as a means of reducing the carbon footprint associated with the design, manufacture and distribution of 
components. Large production volumes are not needed to amortize high tooling costs, hence parts are only made when they are needed. Waste associated with obsolescence is therefore reduced, as are inventory carrying costs. Greenhouse gas emissions associated with large transportation distances can also be reduced.

\subsection{Distributed Additive Manufacturing (EBM) and Centralized Manufacturing (Forging)}

Suppliers of spare parts in centralized manufacturing suffer from high inventory and distribution costs even though these supply chain costs can be reduced by cutting production lead-times, batch constraints, and delivery lead-times. However, rapid manufacturing technologies have the ability to produce parts on demand without the need for tooling and setup. They have the potential to become the basis for new solutions in supply chain management. Distributed manufacturing even makes it possible to produce multiple components in the same machine simultaneously, resulting in further cost reductions.

Due to the elimination of molds and dies, RM can enable cost efficient production of low-volume components. Without tooling and time consuming setups, parts do not have to be produced until they are needed. Put another way, RM enables the strategy of "build on demand". This reduces or even eliminates the need to store parts in warehouses for assembly supplies or spares. Elimination of warehoused parts reduces heating and cooling energy, obsolete part production and disposal, and the carbon footprint associated with all of the above. It also reduces the amount of waste going into landfill.

\subsubsection{Traditional Centralized Manufacturing}

The more traditional process of forging is done using an eccentrically driven press to plastically deform a part into the shape of a die. The fracture criterion expressed by the maximum tensile stress is effectively used for predicting the forming limit of metal at a certain temperature. In conventional hot forging, the forging must be performed in a closed cavity to obtain near-net or net shape parts. However, forging cannot produce complex geometries associated with many parts; hence, a considerable amount of finish machining is often required to complete the part. 
Finish machining is a subtractive manufacturing technique that manipulates material through a series of cutting, milling and grinding operations that require electricity, coolants, lubricants, and cutting tools. Metal chips are the primary byproduct of machining processes. Naturally, more material is required than is used in the final product. As shown in Figure 1, in the aerospace sector, the "buy-to-fly" ratio of a manufactured part is the weight of material purchased to make the part divided by the weight of material in the final part that flies (Taminger, 2008). For high-value aerospace components, material buy-to-fly ratios of 15:1 or worse are not uncommon (Loughborough University, 2007). This uses more virgin material than required and results in increased energy usage during the transportation and recycling of metal chips. The influence of conventional operations on environmental burden is mostly due to machine tool energy consumption, the use of coolants and lubricants, replacement of cutting tools, and production of metal chips that must be recycled.

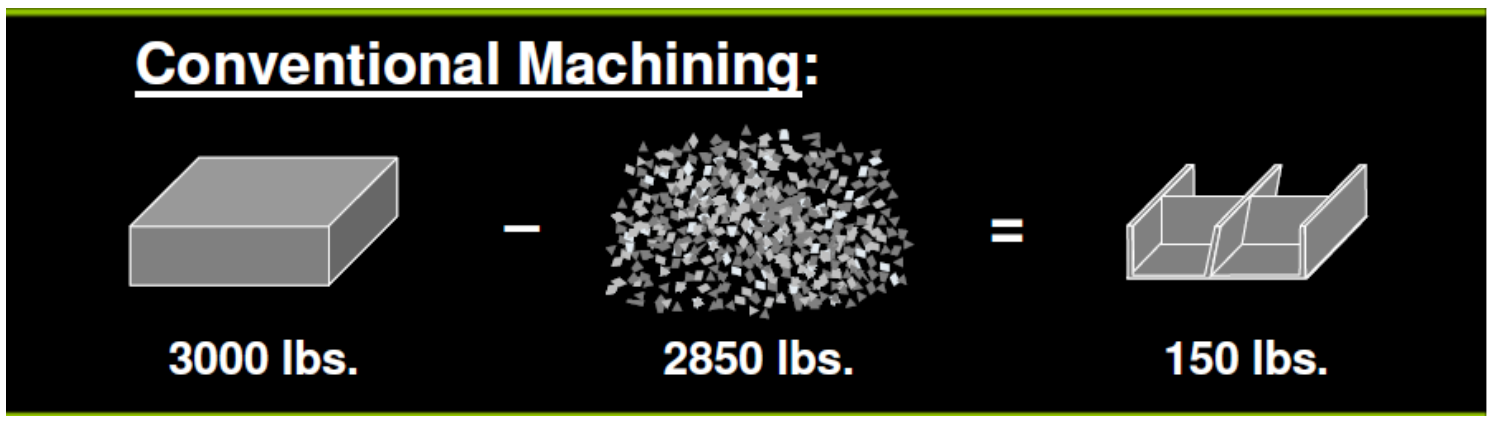

Figure 1 Example of buy-to-fly ratio of a conventional manufacturing (Taminger, 2008)

\subsubsection{Distributed Additive Manufacturing}

As shown in Figure 2, one technique to reduce material scrap rates is to use near-net shape processing such as Electron Beam Freeform Fabrication (EBF ${ }^{3}$ ) (Taminger, 2008). Distributed Additive Manufacturing, also known as Rapid Manufacturing (RM), is a near-netshape production method that builds components by depositing one layer of material on top of the next. A key feature of this approach is that it eliminates the need for tooling such as molds or dies. 


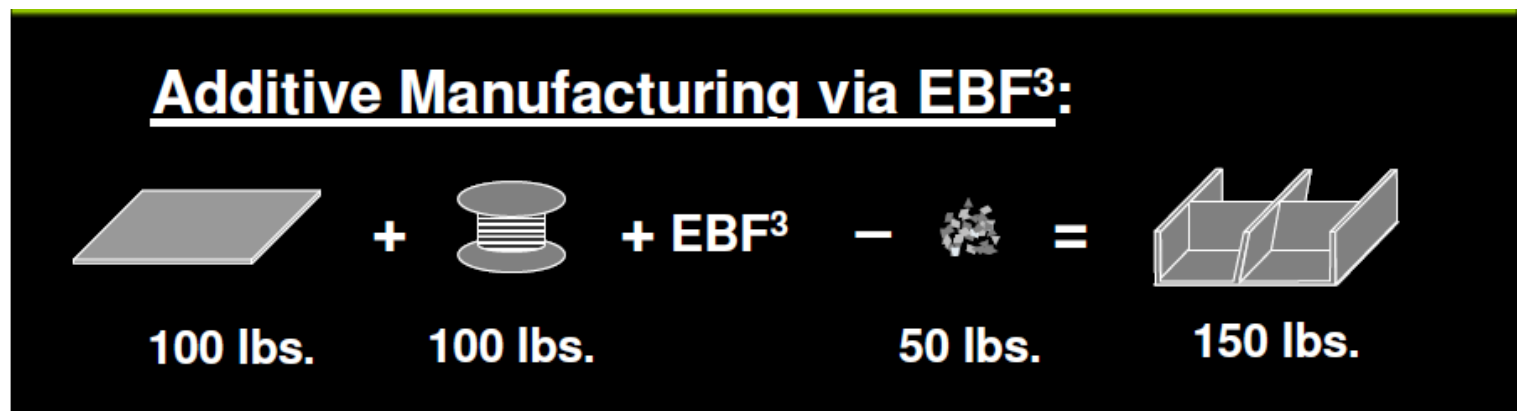

Figure 2 Example of buy-to-fly ratio of Electron Beam Free Form Fabrication (Taminger, 2008)

The technology saves raw materials through elimination of molds/dies and through the reduction in buy-to-fly ratio. It is reasonable to assume that significant carbon footprint savings are realized through reduction of raw material use, water consumption, and the use of potentially hazardous materials. This technology also reduces environmental emissions and energy consumption relative to conventional manufacturing pathways. Those savings are realized due to the combination of RM with optimal design methods.

Distributed manufacturing is performed using technologies such as Electron Beam Melting (EBM). The basis for the technology of Electron Beam Melting is that metal parts are built up layer-by-layer from metal powder that is melted by a scanning electron beam. Each layer is melted to the exact geometry defined by the 3D CAD model. Parts are built in a vacuum at elevated temperatures. For each layer of powder, the electron beam first scans the powder bed to maintain a certain elevated temperature that is specific for the alloy being processed. Thereafter, the electron beam melts the contours of the part and finally the bulk (www.arcam.com).

Kuchi (2009) pointed out that Electron Beam Manufacturing has many advantages. As an electron beam is electronically focusable, the output power can be scaled over a wide range. In addition, more control over the electron beam allows fabrication of finer details with a low power setting. As the electron beam fabrication process is operated in a vacuum environment, inert gas is not needed to preserve the chemical integrity of the metal powder and the part being fabricated. A portion of the incident energy is reflected by the melt pool and lost to the atmosphere with optical energy such as a laser beam, whereas up to $90 \%$ of the incident energy is utilized for melting the metal in electron beam fabrication.

In the EBM process, very little of deposited energy is lost due to heat shielding in the system, and heat loss via convection is essentially zero in vacuum. The bulk of the energy 
therefore stays in the metal powder to minimize heat loss during processing. The elevated bed temperature, in turn, reduces the heating requirements and energy use for the melting process.

Although this research is focused on evaluation of the EBM process, other metal additive processes that enable distributed manufacturing are commercially available as well. Direct metal laser-sintering systems have been used to create: (1) stainless-steel prototypes for customized spinal surgical instruments (Wehmoller et al, 2005), (2) metallic replacement knee joint prototypes (He et al., 2006), (3) dental models (Wehmoller et al, 2005), and (4) titanium dental implants with porous surfaces that promote osseointegration (Traini et al., 2008). In plastics, EOS laser-sintering nylon is increasingly being used to produce customized medical devices such as drill guides for knee and hip replacement (Hieu et al., 2005).

Electron Beam Free Form Fabrication $\left(\mathrm{EBF}^{3}\right)$ is a related process that uses a wire-feed electron beam welder to fabricate metallic structures (Hafley et al., 2007). BBF $^{3}$ is suitable for production of extremely large parts without forging dies. A very large weld deposit is needed to produce such large parts in a reasonable amount of time, hence a fair amount of finish machining is still needed with this process. However, the amount of finish machining is not as great as it typically would be for a forging.

\subsection{Research Objectives}

As previously described, a distributed manufacturing model involves using many geographically distributed general purpose additive manufacturing machines to produce small quantities of parts close to the end user in an "on demand" basis. This is made possible by the fact that the need for fixed tooling (molds/dies) is eliminated. Although there are potentially many environmental benefits associated with distributed manufacturing, there have been very few studies aimed at quantifying these benefits.

With that said, the high level objective of this proposal is to create models of both centralized and distributed manufacturing that can be used to compare the environmental impacts associated with different scenarios. This will be done by modeling forging and Electron Beam Melting (EBM) process sequences using extensions to the SimaPro environmental analysis software. For centralized manufacturing, the SimaPro extension consists of a process sequence involving forging, machining, and transportation. The model accepts as input the amount of 
material going into the process, the amount of material coming out of it, and the power source(s) used (e.g. nuclear, coal, or hydro). For distributed manufacturing, no SimaPro model exists at all for any of the additive manufacturing processes. Thus an extension for Electron Beam Melting must be created that considers powder metal feedstock production, material quantities going into and coming out of the process, power source(s) used, and transportation distances to the customer.

In summary, both the centralized and distributed manufacturing environmental models consider the following variables:

- Customer and supplier transportation distances

- The method of transportation used

- The volume of material $\left(\mathrm{cm}^{3}\right.$ or in $\left.{ }^{3}\right)$ input to the process

- The volume of material $\left(\mathrm{cm}^{3}\right.$ or in $\left.{ }^{3}\right)$ in the finished part

When the first objective of creating models of centralized and distributed manufacturing has been satisfied, then the second specific objective is to conduct an environmental impact assessment of the two production methods under a variety of scenarios involving the parameters listed above.

Centralized Manufacturing: As a baseline for comparison, a life cycle assessment will be conducted in which a part is fabricated using the original process sequence. The assessment must include consideration of the impact of producing and using forging dies as well as the raw material in ingot form. Subsequent finish machining must also be considered, including all factors such as the use of coolant and chip disposal. The magnitude of finish machining determines the buy-to-fly ratio and is a variable in the model. In centralized manufacturing, the forged parts are made at a very small number of locations and are then transported potentially large distances to the end user. Hence the model must also consider the magnitude of distance traveled as well as the method of transportation used.

Distributed Manufacturing: A life cycle assessment is then conducted for the case where a part is fabricated using the EBM process followed by a small amount of finish machining. The process is assumed to take place very close to the end user with relatively little transportation 
distance. The EBM process uses metal powder rather than ingots as the raw material, hence the model must consider production of the raw material as well.

The final objective of the thesis is to simulate a large number of scenarios involving part size, transportation distances, and buy-to-fly ratios. Simulation results will be analyzed to gain insight into how the environmental impacts of distributed and centralized manufacturing compare under different circumstances. 


\section{Chapter 2 Literature Review}

\subsection{Environmental Studies Involving Traditional Manufacturing}

Traditional manufacturing involves a series of operations including cutting, milling and grinding. As each operation removes material, less material is required for the final product. In the aerospace industry, the ratio of material purchased to material in the end item is known as a buy-to-fly ratio. Near-net shape manufacturing processes allow this material waste to be greatly reduced. In addition to the metal usage aspects of machining operations, cooling lubricants are used to increase cutting speeds, reduce tool wear, increase accuracy, and improve surface finish. Although ease of machining is improved through the use of coolants, they contain a number of potentially harmful constituents including lubricants, emulsifiers, antifoams, biocides and fungicides. Moreover, cooling lubricants can be costly.

Narita and Fujimoto (2007) introduced an evaluation method which can be applied to many machine tool operations. The total environmental burden is calculated from the electric consumption of the machine tool, coolant quantity, lubricant oil quantity, cutting tool status, and metal chip quantity. The developed system can simulate not only end milling processes but also turning, drilling, and grinding processes. In order to verify the effect of high-speed milling, the equivalent $\mathrm{CO}_{2}$ emission due to the simple machining operation is examined. Narita and Fujimoto (2007) determined that the equivalent $\mathrm{CO}_{2}$ emissions of auxiliary devices such as coolant pumps and chip conveyors decreases as spindle speed increases, however, the $\mathrm{CO}_{2}$ emission of the cutting tool increases as the spindle speed increases. Narita and Fujimoto determined that although cutting time is decreased with high-speed milling, the tool wear increases thus increasing the number of cutting tools needed. Thus, in conclusion, Narita and Fujimoto (2007) suggested that one can decide a cutting condition realizing the lowest environmental burden using tool wear information provided by cutting tool makers.

Desmira, Narita, and Fujimoto (2008) introduced an environmental burden analyzer for machine tool operations. The focus of global warming potential over a 100 -year period was considered, and equivalent $\mathrm{CO}_{2}$ emissions were evaluated as the environmental burden. Thus, $\mathrm{CO}_{2}, \mathrm{CH}_{4}$ and $\mathrm{N}_{2} \mathrm{O}$ were evaluated based on data from Japan. Desmira et al. (2008) concluded that the electric consumption of peripheral devices of the machine tool and the cutting tool are the main factors in the machining operation that affect global warming. The influence of the 
peripheral devices of a machine tool, the spindle and the servo motors, the coolant, the lubricant oil, the cutting tool and the metal chips on global warming were analyzed. Among these factors, $\mathrm{CO}_{2}$ emissions were determined to be the dominant contributor to global warming in a machining operation.

In (2009), Desmira, Narita, and Fujimoto published research on an environmental burden system for machine tools focused on global warming. In this work, $\mathrm{CO}_{2}$ emissions are used as the environmental burden criteria. From the three patterns of possibilities available for environmental burden of high-speed milling, high-speed milling optimally minimizes $\mathrm{CO}_{2}$ emissions. Desmira et al. discussed five factors for determining the total environmental burden of machine tools. Each factor has two levels to decrease or increase, with the exception that the metal chip quantity is constant. From these scenarios, three patterns of machine tool environmental burden for high-speed milling were proposed: Minimum patterns of $\mathrm{CO}_{2}$ emissions due to high-speed milling, a parabolic pattern of $\mathrm{CO}_{2}$ emissions due to high-speed milling, and a maximum pattern of $\mathrm{CO}_{2}$ emissions due to high-speed milling. Based on the result that environmental burden reached a maximum value at lowest spindle speed for a minimum pattern on high-speed milling, Desmira et al. concluded that high-speed milling decreased $\mathrm{CO}_{2}$ emissions through reduction of electric consumption due to the shorter machining time.

Researchers at Loughborough University (2007) discussed casting, another type of conventional metal operation. Casting uses metal feedstock that is heated to a molten consistency before being poured into a mold. In addition to the energy needed to melt the metal, holding molten metal in a crucible prior to casting consumes additional energy. The process typically uses release agents to facilitate removal of the part from the mold. Thus, the additional resources and hazardous substances for component removal are counted in the overall environmental burden of the casting process. Neto, Kroeze, Hordijk, and Costa (2008) presented a model that assesses the potential environmental impact of environmental pollutant emissions from a small to medium sized company supplying car manufacturers with aluminum die castings. The model includes 20 options to reduce environmental problems. MIKADO was used to systematically explore those options and simultaneously assess their effectiveness in reducing the environmental impact and the associated costs for the company. The simulation results indicate that the melting and casting sub-process contributes about $90 \%$ of the environmental impact of 
the company. The melting and casting environmental impact is mostly associated with human toxicity problems caused by metal emissions, hydrogen fluoride, emissions of ozone precursors, and the abiotic depletion of natural gas. Both human toxicity and abiotic depletion of natural gas account for about $75 \%$ of the overall environmental impact.

In (2004), Dalquist and Gutowski released a life cycle analysis of the activities which occur within an aluminum foundry doing high pressure die casting. The analysis included a life cycle inventory of (1) the die casting manufacturing process including energy usage and materials such as oil-based lubricants and cooling water, (2) recycled materials, (3) recyclability of products at end-of-life, and (4) waste by-products created during the process. As part of the life cycle analysis, Dalquist and Gutowski included die making and finishing. Die casting machines typically last for decades. The environmental effects of machine manufacture can be considered negligible for each cast part. The authors note that the die casting industry in the U.S. is increasingly threatened by overseas production facilities and that offshore production has forced the closure or consolidation of smaller companies. Manufacturers benefit financially from the significantly lower environmental standards in some countries than those of the United States (Dalquist \& Gutowski, 2004). Most emissions in die casting come from electricity generation or from the combustion of fuels used for furnaces. Dalquist and Gutowki observed that increased demand for die cast parts directly contributes to rising environmental burden in the die casting industry.

Following their analysis, Dalquist and Gutowiski (2004) discuss areas where the most improvement can be made for the sand casting manufacturing process. Dalquist and Gutowiski outlined the sand casting process and considered material and energy inputs and outputs for mold preparation, metal preparation, casting, and finishing stages and their sub-processes. Due to the long life of machines, the environmental cost of machines was considered insignificant on a per part basis. In the green sand casting process, molds are made from a mixture of sand, clay, water, and carbonaceous additives such as bituminous, seacoal, anthracite, or ground coke. Sand is used to make each mold at a ratio of about 5.5 tons of sand to one ton of cast product. In addition to mold preparation, much of the sand used in molds comes from molds in previous runs that have been broken down and treated. However, heat reclamation changes the properties of sand over time, eventually preventing its reuse in further molds. 
Regarding metal preparation, the process of melting the metal is the most energy intensive activity in the foundry (Dalquist \& Gutowiski 2004). Dalquist and Gutowski showed that $55 \%$ of foundry energy use is in process heating. The pouring stage in sand casting is less energy intensive than other parts of the process, but organic emissions occur when the metal comes into contact with the sand and binder. These emissions continue throughout the cooling process. After the metal cools, the cast product is removed from the mold during shakeout. The shakeout process produces significant quantities of dust and metallic particulates. Shakeout emissions are related to the binder system. Finally, Dalquist and Gutowiski concluded that the chemicals used in the finishing stage are of more environmental concern than the energy used.

Loughborough University (2007), also discussed injection molding which is also a traditional method of producing high volume net shape products. The authors determined that injection molding machinery consumes the bulk of energy associated with the process. In addition to polymer material consumption in the operation, water is used for cooling the molds, and mold release agents are required. In the previous work done by Thiriez and Gutowski (2006), injection molding energy consumption is analyzed for hydraulic, hybrid, and all-electric machines. Considering the energy consumption of all stages from the compounder to the injection molder, hydraulic, hybrid, and all-electric machines yield average values for specific energy consumption of 19.0,13.2 and $12.6 \mathrm{MJ} / \mathrm{kg}$ respectively, with the exclusion of polymer production. When the polymer production stage was included in the scope of the LCI, the energy consumption values increased up to $100 \mathrm{MJ} / \mathrm{kg}$. In fact, Thiriez and Gutowski (2006) stated that in the whole LCI, producing the polymer has the greatest impact on the environment and is followed by injection molding machinery and extrusion. Concerning emissions, the majority of emissions come from the polymer production stage (Thiriez and Gutowski, 2006).

The work presented by Sokovic and Mijanovic (2001) suggests that equal consideration should be given to the ecological aspects involved with the use of cutting fluids in manufacturing processes. In addition, Sokovic and Mijanovic (2001) suggested that researchers and individual companies have a special responsibility for developing and implementing innovative environment-friendly manufacturing processes. 


\subsection{Environmental Studies Involving Rapid Prototyping (RP)}

Researchers at Loughborough University (2007) stated that many Rapid Manufacturing (RM) processes have evolved from existing Rapid Prototyping (RP) processes. In fact, RM processes use similar materials and processes to manufacture products and components in an additive fashion. So far, the environmental impact of RP polymer systems namely, stereolithography (SLA) laser sintering (LS), and fused deposition modelling (FDM) have been evaluated. In terms of energy consumption, data and Eco-indicators for the case studies are presented. Data for the energy consumption of three different RP systems (SLA, LS and FDM) has been calculated using data derived from the machine manufacturer for the build process. Energy consumption rates (ECR) per kilogram of material consumed are also shown (Table 1).

Table 1 Energy Consumption Rate (ECR) for typical SLA, LS and FDM equipment (Loughborough University, 2007)

\begin{tabular}{l|lll|}
\multicolumn{2}{l}{ Stereolithography } & $\begin{array}{l}\text { Laser } \\
\text { Sintering }\end{array}$ & FDM \\
\hline ECR (kwh/kg material) & SLA 5000 & Model 2500 & 8000 \\
kg CO 2 equivalent per & 9.7 & 29.83 & 23.08 \\
kg material consumed & & 14.02 & 10.85
\end{tabular}

The Loughborough University (2007) report also analyzed the energy costs of three different RP systems namely, FDM 3000, 3D Systems Thermojet and EOSint M250 which is a laser sintering type system. The FDM 3000 and Thermojet were seen to require less energy because they were used to heat a wax or polymer material, whereas the EOSint M250 uses a 200W CO 2 laser used to fuse metal particles in the systems. Results are shown in Table 2. 
Table 2 Total energy consumption for Thermojet, FDM 3000 and EOSint M25023

(Loughborough University, 2007)

Electrical Energy Consumption (Kwh)

\begin{tabular}{l|ll|}
\hline Thermojet & 2.1 & 3.8 \\
FDM 3000 & $0.5(+4)$ & $1.25(+4)$ \\
EOSint M250 & 32 & 56
\end{tabular}

The majority of metal RM/RP systems can be split into two technological categories powder feed and powder bed. Those categories have been recognized as future manufacturing processes for high value metallic components such as Ti-6Al-4V, which are difficult to machine and are expensive in raw form. Among the two categories, powder feed approaches such as Laser Engineered Net Shaping (LENS) are often used as a method of repairing or remanufacturing tools or dies.

Additive RM technologies have potential environmental advantages over conventional processes such as casting, forging, and machining for tooling and end-use part manufacture. In fact, those processes release a significant percentage of the nation's green house gases, consume large amounts of energy, and are among the most significant polluters of freshwater systems as reported by the U.S. Environmental Protection Agency (EPA) (US EPA, 1995). Metallic RM systems are able to process a number of materials such as stainless steels, $\mathrm{CoCr}$, and $\mathrm{Ti}-6 \mathrm{Al}-4 \mathrm{~V}$ (type of Titanium Alloy). The availability of titanium alloys and their costs as well as their methods of extraction is a particular concern for aerospace companies because titanium is expensive and has environmental issues.

\subsection{Environmental Studies Involving Rapid Manufacturing}

The Electron Beam Melting (EBM) process is a near net shape process that reduces the material needed for fabrication of new parts through minimization of machining requirements and through elimination of the need for a mold or die. The 12:1 to 20:1 buy-to-fly ratio typically seen for common manufacturing processes (Kuchi, 2009) can be brought down to 5:1 or less using EBM. Also, manufacturing lead time and the cost of the components is reduced when produced in small volumes. EBM is currently being used to create artificial hip implants made of titanium, for producing structures from high reflectance alloys such as titanium and aluminum 
for the aerospace industry, and for addition of features onto already manufactured parts (Kuchi, 2009).

Previously, Luo, Ji, Leu, and Caudill (1999) stated that while is it necessary to weigh the accuracy of a process, the durability of its materials, and its energy consumption, it is also important to measure the productivity, speed, and cost of the processes. However, the study focused only on the environmental issues of Solid Free Form Fabrication (SFF) processes. The factors that need to be taken into account in terms of environmental performance of a process must also include material extraction, energy consumption, process wastes, and disposal (Luo et al., 1999). A part produced with an SFF process usually goes through several stages including (1) loading the building material into the system, (2) building the part layer by layer, and (3) postprocessing. Although usage and disposal are not exactly parts of a process, their inclusion provides a holistic view of the environmental performance of the process (Luo et al. 1999).

Kuchi (2009) mentions a number of new emerging technologies for fabricating structural metal parts including Electron Beam Freeform Fabrication $\left(\mathrm{EBF}^{3}\right)$. This process can be used to build a complex shape layer by layer in an additive fashion. In (2007), Hafley, Taminger, and Bird authored a paper that discussed the $\left(\mathrm{EBF}^{3}\right)$ process. $\mathrm{EBF}^{3}$ is a layer additive process that uses a computer numerically controlled electron beam welder to build metallic near-net shaped parts. $\mathrm{EBF}^{3}$ is a direct metal deposition process in which metallic feedstock, typically in the form of wire, is fed into a molten pool that is created by an electron beam focused on a substrate (Hafley et al., 2007). The electron beam and wire feeder are translated with respect to the substrate such that the deposited molten metal builds up a part one layer upon the next. Hafley et al. (2007) demonstrated that the $\mathrm{EBF}^{3}$ process will work in zero gravity as long as the distance between the substrate and the wire feeder is carefully maintained. Furthermore, $\mathrm{EBF}^{3}$ deposits were successfully produced in zero gravity with wire entering the molten pool from any direction relative to the translation direction. The demonstrations support the concept of developing a simple $\mathrm{EBF}^{3}$ system to fabricate near-net shaped components in a microgravity environment to support long duration human exploration missions in space. Also, laboratory testing of the process in $1 \mathrm{~g}$ and $2 \mathrm{~g}$ reasonably approximates the results obtained in $0 \mathrm{~g}$. This was very important because testing in $0 \mathrm{~g}$ was difficult, costly, and had severe limitations due to the short duration in $0 \mathrm{~g}$ and vibrations introduced through the airframe. 
Kuchi (2009) describes Laser Based Manufacturing (LBM) techniques which include Laser Engineered Net Shaping $\left(\right.$ LENS $\left.^{\mathrm{TM}}\right)$. LENS is an additive manufacturing process in which the parts are directly fabricated from a 3-D solid model line by line and then layer by layer. The process is generally referred to as a small-scale process. The process produces parts with material properties equal to or better than those processed by conventional techniques. When

compared to conventional manufacturing processes, the LENS $^{\mathrm{TM}}$ process eliminates excessive material waste during material removal due to the fact that this process builds parts by material addition.

\subsubsection{Rapid Manufacturing (RM) Influence On Part Design}

Loughborough University researchers (2007) indicated that one of the largest drivers for the potential uptake of RM involves product design optimization. They note that traditional Design for Manufacture (DFM) restrictions are removed when a part is fabricated via an RM process. With RM, the focus is on design for function rather than what the manufacturing system is capable of producing. Design for function allowed by RM provides opportunities for geometrical freedoms which contribute to more efficient products. This can reduce material usage and/or energy consumption through the lifecycle of the components. The use of RM processes also opens up the possibility of consolidating an assembly of components into a single part, hence, reducing the part count for that assembly.

The Loughborough researchers (2007) conducted three case studies in which the carbon footprint was evaluated before and after the components were redesigned for additive manufacturing. In the example shown in Figure 3(a), cooling channels are produced in the traditional design by drilling straight holes in the casting. In addition to the drilling operation, selected holes need to be blocked to prevent leakages of diesel in the pump. In the RM redesigned part (Figure 3b), the hole drilling and plugging operations are eliminated. The evolution from the traditional design to that enabled through RM eliminates waste and removes machining and cleaning operations as the internal channels are able to be produced in-situ during Rapid Manufacture. 


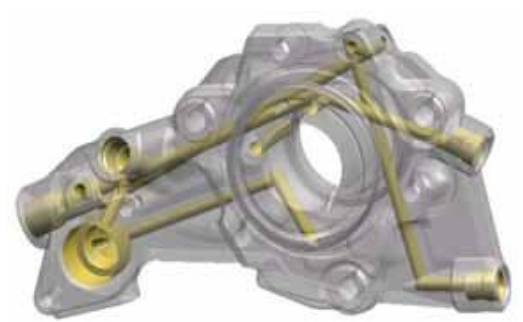

(a)

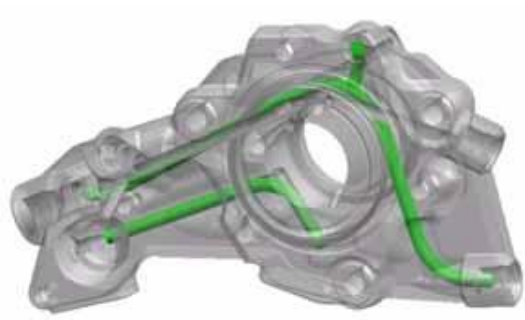

(b)

Figure 3 Evolution from original design (a) and RM design (b) (Loughborough University, 2007)

In Figure 4, the component has been designed around the flow channels rather than adding the flow channels as a later process. The benefit is that no waste is created internally that requires electro-chemical machining. Moreover, the channels do not need sealing with additional material.

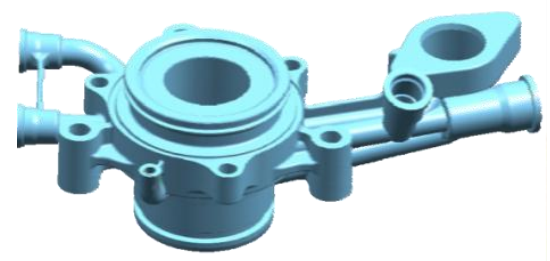

(a)

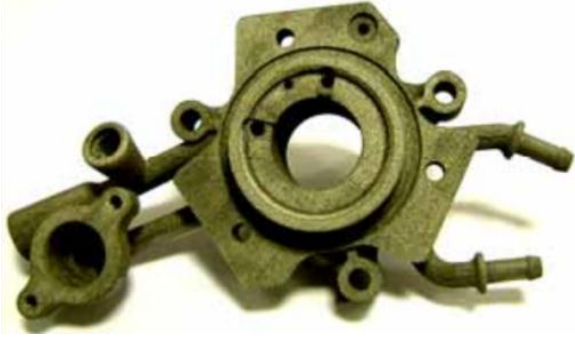

(b)

Figure 4 (a) Re-designed front-plate component; (b) an example manufactured using SLM (Loughborough University, 2007)

The reduced weight of individual components saves material and can have a great effect on fuel consumption during a component's lifetime. Table 3 shows that a reduction of almost $40 \%$ in material volume was seen for this example through the use of redesigns made possible by additive manufacturing. 


\section{Table 3 Comparison of optimized RM design and traditional design on part volume and weight (Loughborough University, 2007)}

\begin{tabular}{l|lll|} 
Design & Volume of part $(\mathrm{m} 3)$ & $\begin{array}{l}\text { Volume Fraction } \\
(\%)\end{array}$ & $\begin{array}{l}\text { Part Weight Aluminium } \\
(\mathrm{kg})\end{array}$ \\
\hline Optimized & $1.51 * 10-4$ & 63 & 0.418 \\
Original & $2.39 * 10-4$ & 100 & 0.65 \\
\cline { 2 - 4 } & &
\end{tabular}

According to further analysis done by Loughborough University (2007), the authors compared traditional and metallic RM manufacturing techniques in terms of environmental impact. The analysis considered energy efficiency, water use, and solid and gaseous waste produced. It revealed that using RM radically reduces the number of manufacturing operations such as casting and machining due to the net shape nature of the process (Figure 5).

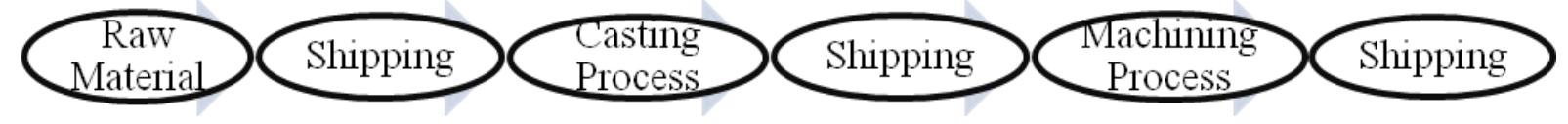

(a)

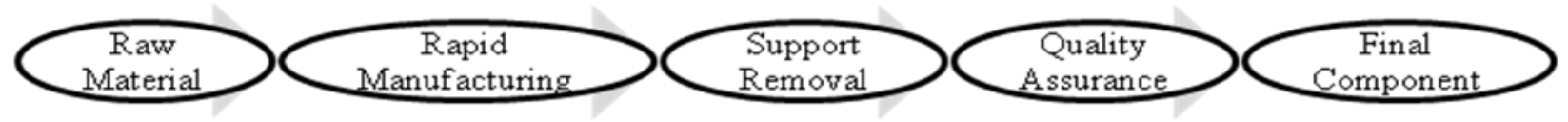

(b)

Figure 5 (a) Manufacturing processes for original front-plate design; (b) Process flow for Rapid Manufacturing. (Loughborough University, 2007)

Environmental impacts associated with traditional and RM design alternatives from the Loughborough study are shown in Table 4. The RM system shows environmental improvement in the water usage, hazardous waste and virgin materials categories; however, the system falls down in the use of energy per component for this example. Comparing the optimal design with RM with data for manufacturing the original design via a traditional approach, it is difficult to conclude which technique is better. However, factors such as transportation distances and elimination of tooling are not considered in this particular study. 
Table 4 Environmental metric changes for traditional versus rapid manufacturing of original and optimal Front-plate design. Environmental benefits are highlighted in red. (Loughborough University, 2007)

\begin{tabular}{c|ccccc}
$\begin{array}{l}\text { Original } \\
\text { Design }\end{array}$ & $\begin{array}{c}\text { Energy Use kg } \\
\mathbf{C O}_{2} \text { equivalent } \\
\text { per } \\
\text { component }\end{array}$ & $\begin{array}{c}\text { Water } \\
\text { Usage (kg } \\
\text { per } \\
\text { component) }\end{array}$ & $\begin{array}{c}\text { Landfill } \\
\text { waste } \\
\text { (kg) }\end{array}$ & $\begin{array}{c}\text { Virgin } \\
\text { Material } \\
\text { Use (kg per } \\
\text { component) }\end{array}$ & $\begin{array}{c}\text { Hazardous } \\
\text { Waste (kg } \\
\text { per } \\
\text { component) }\end{array}$ \\
\hline $\begin{array}{c}\text { Traditional } \\
\text { RM (SLM) }\end{array}$ & 4.3 & 0.23 & 0 & 2 & 0.0064 \\
$\begin{array}{c}\text { Difference } \\
\text { Optimal } \\
\text { Design }\end{array}$ & 13.15 & 0 & 0 & 0.67 & 0 \\
RM (SLM) & 8.85 & -0.23 & 0 & -1.33 & -0.0064 \\
Difference & 8.72 & 0 & & & \\
\cline { 3 - 6 } & 4.42 & -0.23 & 0 & 0.43 & 0 \\
\hline
\end{tabular}

In work published by Hague, Campbell, and Dickens (2003), it was suggested that Rapid Manufacturing (RM) offers profound possibilities for designing parts without constraints imposed by the necessity of being able to demold a part. Additionally, the use of RM processes with dissimilar powder feedstocks provides designers with new and exotic materials that are not possible using traditional manufacturing processes. At the design phase, Rapid Manufacturing (RM) allows parts to be designed that have re-entrant features, no draft angles, unlimited or nonuniform wall thickness, and increased complexity.

\subsubsection{Effect of Rapid Manufacturing on Supply Chains and Logistics}

Loughborough University (2007) researchers stated that the use of RM has the potential to radically change the way supply and logistics chains are organized. RM enables a localized supply chain that takes delivery of digital data via the internet and produces components on demand for local users. The integration of RM with Internet technology results in rapid exchange of data between designers and manufacturers. The application of RM can also significantly reduce stock costs and inventory levels. As such, finished goods inventory is essentially replaced by raw material inventory, and any obsolescence risks associated with the part or product design are eliminated. In fact, the study's authors mentioned that restructuring of the supply chain is possible. The transportation of parts over long distances is unnecessary, thus saving fuel and 
energy. The application of RM in a manufacturing environment therefore results in a reduction of material distribution and stock holding or warehousing costs. In addition to these benefits, RM eliminates time that is traditionally lost for the production of tooling and/or production time associated with tooling changeovers.

An analysis of spare part orders by Walter, et al. (2004) revealed that most parts are only infrequently needed. To meet this need, a great number of infrequently sold parts have to be stored for a very long time, which generates high inventory holding and logistics costs. The authors further state that aerospace Original Equipment Manufacturers (OEMs) incur high costs associated with producing and storing spare parts to cover the whole life cycle of their products. Replacement parts must be held for long life cycles despite the fact that the number of airplanes in service declines. There is a risk that the OEM will never be able to sell all the parts it has warehoused for years. Unfortunately, the time and expense of producing the required parts on demand using conventional production technologies is prohibitive.

Helms and Lambrecht (2007) state that redesigning a part to reduce weight (i.e. lightweighting) is one way of reducing transportation energy consumption. The potential contribution of light-weighting to reduce transportation energy use depends on the weight reduction potential and the total energy consumption of different vehicle groups. Energy savings have been applied to the baseline energy consumption. The total potential energy savings by light-weighting of different vehicle groups has been calculated in a top down approach based on data for global transportation energy consumption for the year 2000. Helms and Lambrecht (2007) identified three different groups in terms of order of magnitude for use phase primary energy savings. Road and rail vehicles have similar use phase energy savings. High-speed ferries show about ten times higher energy savings compared to rail vehicles due to the high specific energy consumption. The authors concluded that weight reduction leads to considerable use phase energy savings for all transportation types. On a global scale, the facilitation of light-weighting could make a significant contribution in the reduction of global transport energy consumption. 


\subsubsection{Environmental and Cost Considerations Among RM and Conventional}

\section{Manufacturing}

Morrow et al. (2007) presented three case studies that involved an injection mold insert, a mirror fixture, and remanufactured tooling. The intent of these studies was to highlight situations where conventional or laser-based tooling production pathways may hold environmental advantages. In the study involving an injection mold tool insert plate, energy consumption and other process effluents were calculated. These were applied in the other two studies in order to predict the lifecycle energy consumption and emissions of direct metal deposition (DMD) and CNC milling process routes for tooling production. The relative energy consumption values for the CNC milling and DMD pathways are shown in Figure 6. The energy consumption in the milling pathway is dominated by production of the tool steel plate. Energy consumption in the DMD pathway is dominated by the manufacturing processes.

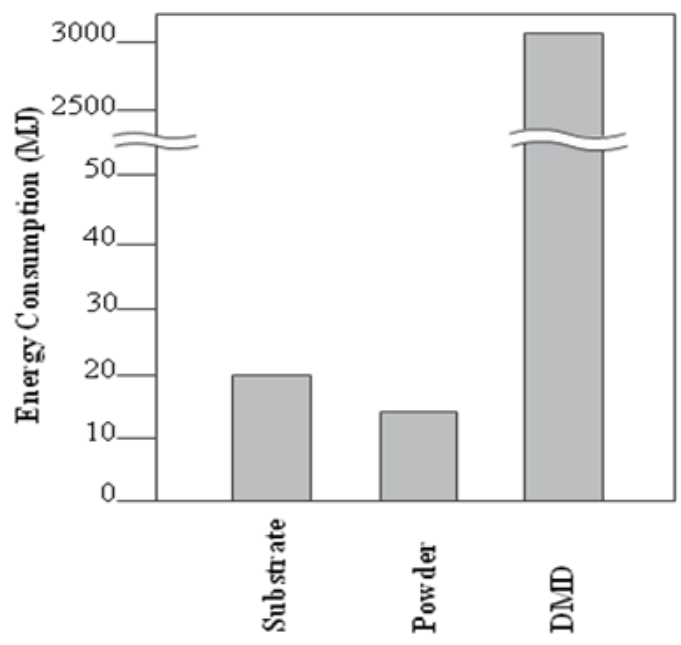

(a)

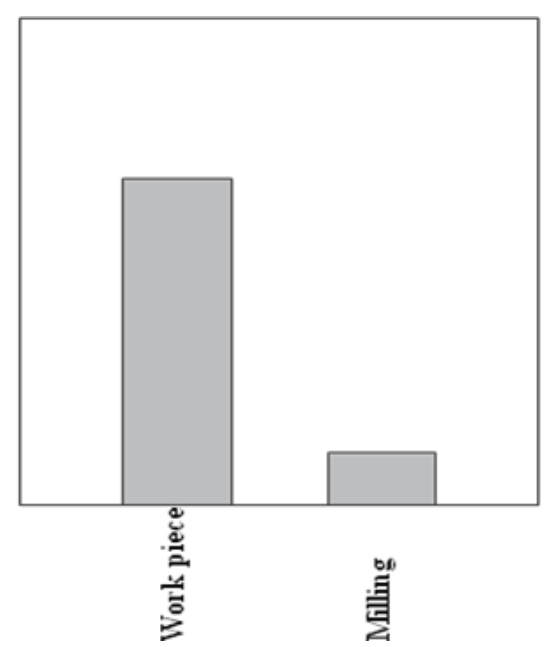

(b)

Figure 6 Total energy consumption for insert production via the DMD process pathway (a), against that for the milling pathway (b) (Morrow et al., 2007)

Morrow et al. (2007) mentioned that although the insert production case study revealed that the conventional pathway is the obvious choice for minimal energy consumption, the mirror fixture analysis revealed that DMD is the best choice for minimal energy consumption. This is due to a thin-walled structure that leads to a low solid-to-cavity volume ratio. This value is defined as the ratio of the tool's actual mass to the mass of the tool's bounding volume (e.g. the 
mass of the block from which the tool is machined). In the remanufactured tool study, the remanufacturing process only involved minor surface modifications. The study concluded that remanufacturing via DMD reduced energy consumption and emissions as well as the cost during the lifecycle of the tool.

Walter et al. (2004) state that the aerospace industry was one of the first commercial users of RM technologies. Aerospace performance requirements often impose stringent quality demands. The most profitable field of application for RM is currently found in the medical industry - most notably in the production of customized hearing aids. For small volumes of small plastic parts, the stereolithography process compares favorably with injection molding on a cost and lead time basis. The Walter et al. (2004) cost analysis showed that RM is competitive due to the high throughput and low material costs incurred when producing small volumes of small parts using stereolithography. For large size parts, injection moulding is still more cost efficient. The production costs for a part produced using RM depends primarily on the production volume because of both the high raw material price compared to conventional materials and the process of building up the part layer by layer, where each layer takes a specific amount of time.

Walter et al. (2004) stated that conventional manufacturing costs increase as geometric complexity increases and as production volumes decrease. Material costs do not typically count for much in relation to the set-up costs for a production run and tooling costs for geometrically complex parts. Rather it is the size of the part that is the primary cost driver. When a part is made via RM close to the point of use, the costs of warehousing and delivery are eliminated. The problem of expensive and difficult delivery to remote locations disappears. Even though RM cannot yet compete with traditional mass production techniques for high volumes, the situation may already be different for low volume production parts that are not needed very often and where inventory holding and logistics costs are high in relation to production costs.

Ruffo and Hague (2007) extended a well-known cost modeling method to the costing of parallel production in which batches of different components are simultaneously fabricated on an RM machine. Three methods were tested in a real case study concerning two automotive components. Only one of the three models proved to be sufficiently detailed for accurate cost assignment. When different components are efficiently batched for simultaneous production in the RM machine, the cost of each component decreases. 
Luo et al. (1999) compared the environmental performance of various solid freeform fabrication (SFF) processes. The authors used the Environmental and Resource Management (ERMD) Data and Eco-indicator to provide quantitative measures for each phase of the process. Based on the process model and the evaluation method, the authors analyzed the environmental performance of three widely used SFF processes: Stereolithography (SL), Selective Laser Sintering (SLS) and Fused Deposition Modeling (FDM). The authors stated that the process productivity and energy consumption rate for SL, SLS, and FDM can be determined according to the principle of layered fabrication. The authors concluded that material, energy, and disposal scenarios such as recycling, landfill, and incineration are important issues for assessing environmental performance of a process. The results are varied for each process for different combinations of building material, process equipment, and disposal scenarios. The results of the study only consider environmental effects for SFF processes, and the authors recommended considering other technical issues such as accuracy, capacity, cost, and efficiency to assess the whole value of any SFF process (Luo et al., 1999).

Ruffo et al. (2006) discuss research conducted by Hopkinson and Dickens (2003) in which an RM study calculated the cost of a part assuming that the machine was producing only copies of the same part with constant production times. Their model was used to calculate a first approximation break-even analysis comparing LS manufacture with injection molding (IM) techniques in order to determine when RM was economically preferred. Figure 7 shows a typical example of the results of the study conducted by Hopkinson and Dickens (2003).

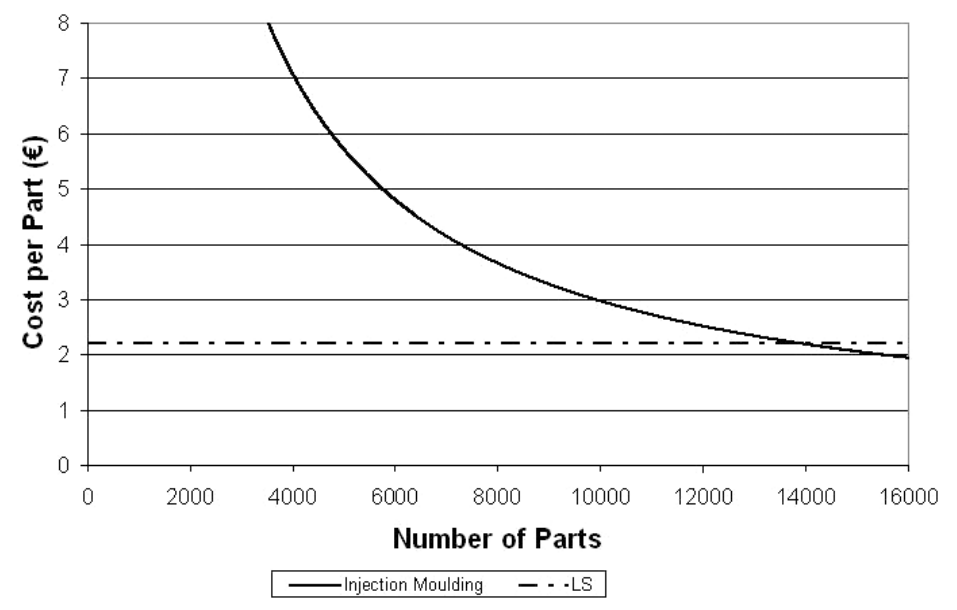

Figure 7 Example of break-even analysis comparing LS with injection moulding (Ruffo et al., 2006) 
Ruffo et al. (2006) observe that the model provides a good approximation but is only valid where the RM method is making relatively high production volume copies of the same part. However, the analysis shown in Figure 7 is less accurate for lower production volumes as well as parallel production of dissimilar parts. Ruffo et al. (2006) extend Hopkinson and Dicken's model to be valid for both low and high volume production. They furthermore find a relationship between a part and its cost in the case of LS manufacturing. The model incorporates the full cost of an RM organization including all costs of plant and production, costs of administration, and costs of the necessary overheads. The time and material used during the build were the main variables of the costing model.

Ruffo et al. (2006) apply their extended cost model to a lever case study shown in Figure 8 (a). The study compared four costing approaches for production of the lever using similar material and machine settings. Figure 8 (b) compares (1) the IM and Hopkinson and Dickens (HD) curves from the original model, dated 2003; (2) an RM curve obtained utilizing the new mathematical model driven by the assumptions used by Hopkinson and Dickens (RM2003) (3) an RM curve similar to (2) but with the introduction of a 50\% material recycling rate (RM2003 R50), and (4) an RM curve obtained using the new model and adopting a full costing system based on up-to date data in 2005 (RM2005).

Ruffo et al. (2006) observe that LS is still an expensive process due primarily to the initial investment of the machine purchase and its maintenance. According to this result, the machine cost for RM process could be an indicator for the next generation of machines dedicated to layer manufacturing (Ruffo et al., 2006). In conclusion, a deeper analysis was conducted to ascertain the roots of the cost model evolution (Ruffo et al., 2006). Moving on a timescale from the old to the current model, there was a significant increase in the indirect costs. The importance of material cost was reduced from 78 per cent to 33 per cent of the total cost per part. Equally important, the machine investment and its maintenance played a significant role, passing from 24 per cent in the old model to 38 per cent of total costs in the model presented in the study. The study underlines the importance of keeping new technology cost models up-to-date, mainly because the high automation of processes moves costing relevance from labour and material to investments and overheads. 


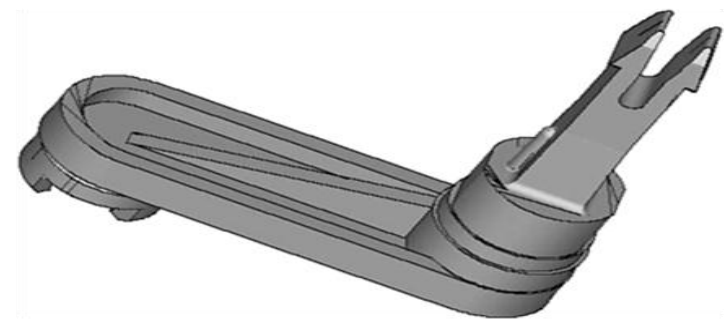

Lever, the object of the study

(a)

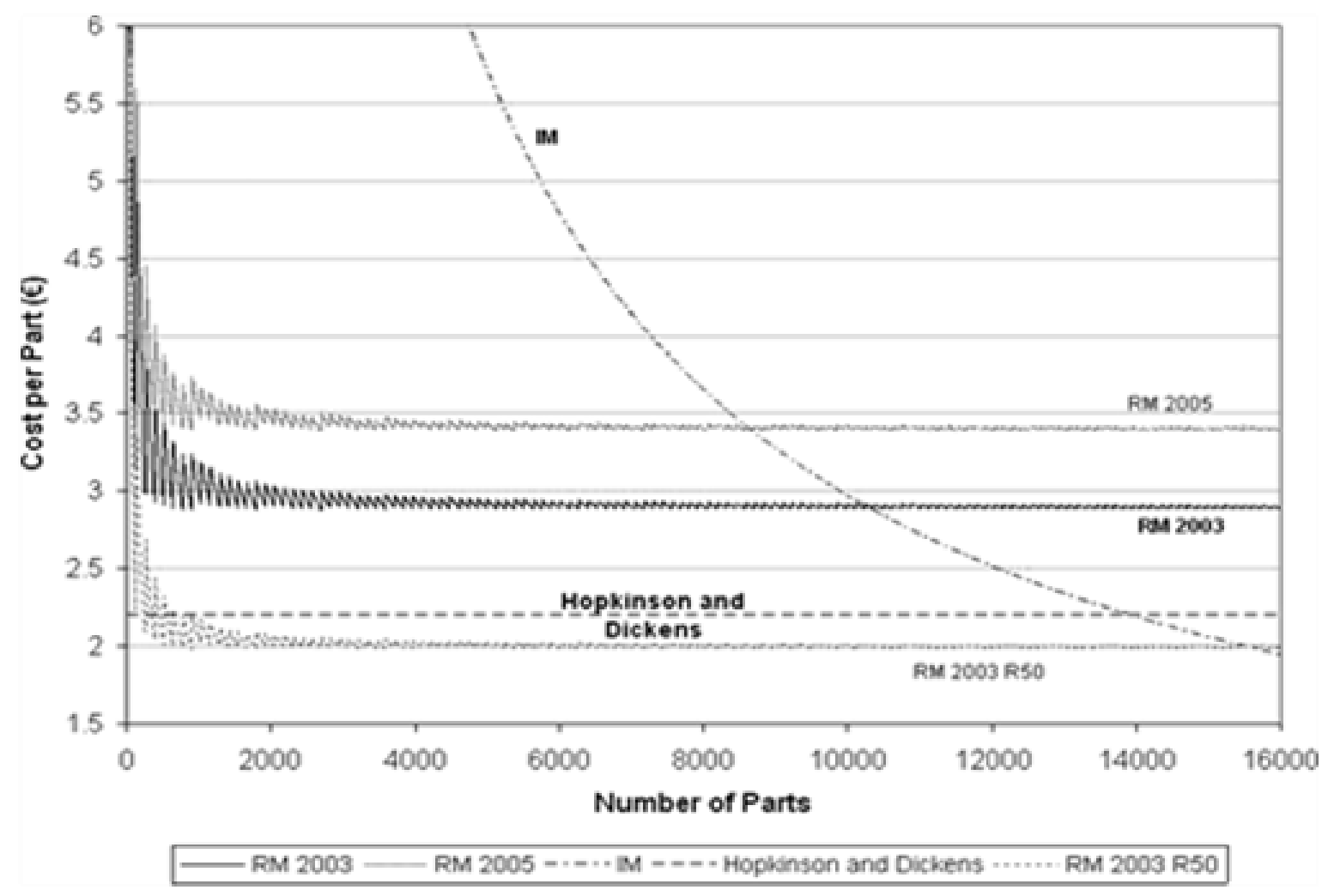

Cost model comparison LS versus IM

(b)

Figure 8 (a) lever (the object of study) and (b) Cost comparison between laser sintering and injection molding (Ruffo et al., 2006) 


\subsection{Problem Statement}

Currently, researchers have done life cycle assessment work on conventional processes such as casting and forging. These processes require very expensive molds and dies; hence, the parts made from these expensive tools tend to be made at a single location. If the parts were made at numerous locations, the fixed tooling costs associated with each part would be much too high. This is therefore called "centralized manufacturing". With centralized manufacturing, raw materials are shipped from the point of production to the location where the molds or dies are located. The components are then fabricated, and the components must then be shipped from the location of manufacture to wherever the product is ultimately used. The typical model is that very large quantities of parts are made at one location. They are then shipped to a warehouse near the assembly plant(s). The assembled product is then delivered to a retail store or directly to a customer. Spare parts are also shipped from the warehouse to customers.

New additive manufacturing processes are able to make parts without any molds or dies. This opens up the possibility of "distributed manufacturing" in which parts are made close to the point of use, and they are made only when needed. In this model, raw materials are shipped to distributed locations. Upon receipt of an order, an additive manufacturing process close to the customer is used to fabricate the part.

Although the environmental impact of conventional processes and a small number of additive processes have been studied, they have tended to focus on issues such as raw material usage and energy consumption during manufacturing. Detailed models comparing different centralized and distributed manufacturing scenarios have not been created. More specifically, the impact of transportation on environmental impact for the two alternative approaches has not been closely studied. The aim of this thesis is to develop a more comprehensive environmental impact model that compares these two approaches.

\subsection{Problem Scope}

The study calls for the gathering of information on all stages of titanium part production under both centralized and distributed manufacturing scenarios. This information is needed to create models of each process stage within titanium production via forging and via electron beam melting. This thesis does not deal with design or analysis of a specific mechanical component, 
although the significant potential for reduction in environmental impact associated with component redesign must be recognized.

For the centralized manufacturing model, the scope of environmental impacts covered includes:

(1) Production of ingot and transportation of it to the appropriate factory (die machining or part forging),

(2) Production of tooling (transportation of steel to a machining factory, machining of die, and transportation of dies to forging factory),

(3) Forging (electricity needed),

(4) Milling of the forged part, and

(5) Transportation of finished part to the customer location.

For the distributed manufacturing model, the scope of environmental impacts covered includes:

(1) Refining of feedstock materials and their transportation to a powder production facility (Ti-6Al-4V ingot, Helium gas),

(2) Production of powder feedstock material via gas atomization (melt energy, gas flow requirements, etc). Transportation of powder from a gas-atomization factory to an EBM factory is not counted at this stage,

(3) Electron beam melting (electricity needed),

(4) Milling of an EBM part, and

(5) Transportation of the finished part to the customer location. 


\section{Chapter 3 Fundamental Approach}

\subsection{System description}

The work presented herein shows a thesis of two methods for production of titaniumparts. One involves centralized manufacturing via forging, and the other involves distributed manufacturing via electron beam melting (EBM). SimaPro 7.2 software was used to model these two production methods and the resulting environmental impacts. SimaPro currently has an available model for the forging of aluminum, but it does not have a model for the forging of titanium. It does not currently have a model of the EBM process either. For this research, it was therefore necessary to create a detailed model of the titanium forging and titanium EBM processes.

\subsection{Modeling of the Forging Process}

The forging process requirements include raw material acquisition (die and parts) and preparation of the forging dies, transportation of raw materials and dies needed by suppliers to the forging factory, the forging process, finish machining of the forged part, transportation of the desired part to the customer or warehouse location, and recycling of waste that can include chips, defective forging tools, and obsolete parts.

While the SimaPro database includes a model for the forging of aluminum, it does not include a model for the forging of titanium. In this research, the aluminum-forging model was therefore used as a template to create a new model for forged titanium.

\subsubsection{Forging of Aluminum Parts}

A SimaPro flow chart for the forging of an aluminum part is shown in Figure 9. When simulating an aluminum forging operation and its environmental impacts in SimaPro, the user must specify certain pieces of information. 


\section{Type of Model}

Centralized Manufacturing: Al-6061T6 Final Part at Customer Location

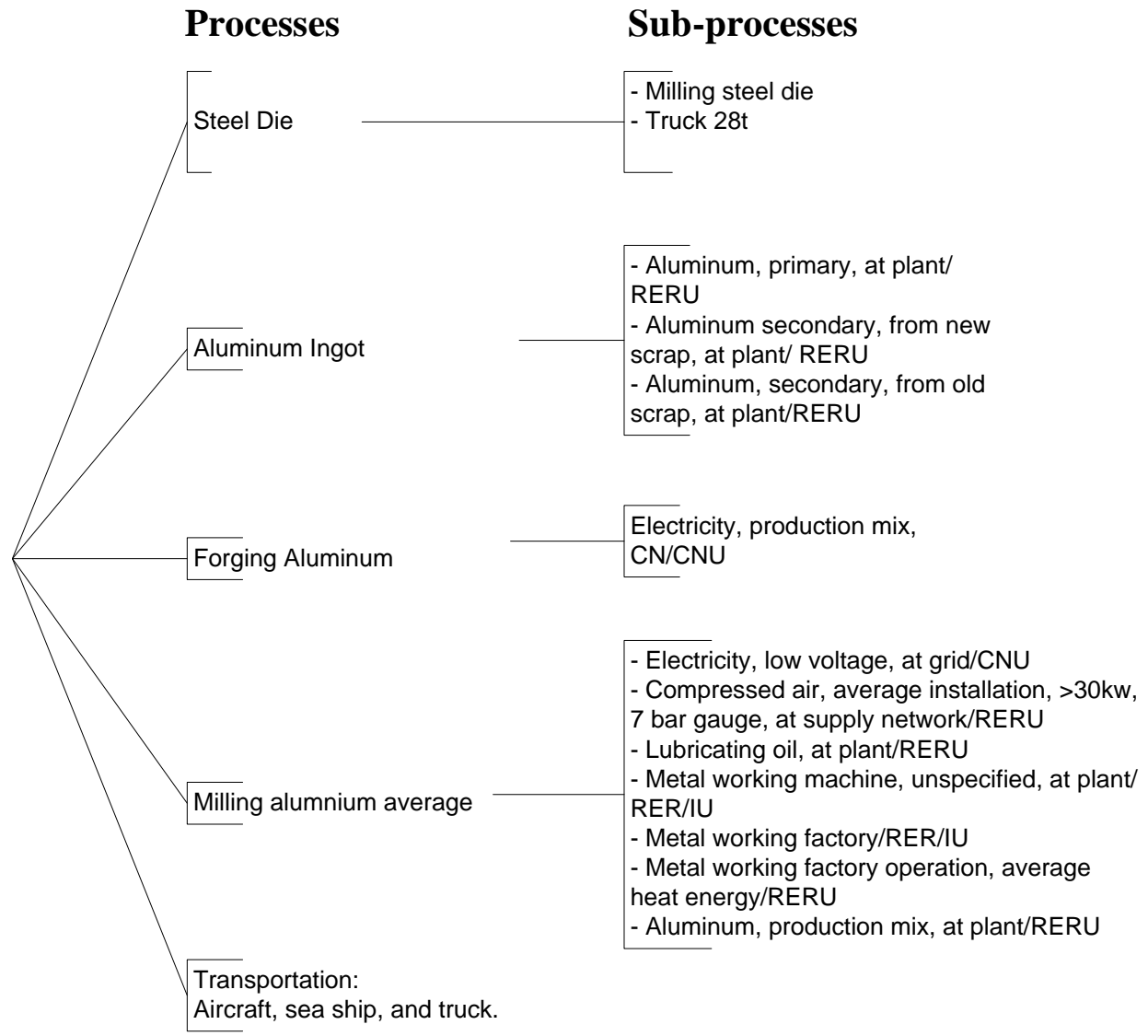

Figure 9 A flow chart of forging an aluminum part.

The SimaPro database has region specific data regarding the environmental impact associated with different power sources (coal, gas, oil, hydro, and nuclear) including water usage and carbon footprint. A user therefore is able to specify the source(s) of power provided to the forging factory along with the energy usage associated with each step of the manufacturing process chain. SimaPro then determines the environmental impact associated with power consumption for the process.

With regards to the processing steps in Figure 9, inputs that are specified by the user include: (1) mass of the part being forged and mass of the forging die (kg), (2) mass of raw material to be transported $(\mathrm{kg})$, (3) mass of materials that will undergo processing (forging and milling) including any waste/scrap (nominally 10\% for this research), and (4) transportation distances $(\mathrm{km})$ for raw materials, dies, and the final part. 
Once the user has specified all inputs to the model, a simulation for those specific input conditions can be conducted. SimaPro will then determine the environmental impacts associated with the processes and will prepare an output report for the user. Note that the model allows users to quickly and easily simulate a variety of different scenarios in order to assess how the environmental impact changes as conditions such as part size, production volume, amount of

finish machining, and transportation distance change. For the case of forged aluminum, the SimaPro model will provide the user with the following information:

- Number of Eco-Points in case of low and high buy-to fly ratio

- Number of Eco-Points in case of low and high production quantity

- Number of Eco-Points in case of low and high transportation distance

The Eco-Point score is a measure of the overall environmental impact of a particular product or process. More Ecopoints indicate a higher environmental impact. The environmental impacts considered when computing the number of Eco-Points are climate change, fossil fuel depletion, ozone depletion, freight transportation, human toxicity from air pollution, human toxicity from water pollution, waste disposal, water extraction, acid deposition, ecotoxicity, eutrophication, summer smog, and mineral extraction (Source: aggregain.wrap.org.uk).

\subsubsection{Forging of Titanium Parts}

As noted previously, SimaPro does not have a predefined model for the forging of titanium. The aluminum forging model was therefore used as a template to produce a titanium forging model. In order to do this, a number of modifications to the model were required.

Although SimaPro's model for the forging of aluminum can be easily adapted for the forging of titanium, it is important that the model reflect the fact that production of the titanium forging preform will have different environmental impacts than those of an aluminum preform. For example, titanium requires more energy to deform than aluminum during the forging process. It was therefore necessary to replace energy consumption values for the aluminum model with reasonable estimates for energy consumption in the new titanium model. Ashby (2009) estimates that the energy needed to forge Ti-6Al-4V alloy is between 4.71 and $5.7 \mathrm{MJ} / \mathrm{kg}$. The existing SimaPro model for aluminum forging estimates the energy needed to deform aluminum as $1.61 \mathrm{MJ} / \mathrm{kg}$. Stress-strain curves for Al6061T6 (Tang et al., 2006) and of Ti-6Al- 
4V(Xue et al., 2002) alloys are shown in Figure 10. The energy absorbed by a deformed material can be estimated by the area under the stress-strain curve. The typical strain experienced in a forging operation is between 0.1-0.5 (Guo et al., 2005). The maximum strain at failure for Ti$6 \mathrm{Al}-4 \mathrm{~V}$ alloy is often closer to the 0.1 value. The black vertical line in Figure 10 shows the stress values for the aluminum and titanium alloys at a strain of 0.1 . At this strain, the stress for titanium is approximately 3.1 times greater than the stress for aluminum. If the SimaPro aluminum forging energy of $1.61 \mathrm{MJ} / \mathrm{kg}$ is multiplied by 3.1 for titanium, then a value of 4.99 $\mathrm{MJ} / \mathrm{kg}$ is obtained. This value falls within the interval of values suggested by Ashby (2009) for energy needed to forge Ti-6Al-4V.

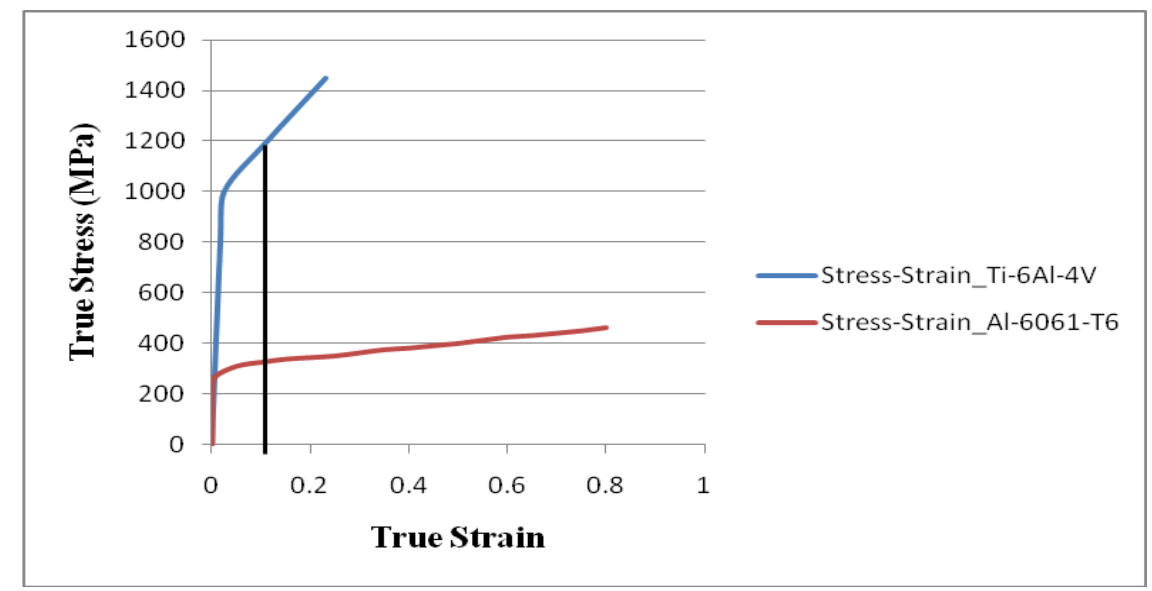

Figure 10 Stress-strain energy curvature.

A SimaPro flow chart for the forging of a titanium part is shown in Figure 11. A Ti-6Al$4 \mathrm{~V}$ titanium alloy consists primarily of titanium, aluminum and vanadium, hence production of those three elements must be included in the model. The "aluminum primary" sub-process shown in Figure 9 refers to the infrastructure needed to produce aluminum from ore. For Ti-6Al-4V alloy, it is also necessary to include the processes of refining titanium and vanadium. Detailed information on the infrastructure required to refine titanium and vanadium could not be located for this research; hence, Simapro's existing model for refinement of aluminum was used as an approximation. For future work, it is recommended that the titanium and vanadium refinement models be further developed. 
Type of Model

Centralized Manufacturing: -Ti-6Al-4V Final Part at Customer Location

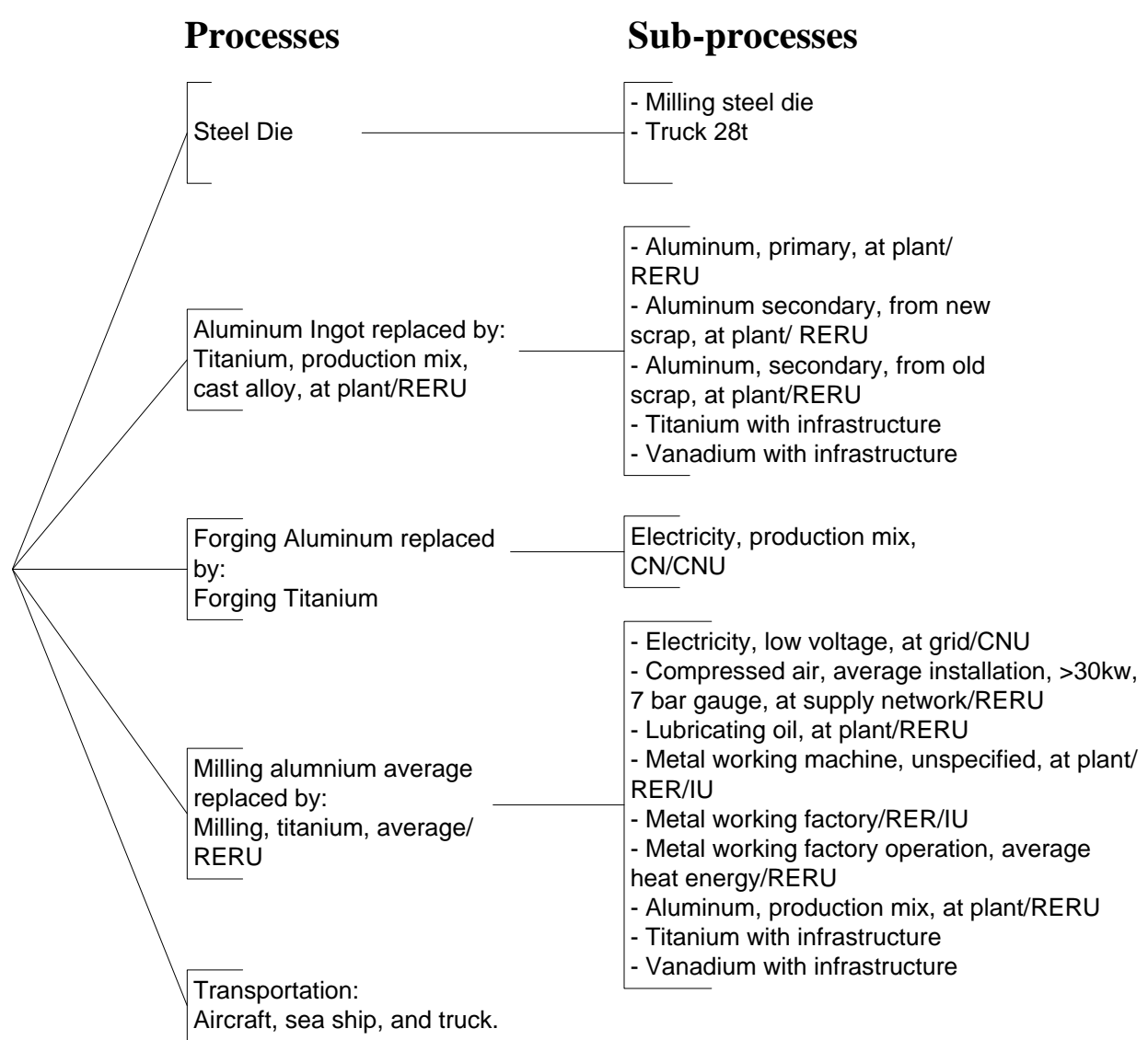

Figure 11 A flow chart of forging a titanium part.

Once the user has specified all inputs to the model (e.g. part size, amount of machining, transportation distance, etc), a simulation for those specific input conditions can be conducted. SimaPro will then determine the environmental impacts associated with the processes and will prepare an output report for the user. For the case of forged titanium, the SimaPro model will provide the user with the following information:

- Number of Eco-Points in case of low and high buy-to fly ratio

- Number of Eco-Points in case of low and high production quantity

- Number of Eco-Points in case of low and high transportation distance

\subsection{Modeling of the EBM Process}

Forging represents a centralized approach to part production. Due to the high cost of forging dies and equipment, forging is typically done at a small number of locations. Large 
quantities of parts are then transported long distances to the warehouse or end user. The previous sections provide details on how the forging processes for aluminum and titanium are modeled in SimaPro, and they describe the environmental impact analysis that comes out of those models.

In this section, the distributed manufacturing model based on the EBM process is described. The EBM process requires no tooling, hence it can more easily be implemented at a large number of locations that are much closer to the point of use (i.e. distributed manufacturing). The need for tooling is eliminated, and the transportation distances are much smaller.

Figure 12 shows a SimaPro flow chart for the EBM process that includes processing steps such as powder production and electron beam melting that are quite different from forging.

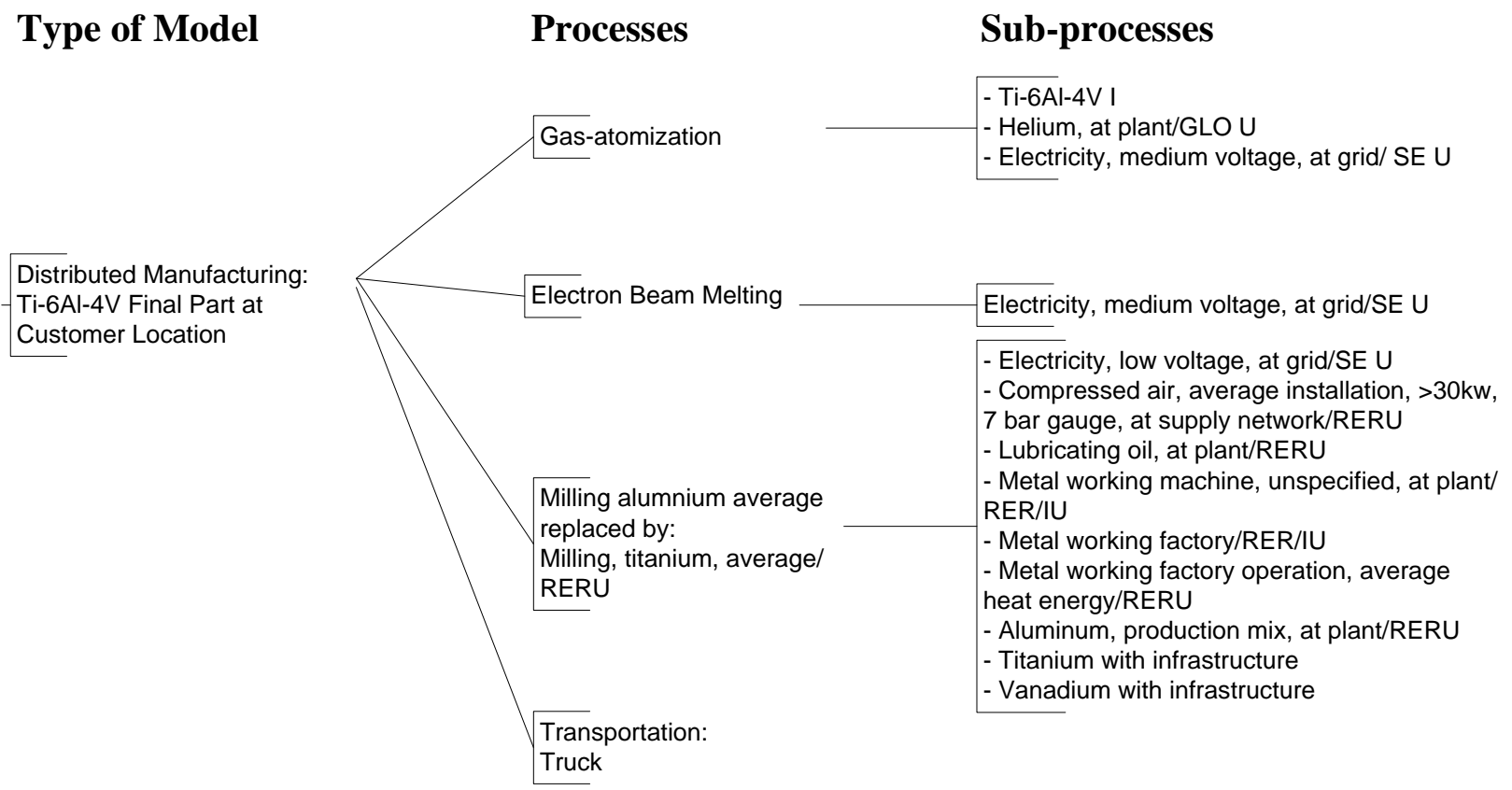

Figure 12 A flow chart of EBM titanium process

\subsubsection{Gas Atomization}

In the creation of a new model of the EBM process, it was first necessary to estimate the impacts of the powder production method. There are many ways to produce metal powders. Gas atomization is one of the more prevalent methods, hence it was used for this model. In the gas atomization procedure, metal billet/rod/wire is melted under a protective gas atmosphere (e.g. argon, nitrogen, and/or helium) in a crucible by means of medium frequency induction heating, 
and the melt is brought to the operating temperature (Unal, 1987). Atomization is started by blowing the atomizing gas across the tip of the nozzle. This causes the metal to be drawn up the metal flow tube to the tip of the nozzle where the jet of gas atomizes the molten metal (Unal, 1987).

The primary considerations for gas atomization are the energy needed to melt the metal and the amount of inert gas consumed. According to Groover (2010), the energy used to melt a given quantity of metal is:

$$
H=\rho V\left\{C_{S}\left(T_{m}-T_{0}\right)+H_{f}+C_{l}\left(T_{p}-T_{m}\right)\right\}
$$

where $H$ is total heat required (joules) to raise the temperature of the metal to the pouring temperature, $\rho$ is the density of titanium $=4600 \mathrm{~kg} / \mathrm{m}^{3}, C_{S}$ is the weight specific heat for the solid metal $=0.5263 \mathrm{~J} / \mathrm{g}^{\circ} \mathrm{C}, T_{m}$ is the melting temperature of titanium $=1632^{\circ} \mathrm{C}, T_{0}$ is the starting temperature-usually ambient $=70^{\circ} \mathrm{F}$ or $21.11^{\circ} \mathrm{C}, H_{f}$ is the heat of fusion $(\min , \max )=(275.56 \mathrm{~J} / \mathrm{g}$, $296.23 \mathrm{~J} / \mathrm{g}), C_{l}$ is the weight specific heat of the liquid metal of titanium $=931 \mathrm{~J} / \mathrm{Kg}-{ }^{\circ} \mathrm{K}$ (Kaschnitz et al.), $T_{p}$ is the pouring temperature $=1958.4^{\circ} \mathrm{C}$, and $V$ is the volume of metal being heated $\left(\mathrm{m}^{3}\right)$. Unless otherwise noted, the material properties listed were obtained from www.matweb.com.

To estimate the heat of fusion for a quantity Ti-6Al-4V to be atomized, the enthalpy of fusion for titanium $\left(3161 \pm 120 / \mathrm{cal} \mathrm{mol}^{-1}\right)$ (Treverton, \& Margrave, 1971) was multiplied by 0.90 and the molecular weight of titanium. The enthalpy of fusion for aluminum $(10,580 \pm 150 \mathrm{~J} / \mathrm{mol})$ (Desai, 1987) was multiplied by 0.06 and the molecular weight of aluminum and the enthalpy of fusion of vanadium of $4136 \pm 170 / \mathrm{cal} \mathrm{mol}^{-1}$ (Treverton, \& Margrave, 1971) was multiplied by 0.04 and the molecular weight of vanadium. The multiplication values correspond to the alloying percentage of each element in Ti-6Al-4V. Adding the above min/max quantities, the heat of fusion is estimated to be between 275.56 and $296.23 \mathrm{~J} / \mathrm{g}$. Boivineau et al (2006) experimentally estimated the heat of fusion for Ti-6Al-4V alloy to be $290+/-5 \mathrm{~kJ} / \mathrm{kg}$ which falls within the calculated range above. In the formula of total heat, $\rho \times \mathrm{V}$ is the mass of the part. In this research, a small part is defined to have a mass of $1 \mathrm{~kg}$ and a large part has a mass of $46 \mathrm{~kg}$. Plugging these mass values into the heat of fusion equation, the energy needed to melt a small $1 \mathrm{~kg}$ quantity is estimated to be $1.45 \mathrm{MJ}$. Likewise, the energy needed to melt the larger $46 \mathrm{~kg}$ quantity of metal is estimated to be $66.6 \mathrm{MJ}$. 
In the atomization process, the molten metal is atomized by a jet of inert gas. Unal (1987) describes the effect of atomization parameters on aluminum powder production. Unal (1987) used helium/metal gas flow ratios ranging from 1.26 - 3.65 for atomization of aluminum at a pressure $(P)$ of $1.56 \mathrm{MPa}$. For this research, a comparable gas flow rate for titanium is assumed, however, the metal/gas flow ratio is adjusted to reflect the different densities of titanium and aluminum powders. The adjusted metal/gas flow ratio of titanium therefore ranges from 0.7 2.15 .

\subsubsection{Electron Beam Melting}

Baumers et al. (2010) present a comparative assessment of electricity consumption for two major metallic additive manufacturing (AM) processes - selective laser melting and electron beam melting. In the study, the researchers studied mean real power consumption per measurement cycle and total cumulative energy consumed. Five parts were built in an Arcam A1 EBM machine, and energy consumed during each build was recorded. Energy consumption per gram of titanium processed, assuming $100 \%$ dense parts, was therefore calculated to be $0.017 \mathrm{kwh} / \mathrm{g}$. Although the exact energy consumption will vary depending on part size, the 0.017 $\mathrm{kwh} / \mathrm{g}$ value published by Baumers et al. (2010) has been adopted in the SimaPro EBM model developed in this research.

SimaPro EBM model inputs that are specified by the user include: (1) mass (kg) of gasatomized powder needed to produce the part, (2) mass $(\mathrm{kg})$ of material melted in the EBM process, (3) mass $(\mathrm{kg})$ of material to be finish machined following the EBM process, (4) waste/scrap factor (taken as $10 \%$ for this research), and (5) transportation distance $(\mathrm{km})$ needed to deliver the finished part to the end user.

Once the user has specified all inputs to the model, a simulation for those specific input conditions can be conducted. SimaPro will then determine the environmental impacts associated with the processes and will prepare an output report for the user. For the case of EBM, the SimaPro model provides the user with the following information:

- Number of Eco-Points in case of low gas/metal flow and low energy H

- Number of Eco-Points in case of low gas/metal flow and high energy H

- Number of Eco-Points in case of high gas/metal flow and low energy $\mathrm{H}$

- Number of Eco-Points in case of high gas/metal flow and high energy H 
As indicated above, the number of Eco-Points associated with the process depends on imprecise input data. Sensitivity analysis is therefore conducted to determine the extent to which the low/high range values change the analysis results. If there is very little impact, then the value that one uses within the range is relatively unimportant. If the number of Eco-Points changes significantly as the input parameter value ranges from low to high, then the importance of getting precise values for those parameters increases.

\subsection{Fundamental Tools}

Using the forging and EBM models just described, it is possible to compare the environmental impacts associated with centralized and distributed manufacturing under different production scenarios (e.g. part size, amount of finish machining, transportation distance). SimaPro was first used to run preliminary simulations involving production of a forged Al6061T6 aluminum part. SimaPro was subsequently used to compare the environmental impact associated with centralized manufacturing and distributed manufacturing for the Ti-6Al-4V titanium alloy.

Simapro software's default unit of mass is the kilogram, and the default unit for transportation of goods is $\mathrm{Kg}-\mathrm{Km}$. Simulations are performed for specific parts of known dimensions. The mass of the part can be determined using the standard relationship between mass, volume, and density. In order to forge a part, it is necessary to produce a steel forging die having specific overall dimensions. The relationship between mass, volume, and density may also be used to determine the mass of steel needed to produce a forging die of a particular size. While the size of a forging die is specific to a given part, this research assumes a reasonable die volume of three times the volume of the part to be forged. That value can easily be changed for a specific case study though.

Simulations approximate a real system, and the modeling process often requires a number of assumptions and averaging of data. For instance, forging involves plastic deformation of a metallic part. The amount of energy needed to deform the material is a function of the alloy and its heat treat condition as well as the specific part geometry. When one looks up mechanical properties of a given alloy in handbooks, values such as tensile strength and modulus are usually provided as a range of values between some upper and lower limit. It is therefore necessary to 
make reasonable assumptions when precise data is not available. In this research, the simulations conducted included some sensitivity analysis in order to determine the extent to which certain assumptions influence the simulation output. If small changes in an input value produce large changes in the environmental impact (i.e. the number of eco-points), then it is clear that great care must be taken to get the most accurate estimates possible for that input parameter. If the model output is relatively insensitive to changes in the input value, then the precision associated with that parameter can be assumed to be less critical.

The simulation model considers four factors: the production quantity (low or high), the transportation distance (short or far), the buy-to-fly ratio of the finish machining process (small or large), and the size of the part (small or large). For purposes of this research, a small part (aluminum or titanium) is defined as having a mass of $1 \mathrm{~kg}$. A large aluminum part is defined as having a mass of $27 \mathrm{~kg}$, and a large titanium part is defined as having a mass of $46 \mathrm{~kg}$. The large part sizes were determined by the upper limit on part size producible within the EBM machine's build volume (approximately $20 \times 20 \times 25 \mathrm{~cm}^{3}$ ).

Regarding transportation distance of raw material and dies, a short transportation distance is defined as $1 \mathrm{~km}$. A large transportation distance is defined as $1000 \mathrm{~km}$. For the buy-to-fly ratio, values of 12:1 and 20:1 are considered to be the small and large values respectively for centralized manufacturing in this research. These are the same values used by Kuchi (2009) for a centralized manufacturing scenario. A buy-to-fly ratio of 1.03:1 is assumed for the distributed manufacturing scenario in which the near net shape EBM process is used with very little finish machining. In terms of production quantity, the large and small production quantities for this research are taken as 100 parts and 1 part respectively. Although 100 parts is not a large production quantity in conventional manufacturing, it would be considered a large production quantity for the EBM process. For production quantities in the thousands or higher, one would likely choose to mass produce the component via forging. Figure 13 shows the simulation structure for all combinations of the four factors: production quantity, transportation distance, part size, and buy-to-fly ratio. 


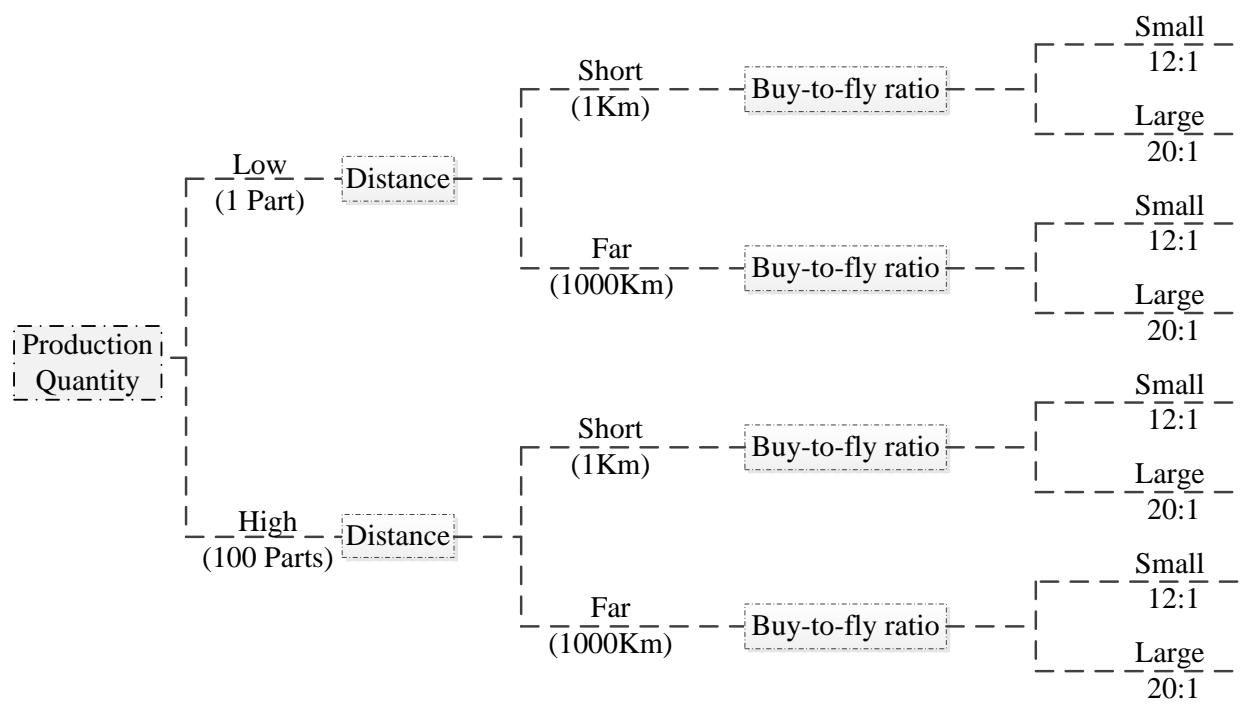

Figure 13 Levels of Simulation analysis structure

Although the transportation distance for raw materials has been discussed, the method of transportation of finished parts is also an important element of the model. Two transportation scenarios have been considered in the model (Figure 14). In the first scenario, a part is assumed to be manufactured in central China and then exported to a port in California by air. The transportation distance through air is $11000 \mathrm{~km}$. From California, the product is then transported by truck to the central United States (Kansas) over a distance of $1900 \mathrm{~km}$. In the second transportation scenario, the product is manufactured in central China and transported by truck to Shanghai over a distance of $1700 \mathrm{~km}$. The product is then shipped by boat to San Francisco over a distance of $9900 \mathrm{~km}$. Finally, the product is transported by truck to Kansas from San Francisco over a distance of $2100 \mathrm{~km}$.

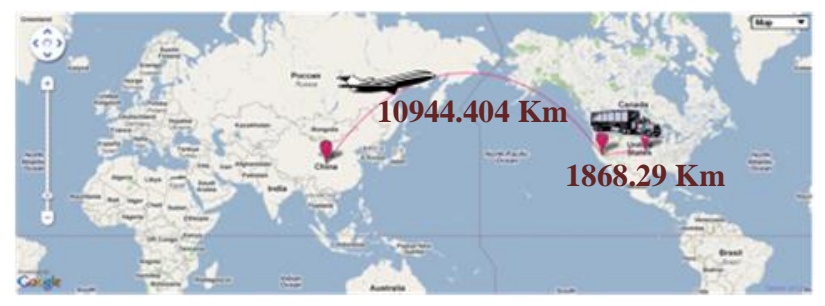

Shipment from China to USA by aircraft

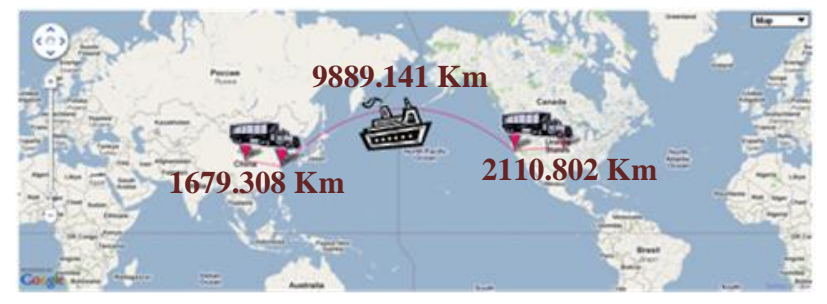

Shipment from China to USA by boat

Figure 14 Possible modes of shipment 


\subsection{Model capability}

In this research, an environmental impact model for both centralized manufacturing and distributed manufacturing has been developed using SimaPro7.2 software. The models have been created through assemblies of materials and processing steps. For each element of an assembly, the user typically inputs values used by SimaPro to determine the environmental impact. In Figure 15 for example, a steel die and an aluminum ingot are considered to be inputs to a forging factory under the Materials/Assemblies heading. The unit "p" refers to the number of pieces. Under the Processes heading, the user inputs data regarding the amount of forged aluminum $(\mathrm{kg})$, the amount of aluminum to be milled $(\mathrm{kg})$, and the transportation quantities $(\mathrm{kg}-\mathrm{km})$ by air, sea, and land (truck). In order to simulate the environmental impact under different scenarios (e.g. large part versus small part, large transportation distance versus short transportation distance, etc), the user merely needs to edit the model inputs and then rerun the simulation model.

Although aluminum is the desired part material in the proposed model in Figure 15, it was possible to create similar models for centralized and distributed manufacturing of Ti-6Al-4V as shown in Figures 9, 11 and 12.

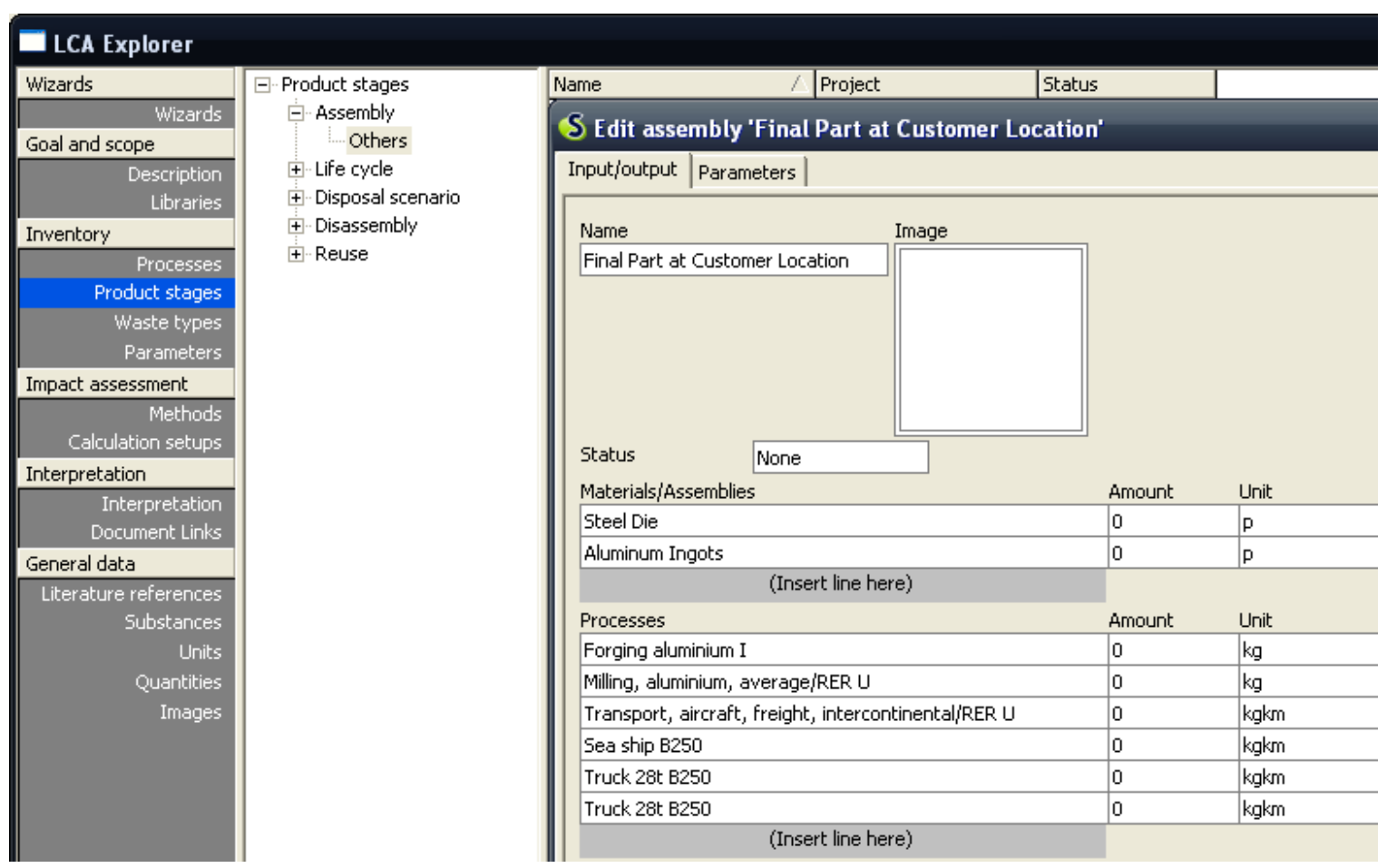

Figure 15 Aluminum forging system model structure in SimaPro 


\section{Chapter 4 Preliminary Results}

This chapter describes preliminary results from SimaPro aluminum forging simulations for all combinations of production quantity (low or high), transportation distance (short or far), buy-to fly ratio (small or large), and part size (small or large). As described in Chapter 3, the model considers aluminum ingot production, the forging process, and finish machining. The complete environmental analysis also considers delivery of the finished part to the end user.

Regarding input materials, the quantity of steel $(\mathrm{kg})$ used to produce the forging dies is specified in the model. Furthermore, the quantity of aluminum ingot (kg) used in the forged part is also included as input to the forging plant. With those material inputs to the forging factory, an ingot is forged. The forged part is then transported directly to a machine shop for finish machining. In this model, machining is assumed to take place in the same factory as forging.

Transportation from the forging factory to the end user is included in the model. Batches of parts ranging from 1 part (small lot) to 100 parts (large lot) may be transported. Shipment of the finished part(s) from China to the West coast of the USA can be done in two ways: via aircraft or boat. All ground transportation in the model is assumed to be done using a 28T truck. That includes road transportation of the final part(s) as well as steel dies. Disposal of waste streams such as old dies, finish machining chips, and defective aluminum parts is not included in the model as separate steps, as waste disposal is taken into consideration in each process used. No manufacturing process has a 100\% yield, hence a scrap rate is built into the model. A $10 \%$ scrap rate has been used in these simulations, although the scrap rate can easily be modified to suit a specific production operation. 


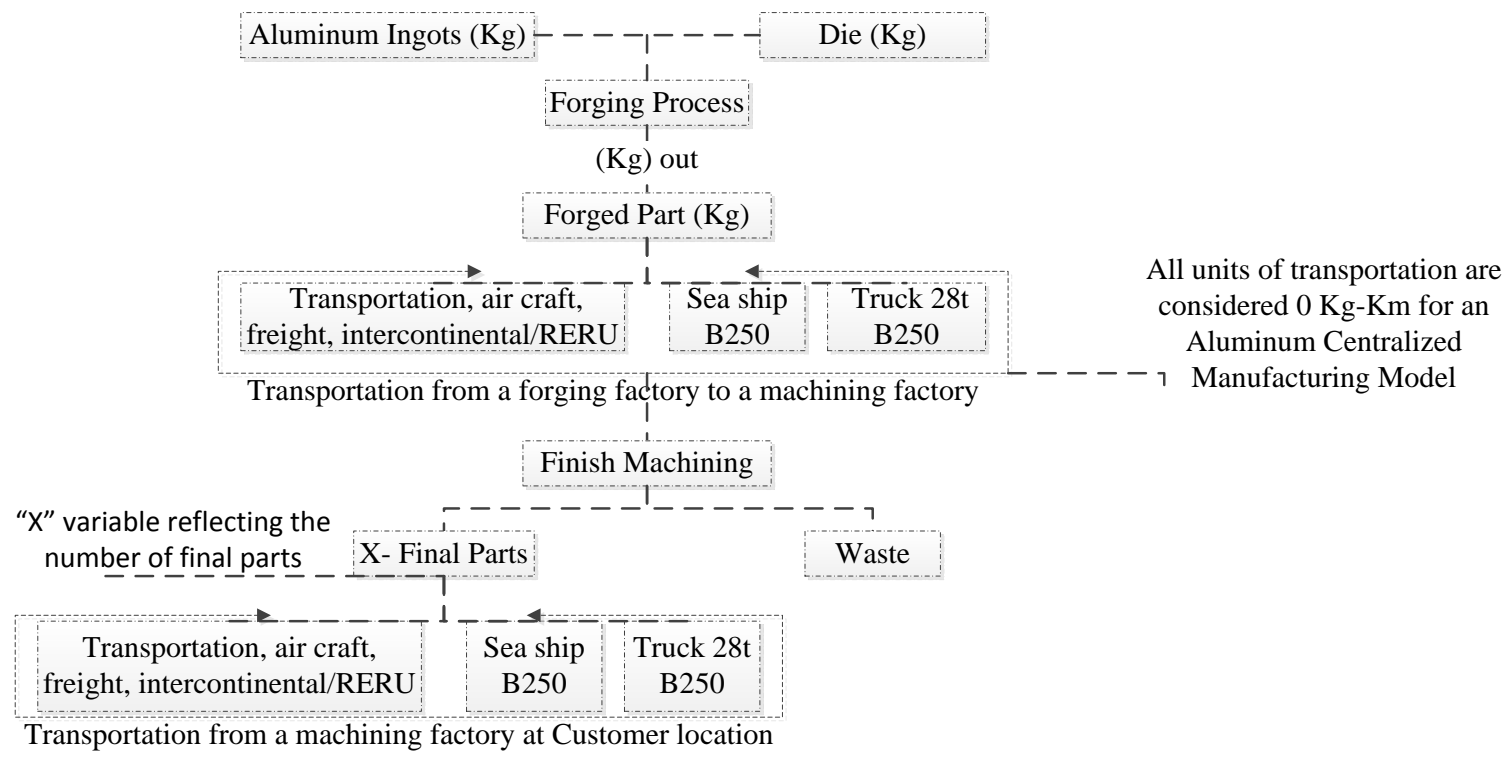

Figure 16 System structure of a centralized system (Forging Process)

The environmental analysis of the system structure conducted in SimaPro involves the Eco-Indicator 99 and Europe Eco-Invent hierarchical analysis models. Eco-Indicator 99 is a damage oriented method for lifecycle impact assessment (www.pre.nl). It is both a science based impact assessment method for LCA and a pragmatic ecodesign method. It offers a way to measure various environmental impacts, and shows the result in a single score (www.pre.nl). Eco-Indicator 99 is a life cycle impact assessment method, and Eco-Invent is a database built into the SimaPro software (www.ecoinvent.org). It is one of the most heavily used databases with consistent and transparent, up-to-date Life Cycle Inventory (LCI) data.

The structure of a centralized system model shown in Figure 16 has two categories: (1) materials/assemblies and (2) processes needed in order to ship the final part to the end-user. Note that an assembly in SimaPro refers to a collection of material inputs and processes that are needed to create an item.

For the first category of SimaPro material/assemblies, the first step is to model production of the steel die. This is done by purchasing a block of tool steel and then machining it to the desired shape. SimaPro's Ecoinvent database includes a model for the process of milling steel. The model for milling steel includes the number of kilograms of low alloy steel machined 
from the die as well as metal working factory operations. Additionally, transportation of the steel raw material to the metal working factory is included.

The second material input to the forging model structure is the aluminum ingot. SimaPro's IDEMAT 2001 database includes a model for the process of refining aluminum and producing ingots. This process also encompasses raw material acquisition and transportation of the raw material.

The steel die and the aluminum ingot represent the material inputs to the forging process. The aluminum forging process model then incorporates the following existing SimaPro processing processes: (1) forging aluminum I, (2) milling, aluminum, average/RERU, (3) transportation, aircraft, freight, intercontinental/RERU, (4) sea ship B250, (5) truck 28t B250 (a) and (6) truck 28t B250 (b). The truck 28t B250 (a) process is used wherever road transportation by truck is needed for shipment of the final part(s). Truck 28t B250 (b) takes into consideration transportation of steel dies from the steel metal working factory to the forging factory.

In order to assess the relative effects of the different factors on environmental impact, eight simulations are run for both small parts $(1 \mathrm{~kg})$ and large parts $(27 \mathrm{~kg})$. The eight simulation runs are the result of having two levels (low and high) for each of the three factors: buy-to fly ratio, production quantity, and transportation distance (i.e. $2^{3}=8$ ). The polyhedron shown in Figure 17 provides a useful tool for visualizing extreme points of the design space. The $\mathrm{X}$-axis represents buy-to-fly ratio, the $\mathrm{Y}$-axis represents transportation distance, and the Z-axis represents production quantity.

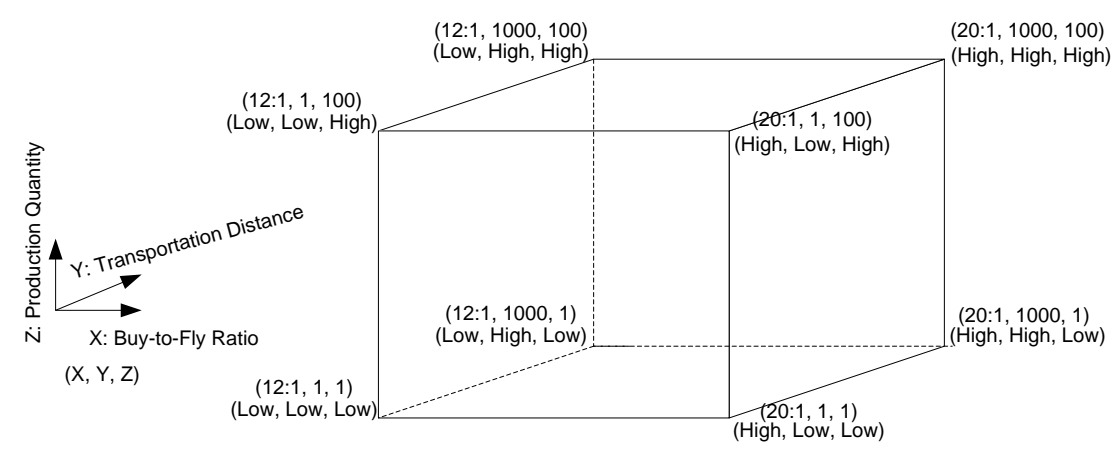

Figure 17 A polyhedron of extreme points: Eight levels of sensitivity

As discussed in Chapter 3, the user specifies inputs to the centralized manufacturing model in SimaPro. Once the user has specified inputs and runs the model, SimaPro calculates the 
environmental outputs for each process and assembly. The following legend maps colors to each source of environmental impact in Chapter 4.

- : Steel Die,

:: Aluminum Ingot,

๓: Forging Aluminum,

๓: Milling Aluminum,

๓: Transportation by aircraft or boat,

m: Truck 28t (Transportation of the final product to the customer by truck),

": Truck 28t (Transportation of the dies to the forging company)

\subsection{Environmental Impact Analysis for Forging of a Small Aluminum Part}

Referring to the environmental analysis design space illustrated in Figure 17, simulations for small $(1 \mathrm{~kg})$ parts were conducted in Simapro corresponding to the eight extreme points in the design space. For each corner of the design space, simulations were conducted for the two primary modes of overseas transportation - by boat and by plane. Figure 18 provides specific input values for each simulation condition. The output variable being measured in each simulation for comparison purposes was the number of Eco-points $(\mathrm{Pt})$. The maximum number of Eco-points recorded over those $8 \times 2=16$ simulations was 3725 Eco-points $(\mathrm{Pt})$. 


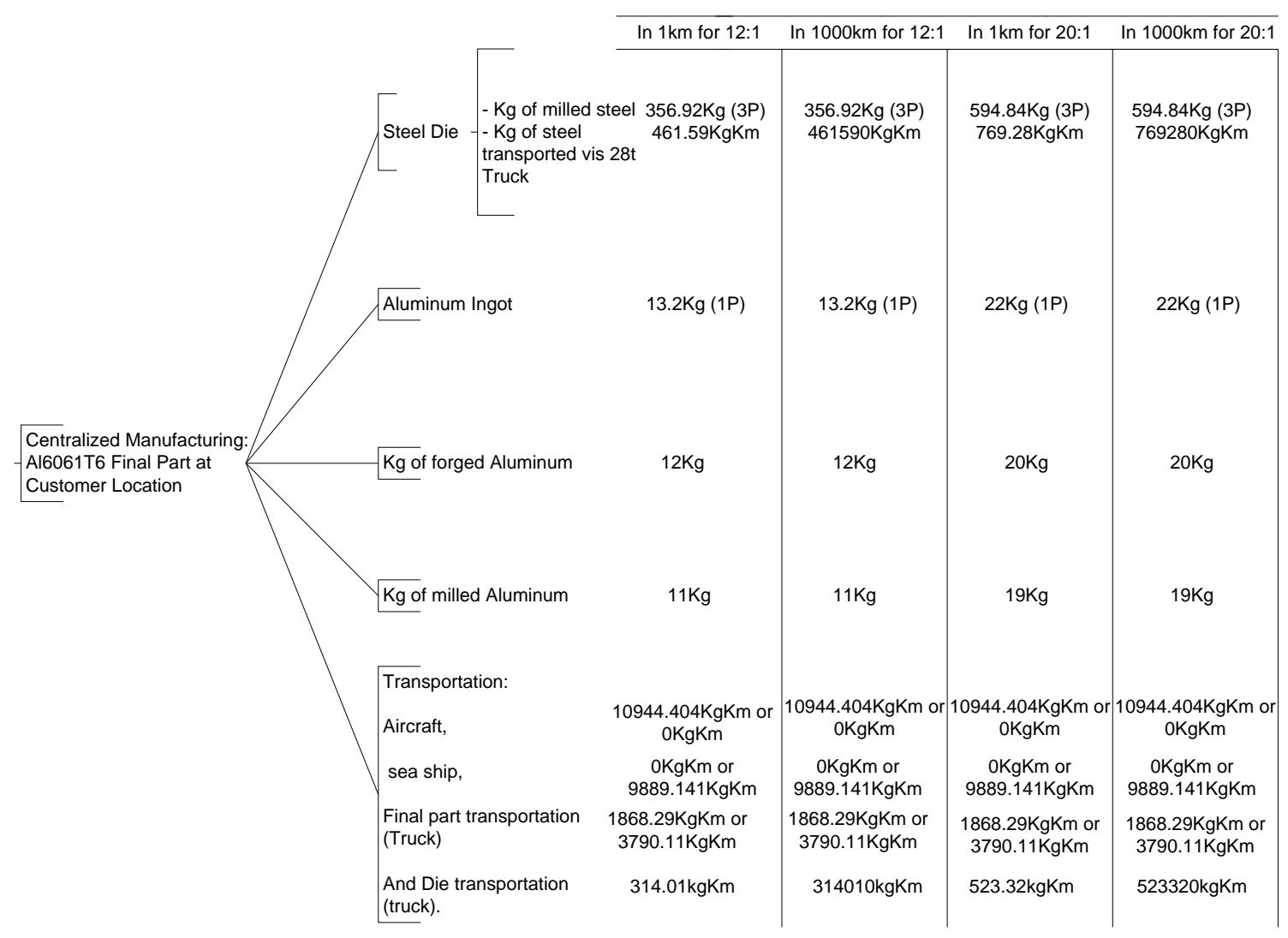

Figure 18 Inputs Entered in SimaPro for a Small Part

Figure 19 graphically compares results from each of the 16 simulations. The vertical axis for each scale is identical in order to simplify direct comparison of the results. Note that two graphs are shown for each corner of the cube. The titles of each graph differentiate whether the primary mode of overseas transportation was by boat or by plane. In order to qualitatively interpret the results, one can compare graphs on the left and right side to see the effect of the buy-to-fly ratio. Comparing graphs on the top and bottom planes illustrates the effect of production quantity. Comparing graphs on the front and back planes shows the effect of transportation distance. 

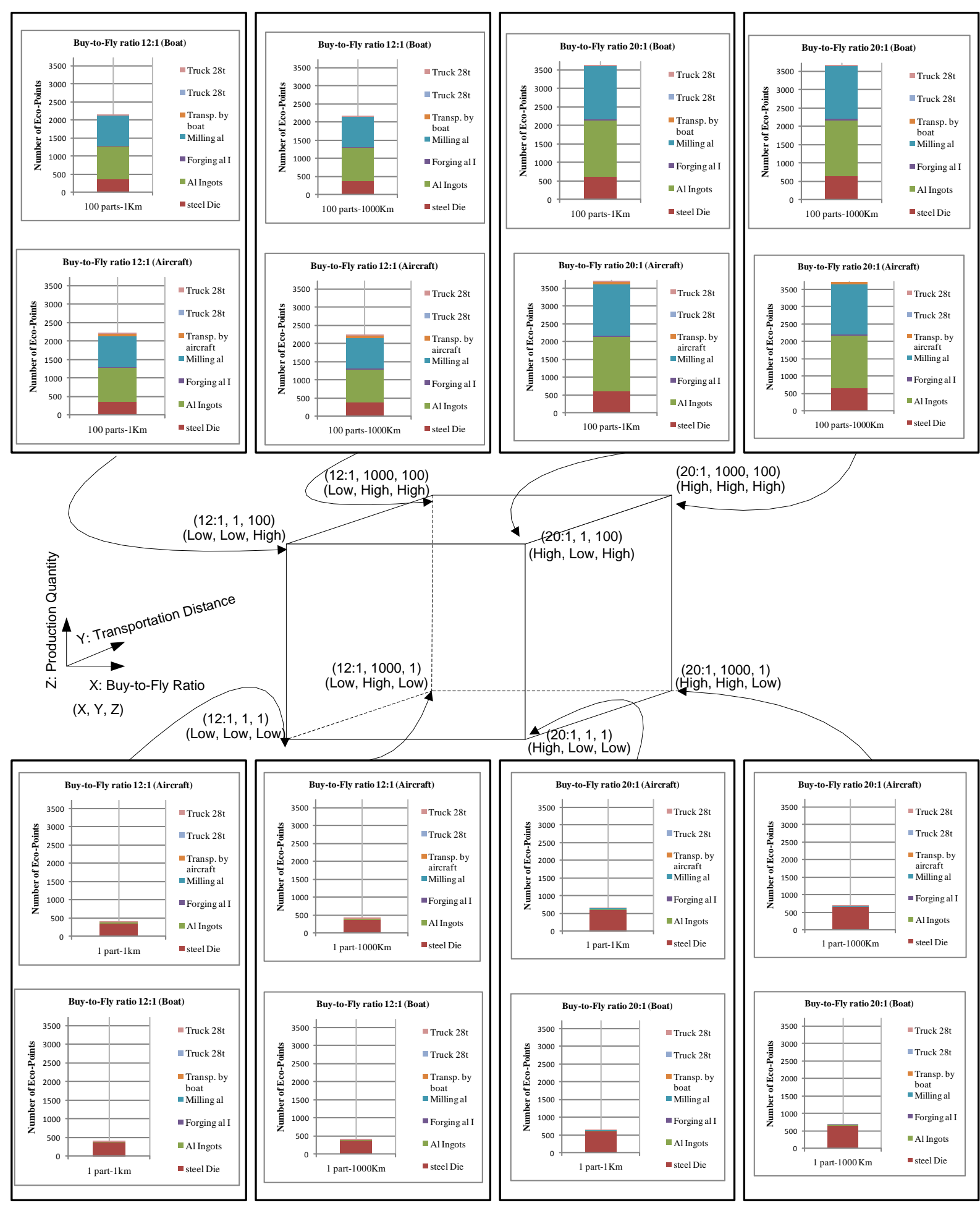

(20:1, 1, 100)

(High, Low, High)

Figure 19 Sensitivity analysis for a small part (1Kg) 


\subsubsection{Environmental Impact of Buy-To-Fly Ratio On Small Aluminum Forgings}

In order to assess the impact that buy-to-fly ratio has on environmental impact, Table 5 shows all pairwise comparisons of data from Figure 19 in which the only factor being varied is the Buy-To-Fly ratio. It is readily apparent that regardless of the production scenario being considered, the number of Eco-Points generated is heavily influenced by the Buy-To-Fly ratio. This makes intuitive sense. As the buy-to-fly ratio increases, the number of Eco-Points logically increases because:

- More raw material must be processed per part

- More raw material must be transported to the forging factory

- More material must be machined and disposed of

Based on the average percentage value of percentage increases for the eight scenarios of a small part in Table $5(67 \%)$, one can conclude that buy-to-fly ratio is significant.

Table 5 Buy-to-Fly Comparison for a Small Aluminum Forging

Buy-to-Fly Ratio

\begin{tabular}{|c|c|c|c|}
\hline $\begin{array}{l}\text { Number of Parts, } \\
\text { Transportation Dist., } \\
\text { Mode of } \\
\text { Transportation }\end{array}$ & 12:1 (Total Pts) & 20:1 (Total Pts) & \% Increase \\
\hline $100,1 \mathrm{Km}$, boat & 2141 & 3615 & $69 \%$ \\
\hline $100,1 \mathrm{Km}$, air & 2208 & 3682 & $67 \%$ \\
\hline $100,1000 \mathrm{Km}$, boat & 2167 & 3657 & $69 \%$ \\
\hline $100,1000 \mathrm{Km}$, air & 2234 & 3724 & $67 \%$ \\
\hline $1,1 \mathrm{Km}$, boat & 391 & 653 & $67 \%$ \\
\hline $1,1 \mathrm{Km}$, air & 392 & 653 & $67 \%$ \\
\hline $1,1000 \mathrm{Km}$, boat & 417 & 695 & $67 \%$ \\
\hline $1,1000 \mathrm{Km}$, air & 418 & 695 & $66 \%$ \\
\hline & & & $67 \%$ \\
\hline
\end{tabular}

Table 5 shows the total number of EcoPoints produced for each scenario in which only the buy-to-fly ratio is varied. In order to isolate only those EcoPoints directly affected by the buy-to-fly ratio, Table 6 shows the number of Eco-Points for the amount of material purchased and the amount of machining done. It is apparent that the buy-to-fly ratio directly influences a significant proportion of the overall Eco-Points generated. 
Table 6 Buy-to-Fly Comparison for Machining Stage

Buy-to-Fly Ratio

\begin{tabular}{|c|c|c|c|}
\hline $\begin{array}{l}\text { Number of Parts, } \\
\text { Transportation Dist., } \\
\text { Mode of } \\
\text { Transportation }\end{array}$ & $\begin{array}{l}\text { 12:1 ( Pts for } \\
\text { Machining) }\end{array}$ & $\begin{array}{l}\text { 20:1 (Pts for } \\
\text { Machining) }\end{array}$ & \%Increase \\
\hline $100,1 \mathrm{Km}$, boat & 1738 & 2948 & $69 \%$ \\
\hline $100,1 \mathrm{Km}$, air & 1738 & 2948 & $69 \%$ \\
\hline $100,1000 \mathrm{Km}$, boat & 1738 & 2948 & $69 \%$ \\
\hline $100,1000 \mathrm{Km}$, air & 1738 & 2948 & $69 \%$ \\
\hline $1,1 \mathrm{Km}$, boat & 17 & 29 & $71 \%$ \\
\hline 1, 1Km, air & 17 & 29 & $71 \%$ \\
\hline $1,1000 \mathrm{Km}$, boat & 17 & 29 & $71 \%$ \\
\hline $1,1000 \mathrm{Km}$, air & 17 & 29 & $71 \%$ \\
\hline & & & $70 \%$ \\
\hline
\end{tabular}

\subsubsection{Environmental Impact of Transportation Distance On Small Aluminum Forgings}

This is an analysis of centralized manufacturing in which the product is shipped overseas to the end user. To be clear, the transportation distance being evaluated in this section applies to distance the die and raw materials travel from where they are produced to the factory where forging takes place.

Table 7 shows all pairwise comparisons of data from Figure 19 in which the only factor being varied is the transportation distance. It is apparent that increasing the transportation distance from $1 \mathrm{~km}$ to $1,000 \mathrm{~km}$ only produces a modest percentage increase in the number of Eco-points. The variation of the travel distance is significant only to the steel die and aluminum ingot. As noted above, this particular analysis assumes overseas transportation of the finished good from China to the USA by boat or plane for a typical centralized manufacturing situation. Based on the average percentage increase of die and raw material transportation distance in Table 7 (4\%), one can conclude that transportation distance of the die and raw material to the forging factory is relatively insignificant when compared with several other factors. 
Table 7 Transportation Distance Comparison for a Small Aluminum Forging

Die/Raw Material Transportation

\begin{tabular}{|c|c|c|c|}
\hline $\begin{array}{l}\text { Number of Parts, } \\
\text { Buy-To-Fly, Mode of } \\
\text { Transportation }\end{array}$ & 1Km (Total Pts) & 1000Km (Total Pts) & \% Increase \\
\hline 100, 12:1BTF, boat & 2141 & 2167 & $1 \%$ \\
\hline 100, 12:1BTF, air & 2208 & 2234 & $1 \%$ \\
\hline 100, 20:1BTF, boat & 3615 & 3657 & $1 \%$ \\
\hline 100, 20:1BTF, air & 3682 & 3724 & $1 \%$ \\
\hline 1, 12:1BTF, boat & 391 & 417 & $7 \%$ \\
\hline 1, 12:1BTF, air & 392 & 418 & $7 \%$ \\
\hline 1, 20:1BTF, boat & 653 & 695 & $6 \%$ \\
\hline 1, 20:1BTF, air & 653 & 695 & $6 \%$ \\
\hline \multicolumn{4}{|c|}{ Avg: } \\
\hline
\end{tabular}

Table 7 shows the total number of EcoPoints produced for each scenario in which only the transportation distance is varied. In order to isolate only those EcoPoints directly contributed by transportation of the die and its raw materials, Table 8 shows the number of Eco-Points for transportation only. It is apparent that transportation of the die and its raw materials is a relatively small percentage of the overall total.

Table 8 Transportation Distance Comparison for Transportation Stage

\begin{tabular}{c|c|c|}
\hline $\begin{array}{c}\text { Number of Parts, } \\
\text { Buy-To-Fly, Mode of } \\
\text { Transportation }\end{array}$ & $\begin{array}{c}\text { 1Km (Pts for } \\
\text { Transportation) }\end{array}$ & $\begin{array}{c}\text { 1000Km (Pts for } \\
\text { Transportation) }\end{array}$ \\
\hline $\mathbf{1 0 0 , 1 2 : 1 B T F , ~ b o a t ~}$ & 0.005 & 5 \\
\hline $\mathbf{1 0 0 , 1 2 : 1 B T F , ~ a i r ~}$ & 0.005 & 5 \\
\hline $\mathbf{1 0 0 , 2 0 : 1 B T F , ~ b o a t ~}$ & 0.008 & 8 \\
\hline $\mathbf{1 0 0 , 2 0 : 1 B T F , \text { air }}$ & 0.008 & 8 \\
\hline $\mathbf{1 , 1 2 : 1 B T F , ~ b o a t ~}$ & 0.005 & 5 \\
\hline $\mathbf{1 , 1 2 : 1 B T F}$, air & 0.005 & 5 \\
\hline $\mathbf{1 , 2 0 : 1 B T F , ~ b o a t}$ & 0.008 & 8 \\
\hline $\mathbf{1 , 2 0 : 1 B T F}$, air & 0.008 & 8 \\
\cline { 2 - 3 }
\end{tabular}

\subsubsection{Environmental Impact of Mode of Transportation On Small Aluminum Forgings}

This is an analysis of centralized manufacturing in which the product is shipped either by boat or by aircraft to the end user. The model compares environmental impact output in case of shipping via boat and the case of shipping via aircraft. 
For small production quantities (e.g. 1 part) there is effectively no difference in the number of ecopoints based on the mode of transportation. Although the number of ecopoints associated with air transportation increases as the production quantity goes up, the percent increase is still modest ( 2 to $3 \%$ increase) for a production quantity of 100 parts. Based on the average percentage value of percentage increases for the eight scenarios of a small part in Table $9(1 \%)$, one can conclude that the mode of transportation is relatively insignificant compared with other more significant factors.

Table 9 Transportation Mode Comparison for a Small Aluminum Forging Mode of Transportation

\begin{tabular}{|c|c|c|c|}
\hline $\begin{array}{l}\text { Number of Parts, } \\
\text { Transportation Dist., } \\
\text { Buy-To-Fly }\end{array}$ & Boat (Total Pts) & Air (Total Pts) & \% Increase \\
\hline $100,1 \mathrm{Km}, 12: 1$ & 2141 & 2208 & $3 \%$ \\
\hline $100,1 \mathrm{Km}, 20: 1$ & 3615 & 3682 & $2 \%$ \\
\hline $100,10^{3} \mathrm{Km}, 12: 1$ & 2167 & 2234 & $3 \%$ \\
\hline $100,10^{3} \mathrm{Km}, 20: 1$ & 3657 & 3724 & $2 \%$ \\
\hline 1, 1Km, 12:1 & 391 & 392 & $0 \%$ \\
\hline $1,1 \mathrm{Km}, 20: 1$ & 653 & 653 & $0 \%$ \\
\hline $1,10^{3} \mathrm{Km}, 12: 1$ & 417 & 418 & $0 \%$ \\
\hline $1,10^{3} \mathrm{Km}, 20: 1$ & 695 & 695 & $0 \%$ \\
\hline \multicolumn{4}{|c|}{ Avg: } \\
\hline
\end{tabular}

Table 9 shows the total number of EcoPoints produced for each scenario in which only the mode of transportation is varied. In order to isolate only those EcoPoints directly affected by the mode of transportation, Table 10 shows the number of Eco-Points for mode of transportation only. It can be seen that transportation by aircraft generates substantially more Eco-Points than transportation by boat. However, the environmental impact of both modes of transportation is relatively small in relation to the impact of other steps in the process chain. 
Table 10 Transportation Mode Comparison for Modes of Transportation

\begin{tabular}{|c|c|c|}
\hline $\begin{array}{l}\text { Number of Parts, } \\
\text { Transportation Dist., } \\
\text { Buy-To-Fly }\end{array}$ & $\begin{array}{c}\text { Boat (Pts for Modes } \\
\text { of Transportation) }\end{array}$ & $\begin{array}{c}\text { Air (Pts for Modes of } \\
\text { Transportation) }\end{array}$ \\
\hline $100,1 \mathrm{Km}, 12: 1$ & 1 & 71 \\
\hline 100, 1Km, 20:1 & 1 & 71 \\
\hline $100,10^{3} \mathrm{Km}, 12: 1$ & 1 & 71 \\
\hline $100,10^{3} \mathrm{Km}, 20: 1$ & 1 & 71 \\
\hline $1,1 \mathrm{Km}, 12: 1$ & 0.01 & 0.71 \\
\hline 1, 1Km, 20:1 & 0.01 & 0.71 \\
\hline $1,10^{3} \mathrm{Km}, 12: 1$ & 0.01 & 0.71 \\
\hline $1,10^{3} \mathrm{Km}, 20: 1$ & 0.01 & 0.71 \\
\hline
\end{tabular}

\subsubsection{Environmental Impact of Production Quantity On Small Aluminum Forgings}

The production quantity has ranged from 1 part to 100 parts in simulations up to this point. In order to better assess the effect of production quantity on environmental impact, this section also considers simulations for production quantities of 10 parts and 1000 parts. The total number of Eco-Points contributed by production of the steel die remains unchanged as the production quantity changes due to the fact that tooling represents a fixed production cost. However, the total number of Eco-Points contributed by other stages of manufacturing, namely production of aluminum ingots and finish machining of the aluminum forging, grow as the production quantity increases.

For purposes of this analysis, the number of Eco-Points per part provides a more meaningful basis for comparison. As the production quantity increases, the number of Eco-Points contributed by production of the steel die is distributed over a greater number of parts. The following formula represents the number of Eco-Points per part.

$$
\text { Pts/part }=\frac{\text { DiePts }}{\# \text { parts }}+(\text { Al.ingot }+ \text { Forg. Al. }+ \text { mill. Al. }+ \text { transp.by air } / \text { boat }+ \text { transp. by truck })
$$

Table 11 shows the number of Eco-Points per part for each scenario under production quantities of 1, 10,100, and 1000 parts. Figure 20 shows this information in a graphical format. Each chart is plotted using the same Y-axis maximum Eco-Points value of 700. The data indicate that there is a substantial drop in Eco-Points between 1 part and 10 parts. The total number of 
Eco-Points for producing 100 parts is almost equal to the total number of Eco-Points for producing 1000 parts. This shows that the term "die pts/ \#parts" goes towards zero and the number of Eco-Points per part tends to be equal to the Eco-Points for everything else. For this thesis, the term "Eco-Points for everything else" represents the number of Eco-Points for: (1) aluminum ingot, (2) forging aluminum, (3) milling aluminum, (4) transportation by aircraft, (5) transportation by boat, (6) and transportation of the final part by truck. It is readily apparent that the Eco-Points contributed by the fixed tooling dominate when production quantities are very small. As the production quantity increases, the Eco-Points generated come primarily from other sources. The distributed manufacturing scenario discussed in Chapter 5 assumes the use of additive manufacturing technologies that do not require fixed tooling. Hence it is reasonable to expect that distributed manufacturing is particularly beneficial from an environmental standpoint when production quantities are very low.

Table 11 Production Quantity Comparison for a Small Aluminum Forging

Production Quantity

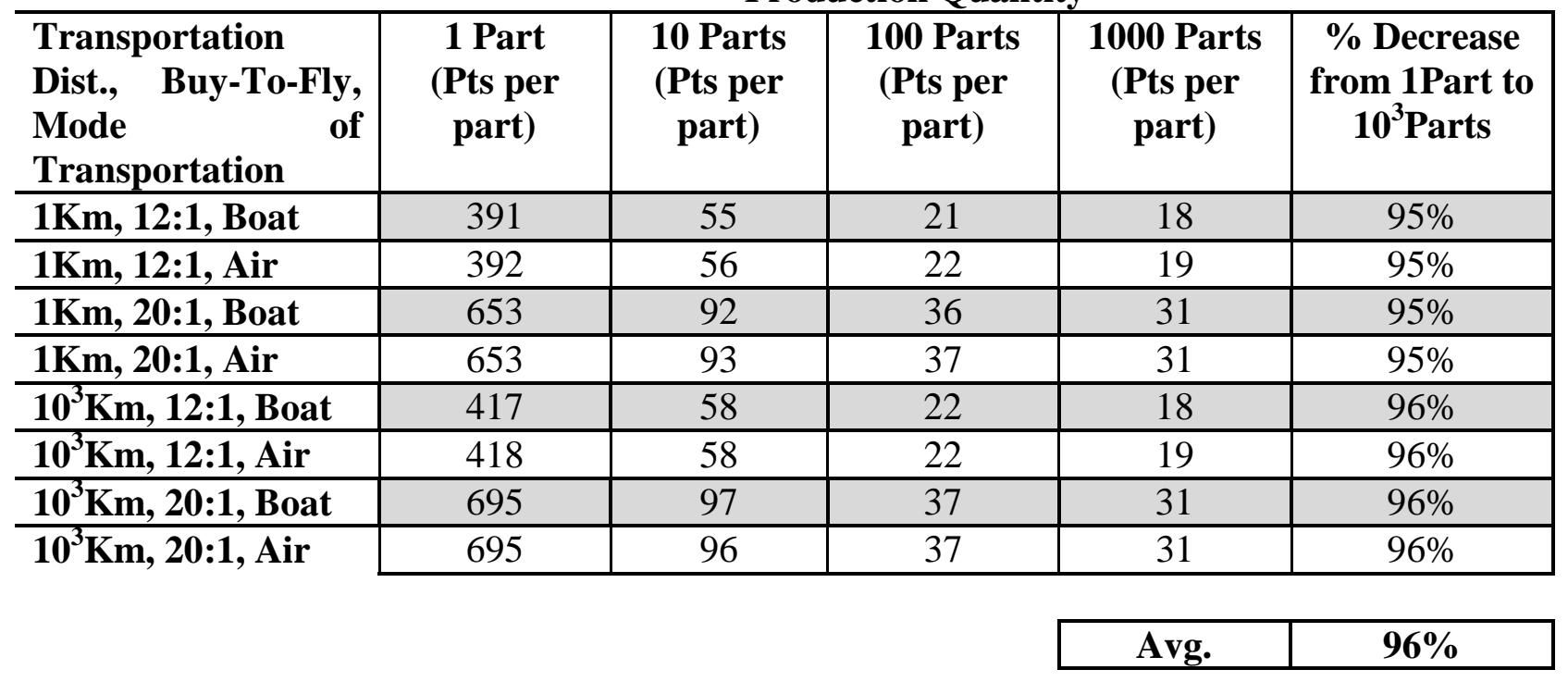



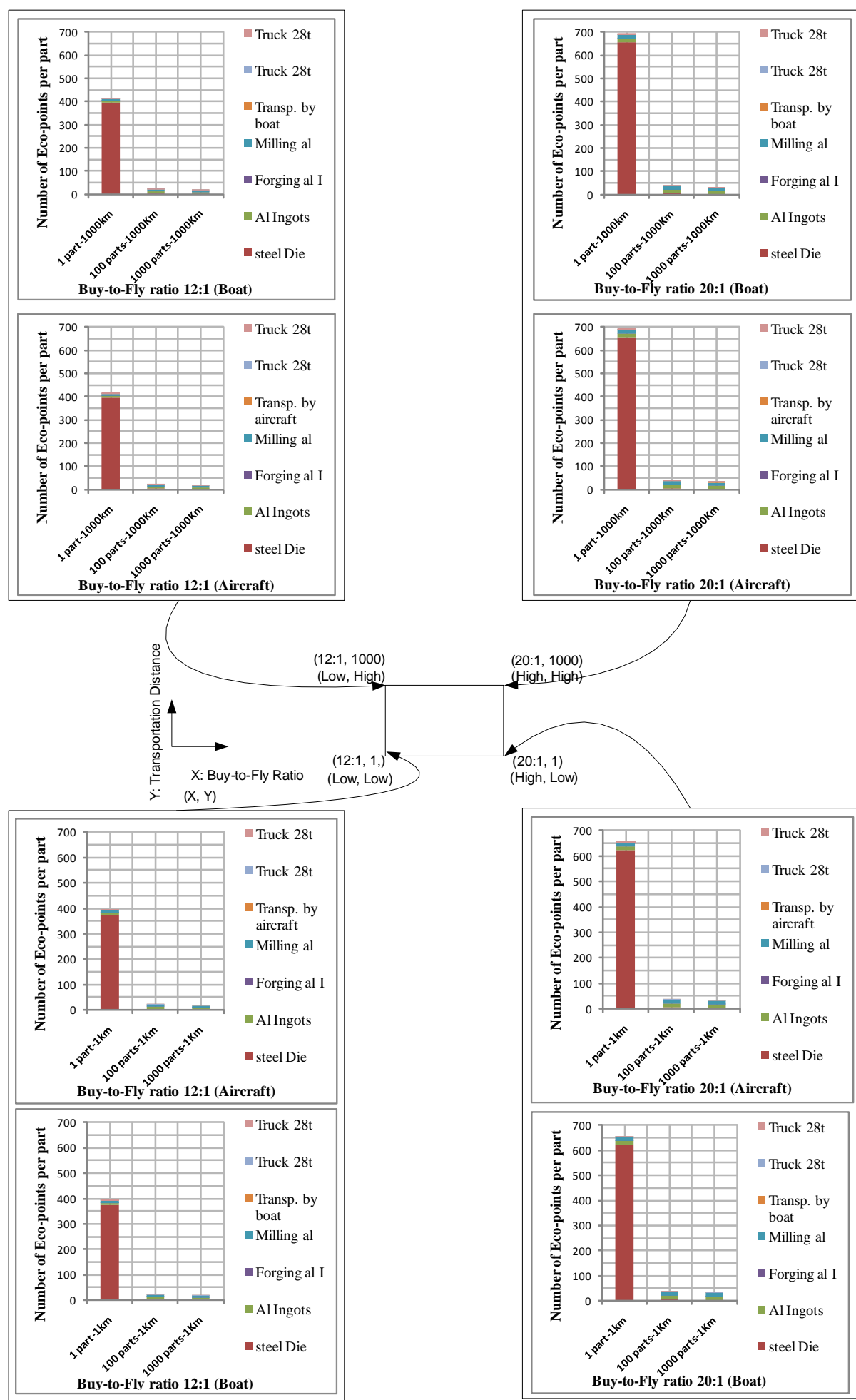

Figure 20 Number of Ecopoints per part for a small part vs. lot size 


\subsection{Environmental Impact Analysis for Forging of a Large Aluminum Part}

The preceding section considered the environmental impacts associated for forging of a small $(1 \mathrm{~kg})$ aluminum part. In this section, a similar analysis is presented for large $(27 \mathrm{~kg})$ aluminum parts. Simulations for the large parts were conducted in Simapro corresponding to the eight extreme points in the design space. For each corner of the design space, simulations were conducted for the two primary modes of overseas transportation - by boat and by plane. Figure 21 provides specific input values for each simulation condition. The output variable being measured in each simulation for comparison purposes was the number of Eco-Points (Pt). The maximum number of Eco-Points recorded over those 8x2=16 simulations was 100550 Ecopoints $(\mathrm{Pt})$.

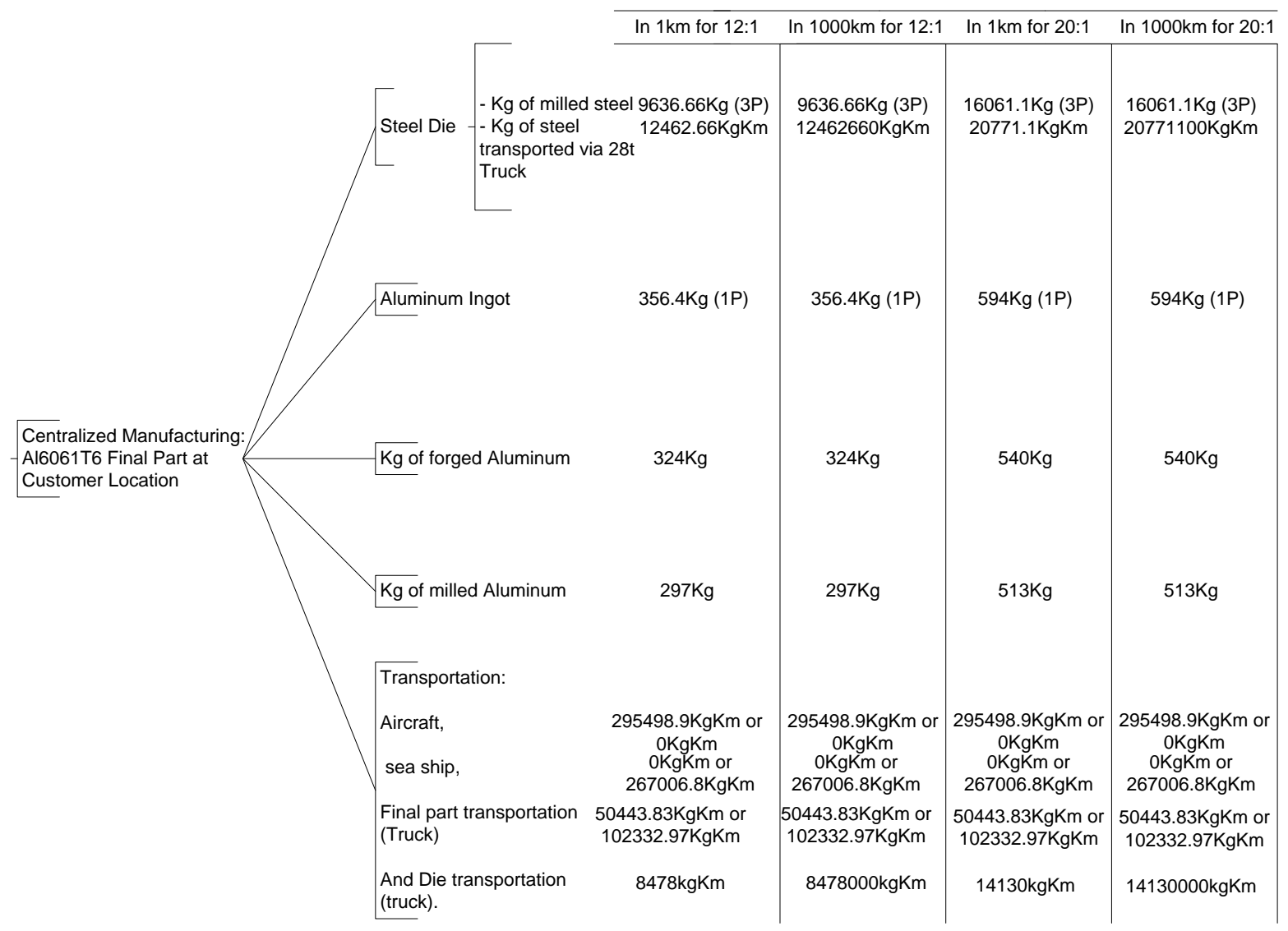

Figure 21 Inputs Entered in SimaPro for a Large Part 
Figure 22 graphically depicts results from each of the 16 simulations. The vertical axis for each scale is identical in order to simplify direct comparison of the results. Note that two graphs are shown for each corner of the cube. The titles of each graph differentiate whether the primary mode of overseas transportation was by boat or by plane. In order to qualitatively interpret the results, one can compare graphs on the left and right side to see the effect of the buy-to-fly ratio. Comparing graphs on the top and bottom planes illustrates the effect of production quantity. Comparing graphs on the front and back planes shows the effect of transportation distance. 


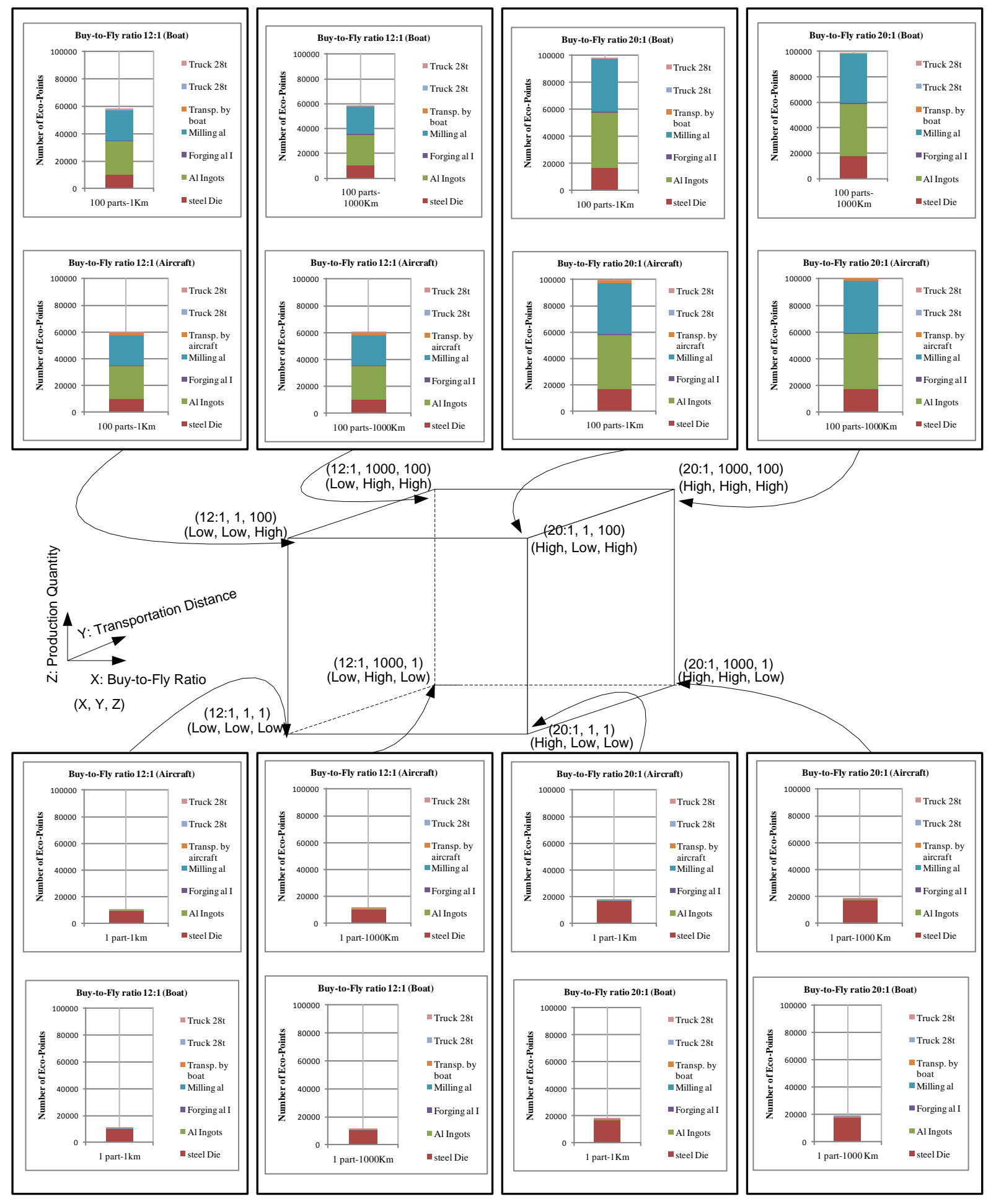

Figure 22 Sensitivity analysis for a large part (27Kg) 


\subsubsection{Environmental Impact of Buy-To-Fly Ratio On Large Aluminum Forgings}

Varying the axis of buy-to fly ratio shows that the number of Eco-points of steel die dominates in low production and the number of Pts in low buy-to-fly ratio become almost half of the number of Pts in high buy-to-fly ratio. As well, in high production, varying the axis of Buyto-fly ratio reveals that in high production, the number of Pt of Aluminum ingots and Milling aluminum processes dominates and the number of Eco-points for a low buy-to-fly ratio become almost half of the number of Eco-points for a high buy-to-fly ratio. Table 12 compares the environmental impact of each production scenario in which the Buy-To-Fly ratio goes from 12:1 up to 20:1. As was the case for small forgings, increases in the Buy-To-Fly ratio have a very large impact on environmental impact regardless of other factors. Based on the average percentage value of percentage increases for the eight scenarios of large part production (68\%), one can conclude that buy-to-fly ratio is very significant.

\section{Table 12 Buy-to-Fly Comparison for a Large Aluminum Forging}

Buy-to-Fly Ratio

\begin{tabular}{|c|c|c|c|}
\hline $\begin{array}{l}\text { Number of Parts, } \\
\text { Transportation Dist., } \\
\text { Mode of } \\
\text { Transportation }\end{array}$ & 12:1 (Total Pts) & 20:1 (Total Pts) & \% Increase \\
\hline $100,1 \mathrm{Km}$, boat & 57806 & 97593 & $69 \%$ \\
\hline $100,1 \mathrm{Km}$, air & 59623 & 99409 & $67 \%$ \\
\hline $100,1000 \mathrm{Km}$, boat & 58484 & 98723 & $69 \%$ \\
\hline $100,1000 \mathrm{Km}$, air & 60301 & 100539 & $67 \%$ \\
\hline $1,1 \mathrm{Km}$, boat & 10565 & 17621 & $67 \%$ \\
\hline 1, 1Km, air & 10583 & 17639 & $67 \%$ \\
\hline $1,1000 \mathrm{Km}$, boat & 11243 & 18751 & $67 \%$ \\
\hline $1,1000 \mathrm{Km}$, air & 11261 & 18770 & $67 \%$ \\
\hline \multicolumn{4}{|c|}{ Avg: } \\
\hline
\end{tabular}

Table 12 shows the total number of EcoPoints produced for each scenario in which only the buy-to-fly ratio is varied. In order to isolate only those EcoPoints directly affected by the buy-to-fly ratio, Table 13 shows the number of Eco-Points for the amount of material purchased and the amount of machining done. As expected based on the small part results, the buy-to-fly ratio directly influences a significant proportion of the overall Eco-Points generated. 
Table 13 Buy-to-Fly Comparison for Machining Stage

\begin{tabular}{|c|c|c|}
\hline $\begin{array}{l}\text { Number of Parts, } \\
\text { Transportation Dist., } \\
\text { Mode of } \\
\text { Transportation }\end{array}$ & $\begin{array}{l}\text { 12:1 (Pts for } \\
\text { Machining) }\end{array}$ & $\begin{array}{l}\text { 20:1 (Pts for } \\
\text { Machining) }\end{array}$ \\
\hline $100,1 \mathrm{Km}$, boat & 46939 & $\overline{79593}$ \\
\hline $100,1 \mathrm{Km}$, air & 46939 & 79593 \\
\hline $100,1000 \mathrm{Km}$, boat & 46939 & 79593 \\
\hline $100,1000 \mathrm{Km}$, air & 46939 & 79593 \\
\hline $1,1 \mathrm{Km}$, boat & 470 & 796 \\
\hline $1,1 \mathrm{Km}$, air & 470 & 796 \\
\hline $1,1000 \mathrm{Km}$, boat & 470 & 796 \\
\hline $1,1000 \mathrm{Km}$, air & 470 & 796 \\
\hline
\end{tabular}

\subsubsection{Environmental Impact of Transportation Distance On Large Aluminum Forgings}

This is an analysis of centralized manufacturing in which the product is shipped overseas to the end user. This section compares short and long transportation distances for the die and raw materials to the factory where forging of the large parts takes place.

As was the case for small parts, the distance with which the die and raw materials are transported to the forging factory appears to have a relatively modest influence on environmental impact. Based on the average percentage increases for the eight scenarios compared in Table 14 (4\%), one can conclude that transportation distance is not one of the more significant factors.

Table 14 Transportation Distance Comparison for a Large Aluminum Forging

Die/Raw Material Transportation

\begin{tabular}{c|c|c|c|}
\hline $\begin{array}{c}\text { Number of Parts, } \\
\text { Buy-To-Fly, Mode of } \\
\text { Transportation }\end{array}$ & $\mathbf{1 K m}$ (Total Pts) & $\mathbf{1 0 0 0 K m}$ (Total Pts) & \% Increase \\
\hline $\mathbf{1 0 0 , 1 2 : 1 B T F , ~ b o a t ~}$ & 57806 & 58484 & $1 \%$ \\
\hline $\mathbf{1 0 0 , 1 2 : 1 B T F , ~ a i r ~}$ & 59623 & 60301 & $1 \%$ \\
\hline $\mathbf{1 0 0 , 2 0 : 1 B T F , ~ b o a t ~}$ & 97593 & 98723 & $1 \%$ \\
\hline $\mathbf{1 0 0 , 2 0 : 1 B T F , ~ a i r ~}$ & 99409 & 100539 & $6 \%$ \\
\hline $\mathbf{1 , 1 2 : 1 B T F , ~ b o a t ~}$ & 10565 & 11243 & $6 \%$ \\
\hline $\mathbf{1 , 1 2 : 1 B T F}$, air & 10583 & 11261 & $6 \%$ \\
\hline $\mathbf{1 , 2 0 : 1 B T F , ~ b o a t}$ & 17621 & 18751 & $6 \%$ \\
\hline $\mathbf{1 , 2 0 : 1 B T F , ~ a i r ~}$ & 17639 & 18770 & $\mathbf{4 \%}$ \\
\hline
\end{tabular}


Table 14 shows the total number of EcoPoints produced for each scenario in which only the transportation distance is varied. In order to isolate only those EcoPoints directly affected by the transportation distance, Table 15 shows the number of Eco-Points for transportation distance only.

Table 15 Transportation Distance Comparison for Transportation Stage

\begin{tabular}{c|c|c|}
\hline $\begin{array}{c}\text { Number of Parts, } \\
\text { Buy-To-Fly, Mode of } \\
\text { Transportation }\end{array}$ & $\begin{array}{c}\text { 1Km (Pts for } \\
\text { transportation) }\end{array}$ & $\begin{array}{c}\text { 1000Km (Pts for } \\
\text { Transportation) }\end{array}$ \\
\hline 100, 12:1BTF, boat & 0.125 & 125 \\
\hline $\mathbf{1 0 0 , 1 2 : 1 B T F , ~ a i r ~}$ & 0.125 & 125 \\
\hline $\mathbf{1 0 0 , 2 0 : 1 B T F , ~ b o a t ~}$ & 0.209 & 209 \\
\hline $\mathbf{1 0 0 , 2 0 : 1 B T F , ~ a i r ~}$ & 0.209 & 209 \\
\hline $\mathbf{1 , 1 2 : 1 B T F}$, boat & 0.125 & 125 \\
\hline $\mathbf{1 , 1 2 : 1 B T F}$, air & 0.125 & 125 \\
\hline $\mathbf{1 , 2 0 : 1 B T F}$, boat & 0.209 & 209 \\
\hline $\mathbf{1}, \mathbf{2 0 : 1 B T F}$, air & 0.209 & 209 \\
\cline { 2 - 3 } & &
\end{tabular}

\subsubsection{Environmental Impact of Mode of Transportation On Large Aluminum Forgings}

This is an analysis of centralized manufacturing in which the product is shipped either by boat or by aircraft to the end user. The model compares environmental impact output in case of shipping via boat and the case of shipping via aircraft.

For small production quantities (e.g. 1 part) there is effectively no difference in the number of Eco-Points based on the mode of transportation. Although the number of ecopoints associated with air transportation increases as the production quantity goes up, the percent increase is still modest ( 2 to $3 \%$ increase) for a production quantity of 100 parts. Based on the average percentage value of percentage increases for the eight scenarios of a large part in Table $16(1 \%)$, one can conclude that the mode of overseas transportation is of minimal significant for the scenarios considered. 
Table 16 Transportation Mode Comparison for a Large Aluminum Forging

Mode of Transportation

\begin{tabular}{|c|c|c|c|}
\hline $\begin{array}{l}\text { Number of Parts, } \\
\text { Transportation Dist., } \\
\text { Buy-To-Fly }\end{array}$ & Boat (Total Pts) & Air (Total Pts) & \% Increase \\
\hline $100,1 \mathrm{Km}, 12: 1$ & 57806 & 59623 & $3 \%$ \\
\hline $100,1 \mathrm{Km}, 20: 1$ & 97593 & 99409 & $2 \%$ \\
\hline $100,10^{3} \mathrm{Km}, 12: 1$ & 58484 & 60301 & $3 \%$ \\
\hline $100,10^{3} \mathrm{Km}, 20: 1$ & 98723 & 100539 & $2 \%$ \\
\hline 1, 1Km, 12:1 & 10565 & 10583 & $0 \%$ \\
\hline 1, 1Km, 20:1 & 17621 & 17639 & $0 \%$ \\
\hline $1,10^{3} \mathrm{Km}, 12: 1$ & 11243 & 11261 & $0 \%$ \\
\hline $1,10^{3} \mathrm{Km}, 20: 1$ & 18751 & 18770 & $0 \%$ \\
\hline \multicolumn{4}{|c|}{ Avg: } \\
\hline
\end{tabular}

Table 16 shows the total number of EcoPoints produced for each scenario in which only the mode of transportation is varied. In order to isolate only those EcoPoints directly affected by the mode of transportation, Table 17 shows the number of Eco-Points for mode of transportation only. As was the case for small parts, transportation by boat is preferred, although the environmental impact is small in relation to the impact of other factors such as the amount of machining.

Table 17 Transportation Mode Comparison for Modes of Transportation

\begin{tabular}{|c|c|c|}
\hline $\begin{array}{l}\text { Number of Parts, } \\
\text { Transportation Dist., } \\
\text { Buy-To-Fly }\end{array}$ & $\begin{array}{c}\text { Boat (Pts for Modes } \\
\text { of Transportation) }\end{array}$ & $\begin{array}{c}\text { Air (Pts for Modes of } \\
\text { Transportation) }\end{array}$ \\
\hline 100, 1Km, 12:1 & 18 & 1911 \\
\hline $100,1 \mathrm{Km}, 20: 1$ & 18 & 1911 \\
\hline $100,10^{3} \mathrm{Km}, 12: 1$ & 18 & 1911 \\
\hline $100,10^{3} \mathrm{Km}, 20: 1$ & 18 & 1911 \\
\hline 1, 1Km, 12:1 & 0.18 & 19 \\
\hline $1,1 \mathrm{Km}, 20: 1$ & 0.18 & 19 \\
\hline $1,10^{3} \mathrm{Km}, 12: 1$ & 0.18 & 19 \\
\hline $1,10^{3} \mathrm{Km}, 20: 1$ & 0.18 & 19 \\
\hline
\end{tabular}

\subsubsection{Environmental Impact of Production Quantity On Large Aluminum Forgings}

As was done in the small part analysis, this section also considers simulations for production quantities of 10 parts and 1000 parts. Table 18 shows the number of Eco-Points per part for each scenario under production quantities of 1, 10, 100, and 1000 parts. Figure 23 shows 
this information in a graphical format. Each chart is plotted using the same Y-axis maximum Eco-Points value of 19000. Although the absolute values are considerably higher for this large part scenario than they are for the small part scenario in Section 4.1.4, the trends are identical. There is a substantial drop in Eco-Points between 1 part and 10 parts which indicates that tooling is the primary contributor of Eco-Points for very small production quantities.

Table 18 Production Quantity Comparison for a Large Aluminum Forging

\begin{tabular}{|c|c|c|c|c|c|}
\hline \multicolumn{6}{|c|}{ Production Quantity } \\
\hline $\begin{array}{l}\text { Transportation } \\
\text { Dist., Buy-To-Fly, } \\
\text { Mode } \\
\text { Transportation }\end{array}$ & 1 Part & 10 Parts & 100 Parts & 1000 Parts & $\begin{array}{c}\text { \% Decrease } \\
\text { from 1Part to } \\
10^{3} \text { Parts }\end{array}$ \\
\hline 1Km, 12:1, Boat & 10565 & 1486 & 578 & 487 & $95 \%$ \\
\hline 1Km, 12:1, Air & 10583 & 1504 & 596 & 505 & $95 \%$ \\
\hline 1Km, 20:1, Boat & 17621 & 2489 & 976 & 825 & $95 \%$ \\
\hline 1Km, 20:1, Air & 17639 & 2507 & 994 & 843 & $95 \%$ \\
\hline $10^{3} \mathrm{Km}, 12: 1$, Boat & 11243 & 1554 & 585 & 488 & $96 \%$ \\
\hline $10^{3} \mathrm{Km}, 12: 1$, Air & 11261 & 1572 & 603 & 506 & $96 \%$ \\
\hline $10^{3} \mathrm{Km}, 20: 1$, Boat & 18751 & 2602 & 987 & 826 & $96 \%$ \\
\hline $10^{3} \mathrm{Km}, 20: 1$, Air & 18770 & 2620 & 1005 & 844 & $96 \%$ \\
\hline & & & & Avg. & $96 \%$ \\
\hline
\end{tabular}



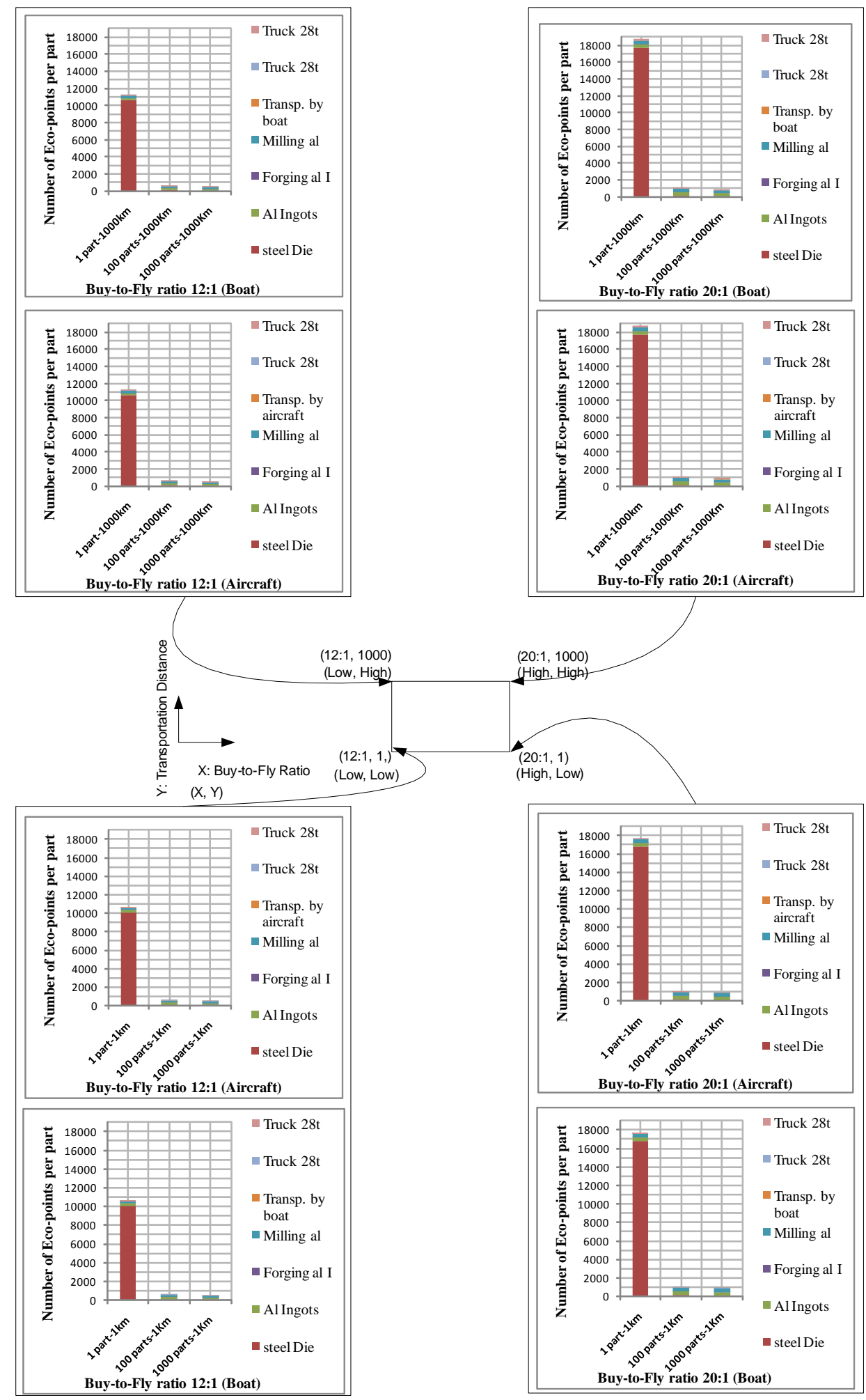

Figure 23 Number of Ecopoints per Part for a Large Part vs. Lot Size 


\subsection{Comparison of Part Size In Aluminum Forging}

In this section, an analysis of simulation results between small $(1 \mathrm{~kg})$ and large $(27 \mathrm{~kg})$ forged aluminum parts is presented. For every scenario considered (Table 19), the number of Eco-Points for a large part is 27 times greater than the number of Eco-Points for a small part. This is logical, as the large part considered has 27 times more material to process and transport. This reveals a major difference in producing a small part over producing a large part.

One could state that the part size is dictated by the mechanical designer and is not influenced by whether the part is made under a centralized or distributed manufacturing scenario. However, component design is dictated not just by mechanical function, but also by whether or not the part can be manufactured. Parts often have more mass than is needed simply because removing unneeded material in certain regions of the part would violate manufacturability guidelines. Additive manufacturing processes, such as Electron Beam Melting, therefore make it possible to produce components in which mass is reduced. This thesis does not deal with design or analysis of a specific mechanical component, but the significant potential for reduction in environmental impact associated with component redesign must be recognized. 
Table 19 Part Size Comparison for a Small and a Large Aluminum Forging

Part Size

\begin{tabular}{|c|c|c|c|}
\hline $\begin{array}{l}\text { Number of Parts, } \\
\text { Transportation Dist., } \\
\text { Buy-To-Fly, Mode of } \\
\text { Transportation }\end{array}$ & A small part (Total Pts) & A large part (Total Pts) & \% Increase \\
\hline 100, 1Km, 12:1, Boat & 2141 & 57806 & $2600 \%$ \\
\hline 100, 1Km, 12:1, Air & 2208 & 59623 & $2600 \%$ \\
\hline $100,10^{3} \mathrm{Km}, 12: 1$, Boat & 2167 & 58484 & $2600 \%$ \\
\hline 100, $10^{3} \mathrm{Km}, 12: 1$, Air & 2234 & 60301 & $2600 \%$ \\
\hline 100, 1Km, 20:1, Boat & 3615 & 97593 & $2600 \%$ \\
\hline 100, 1Km, 20:1, Air & 3682 & 99409 & $2600 \%$ \\
\hline 100, 10 ${ }^{3} \mathrm{Km}, 20: 1$, Boat & 3657 & 98723 & $2600 \%$ \\
\hline $100,10^{3} \mathrm{Km}, 20: 1$, Air & 3724 & 100539 & $2600 \%$ \\
\hline 1, 1Km, 12:1, Boat & 391 & 10565 & $2600 \%$ \\
\hline 1, 1Km, 12:1, Air & 392 & 10583 & $2600 \%$ \\
\hline 1, 1Km, 20:1, Boat & 653 & 17621 & $2600 \%$ \\
\hline 1, 1Km, 20:1, Air & 653 & 17639 & $2600 \%$ \\
\hline 1, 10 ${ }^{3} \mathrm{Km}, 12: 1$, Boat & 417 & 11243 & $2600 \%$ \\
\hline 1, $10^{3} \mathrm{Km}, 12: 1$, Air & 418 & 11261 & $2600 \%$ \\
\hline 1, 10 ${ }^{3} \mathrm{Km}, 20: 1$, Boat & 695 & 18751 & $2600 \%$ \\
\hline 1, 10 ${ }^{3} \mathrm{Km}, 20: 1$, Air & 695 & 18770 & $2600 \%$ \\
\hline \multicolumn{4}{|c|}{ Avg: $2600 \%$} \\
\hline
\end{tabular}

\subsection{Conclusions}

This chapter has presented an analysis of centralized manufacturing of aluminum forgings under a variety of process conditions. For small production quantities close to 1, the environmental impact associated with production of the die dominate. However, that changes very quickly as lot size goes up. At moderate and high volumes, aluminum ingot production and milling dominate. These factors apply to each kilogram of material needed. Simulation results indicated that buy-to-fly ratio and part size, both of which determine the kilograms of material processed, heavily influence the total number of Eco-Points associated with part production. This shows that buy-to-fly ratio and part size are both crucial factors to consider. The number of parts needed by the customer is largely independent of the production method, although a comprehensive economic analysis that considers warehousing and obsolescence costs is an 
interesting topic for future research. In Chapter 5, the use of distributed manufacturing with near net shape processing is considered. Specifically, near net shape processes eliminate the need for tooling, drastically reduce buy-to-fly ratio, and have the potential for component redesign that decreases part size. The preliminary results presented in this chapter suggest that distributed manufacturing has the potential to reduce environmental impact under certain conditions. 


\section{Chapter 5 Simulation Results and Discussion}

The work presented in this chapter compares the fabrication of a titanium part via two methods - conventional centralized manufacturing via forging and distributed manufacturing using metal additive manufacturing processes. For purposes of this analysis, a $100 \%$ yield is assumed. Where appropriate, it would be a simple matter to adjust the model to reflect lower yields. Figure 24 shows the system structure of a centralized manufacturing system similar to the one discussed in Chapter 4. The only difference is that the input of aluminum ingot is replaced by a titanium forging preform.

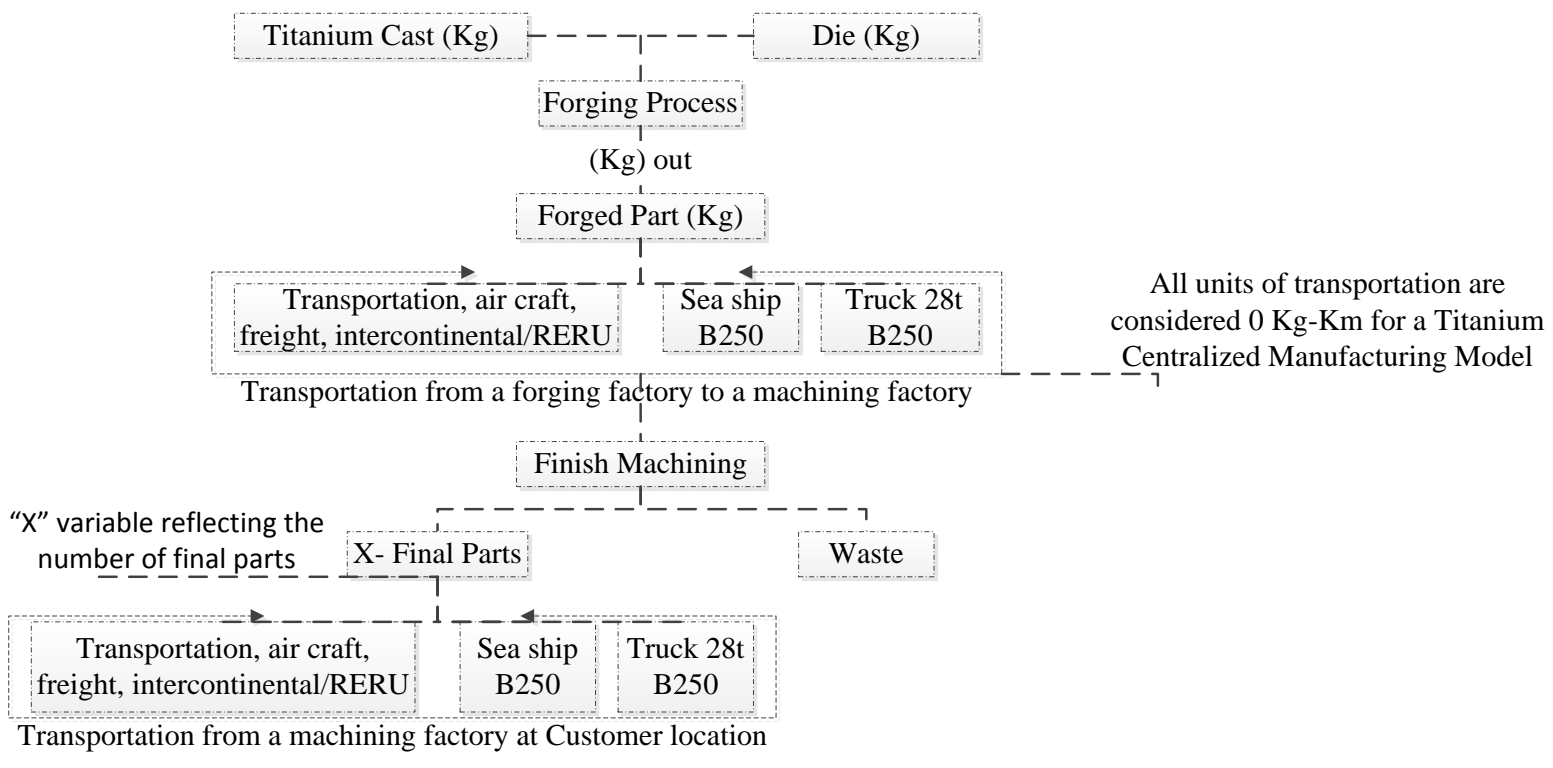

\section{Figure 24 System structure of centralized titanium manufacture via forging}

Figure 25 shows a system structure for distributed manufacturing via electron beam melting that is an alternative to centralized manufacturing via forging. 


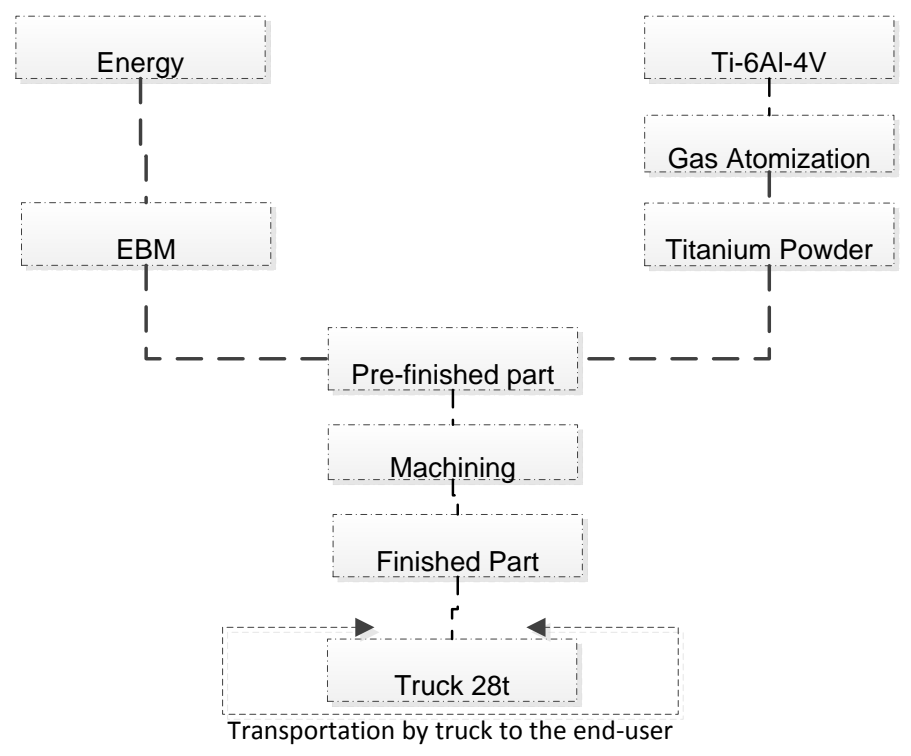

\section{Figure 25 System structure of distributed titanium production via Electron Beam Melting}

In order to assess the relative effects of the different factors on environmental impact, eight simulations were run for both small parts $(1 \mathrm{~kg})$ and large parts $(46 \mathrm{~kg})$. The large $46 \mathrm{~kg}$ part size is obtained by multiplying the approximate maximum EBM part dimensions $(\sim 20 \times 20 \times 25 \mathrm{~cm})$ by the density of titanium $\left(4600 \mathrm{~kg} / \mathrm{m}^{3}\right)$. The eight simulation runs are the result of having two levels (low and high) for each of the three factors: buy-to fly ratio, production quantity, and transportation distance (i.e. $2^{3}=8$ ). The polyhedron shown in Figure 26 provides a useful tool for visualizing extreme points of the design space. The X-axis represents buy-to-fly ratio, the $\mathrm{Y}$-axis represents transportation distance, and the $\mathrm{Z}$-axis represents production quantity.

Ashby (2009) suggests that the forging energy required could vary between a range of values. In order to assess whether or not the forging energy used in the simulation significantly influences environmental impact one way or the other, simulations were conducted using both the low and high forging energy values suggested by Ashby. 


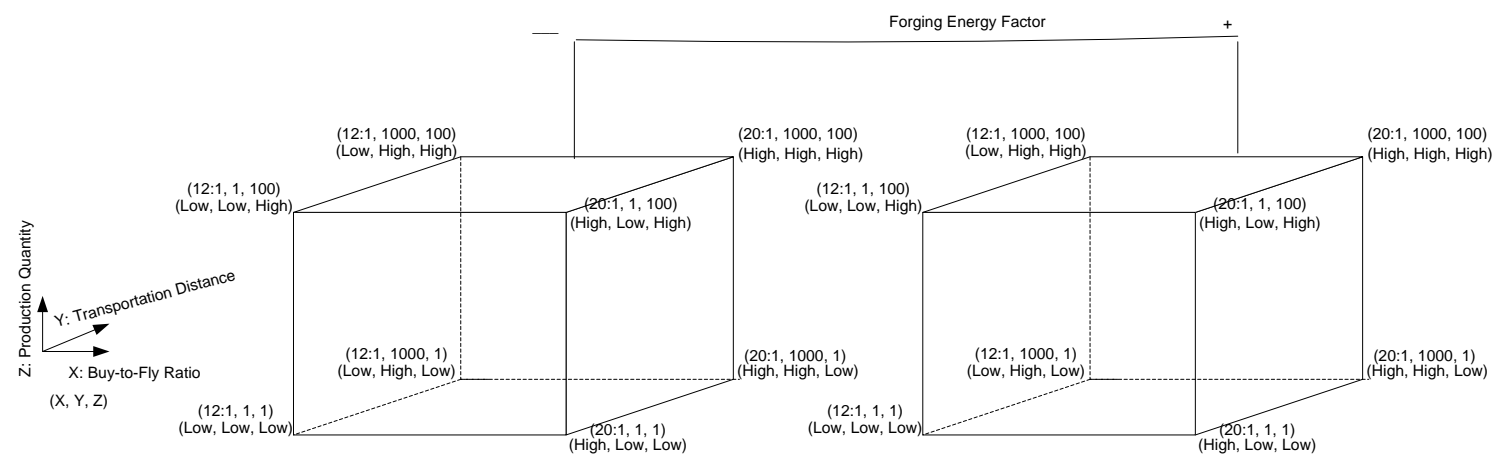

Figure 26 A Polyhedron of Extreme Points: Sixteen Levels of Sensitivity

In order to further assess the sensitivity of environmental impact to process parameter values under the distributed manufacturing scenario, four simulations were run for both small parts $(1 \mathrm{~kg})$ and large parts $(46 \mathrm{~kg})$. The four simulation runs correspond to two levels (low and high) for each of the two process factors specific to the Electron Beam Melting process model: the gas/metal flow ratio and powder atomization energy (i.e. $2^{2}=4$ ). The polyhedron shown in Figure 27 provides a useful tool for visualizing extreme points of the design space. The X-axis represents powder atomization energy and the $\mathrm{Y}$-axis represent gas/metal flow ratio. In Chapter 3 , the energy value for the heat of fusion for $1 \mathrm{~kg}$ and $46 \mathrm{~kg}$ of titanium was determined to be 1.45 and 66.6MJ respectively. To account for energy losses from the outlet to the process, these values were multiplied by $120 \%$ to obtain powder atomization energies of $1.74 \mathrm{MJ}$ and $79.92 \mathrm{MJ}$ respectively.
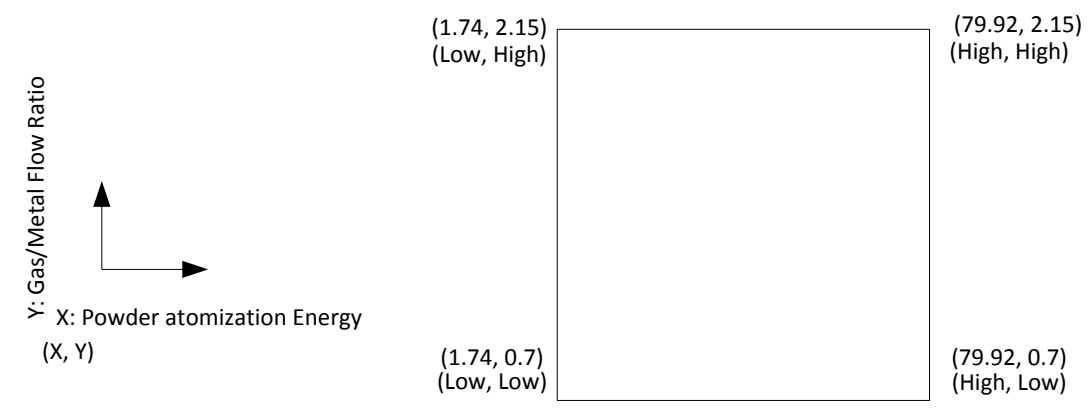

Figure 27 Sensitivity analysis for Electron Beam Melting model

As discussed in Chapter 3, the user specifies inputs to the centralized manufacturing model in SimaPro. Once the user has specified inputs and runs the model, SimaPro calculates the 
environmental outputs for each process and assembly. The following legend maps colors to each source of environmental impact in Chapter 5, Section 5.1.

- : Steel Die,

- : Titanium cast

": Forging Titanium

a: Milling Titanium

घ: Transportation by aircraft or boat,

m: Truck 28t (Transportation of the final product to the customer by truck),

=: Truck 28t (Transportation of the dies to the forging company)

\subsection{Simulation Results for a Centralized Manufacturing of Titanium via Forging}

This section describes environmental impact results for simulations involving centralized manufacturing of a titanium forging in terms of three factors: production quantity (low or high), transportation distance (short or far), and buy-to fly ratio (small or large). Experiments have been run for the case where the part is either small $(1 \mathrm{Kg})$ or large $(46 \mathrm{Kg})$.

\subsubsection{Environmental Impact Analysis for Forging of a Titanium Part}

Referring to the environmental analysis design space illustrated in Figure 26, simulations for small $(1 \mathrm{~kg})$ parts were conducted in SimaPro corresponding to the eight extreme points in the design space. For each corner of the design space, simulations were conducted for the two primary modes of overseas transportation - by boat and by plane. Figure 28 provides specific input values for each simulation condition. The output variable being measured in each simulation for comparison purposes was the number of Eco-points $(\mathrm{Pt})$. The maximum number of Eco-points recorded over those 8x2=16 simulations for a small part was 6500 Eco-points $(\mathrm{Pt})$. The maximum number of Eco-points recorded over those $8 \times 2=16$ simulations for a large part was 300000 Eco-points $(\mathrm{Pt})$. 


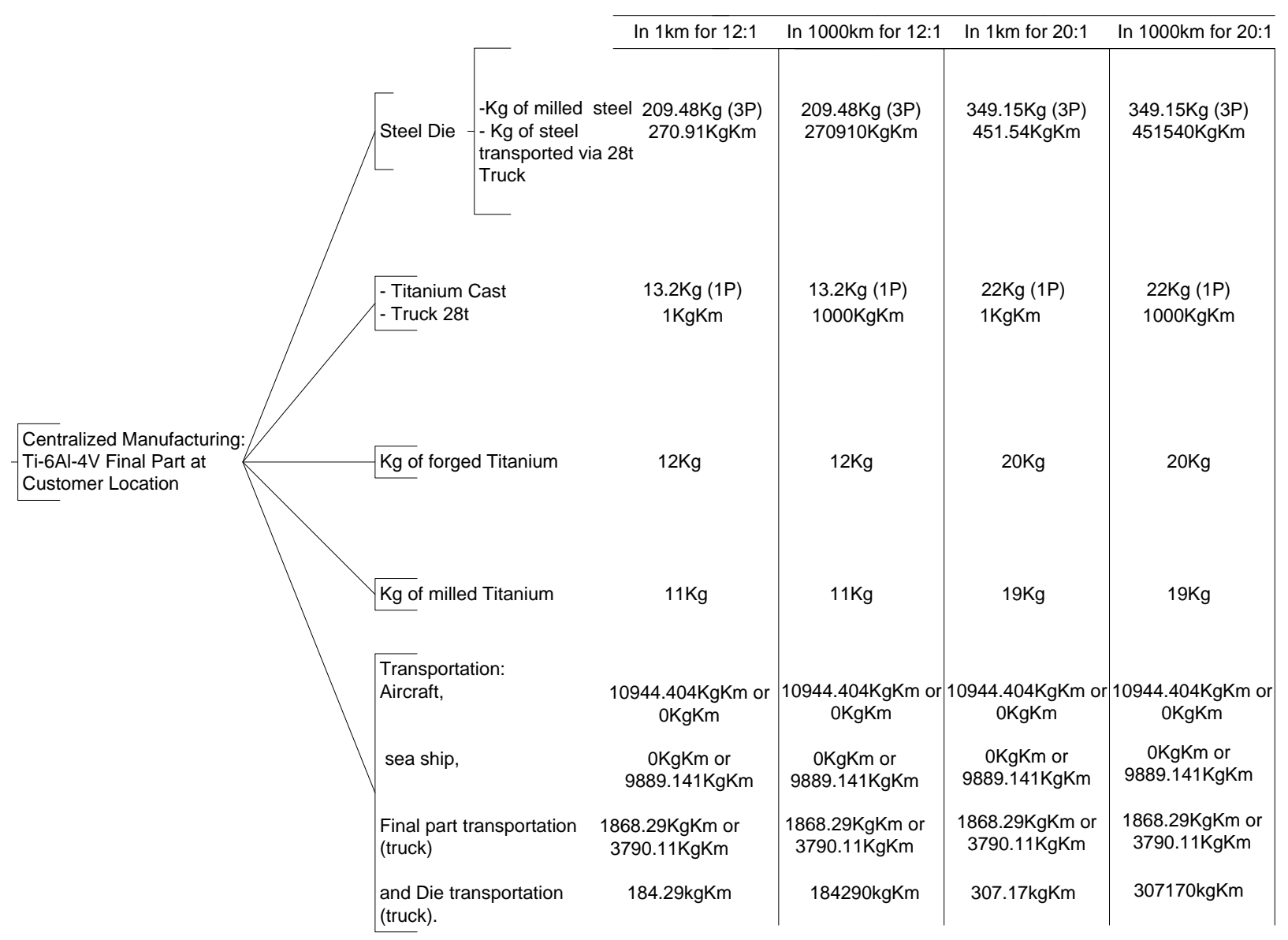

Figure 28 Inputs Entered in SimaPro for a Small Part

In Figure 29, the input values for the steel die are exactly the same as the inputs value for a steel die in the case of a large aluminum part. This is predictable given that production of a forging die is unrelated to material that will be forged in that die. 


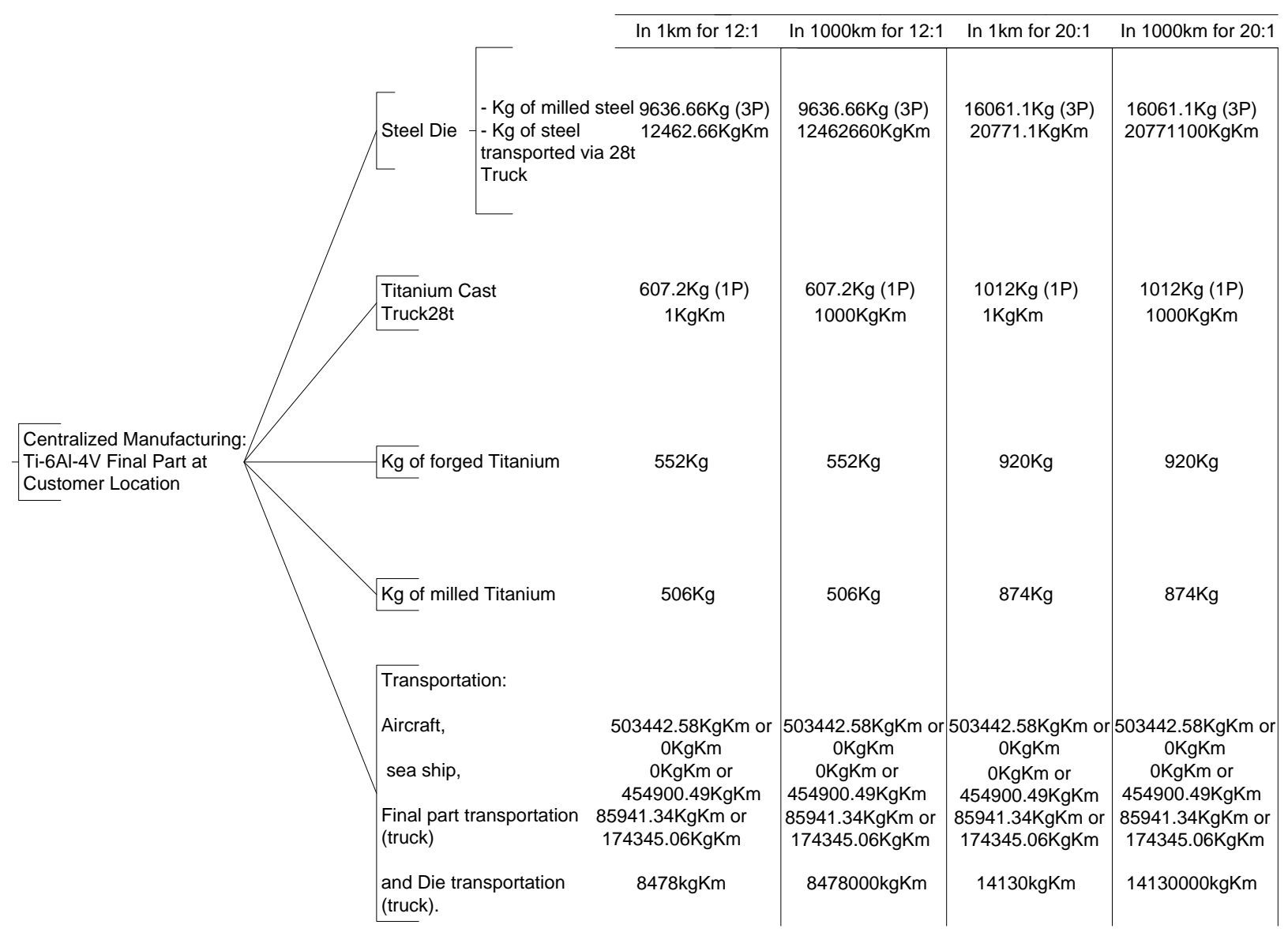

Figure 29 Inputs Entered in SimaPro for a large Part

Figure 30 and Figure 31 graphically compare results from each of the 16 simulations. The vertical axis for each scale is identical in order to simplify direct comparison of the results. Note that two graphs are shown for each corner of the cube. The titles of each graph differentiate whether the primary mode of overseas transportation was by boat or by plane. In order to qualitatively interpret the results, one can compare graphs on the left and right side to see the effect of the buy-to-fly ratio. Comparing graphs on the top and bottom planes illustrates the effect of production quantity. Comparing graphs on the front and back planes shows the effect of transportation distance. 


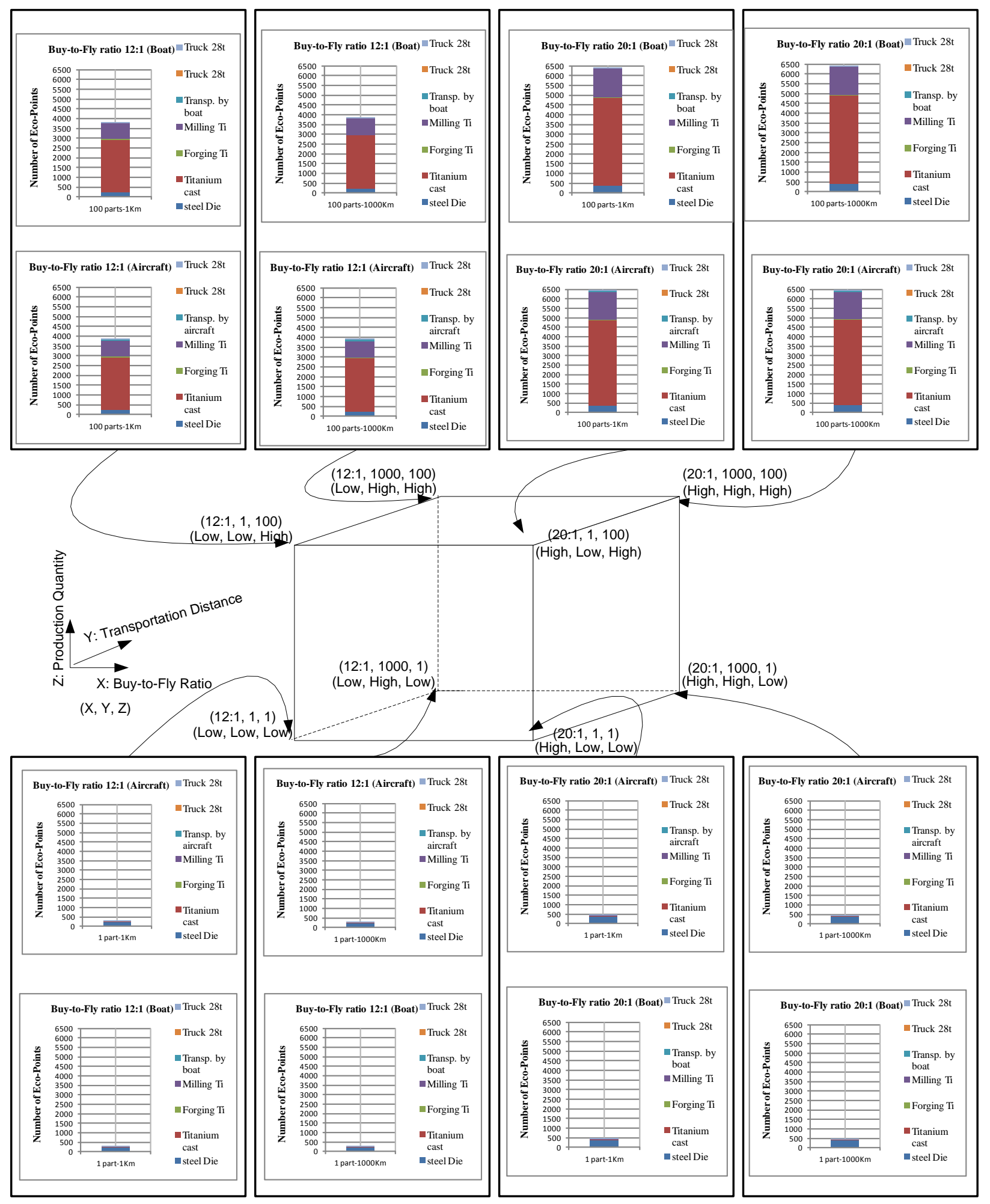

Figure 30 Sensitivity analysis for a small part (1Kg) 


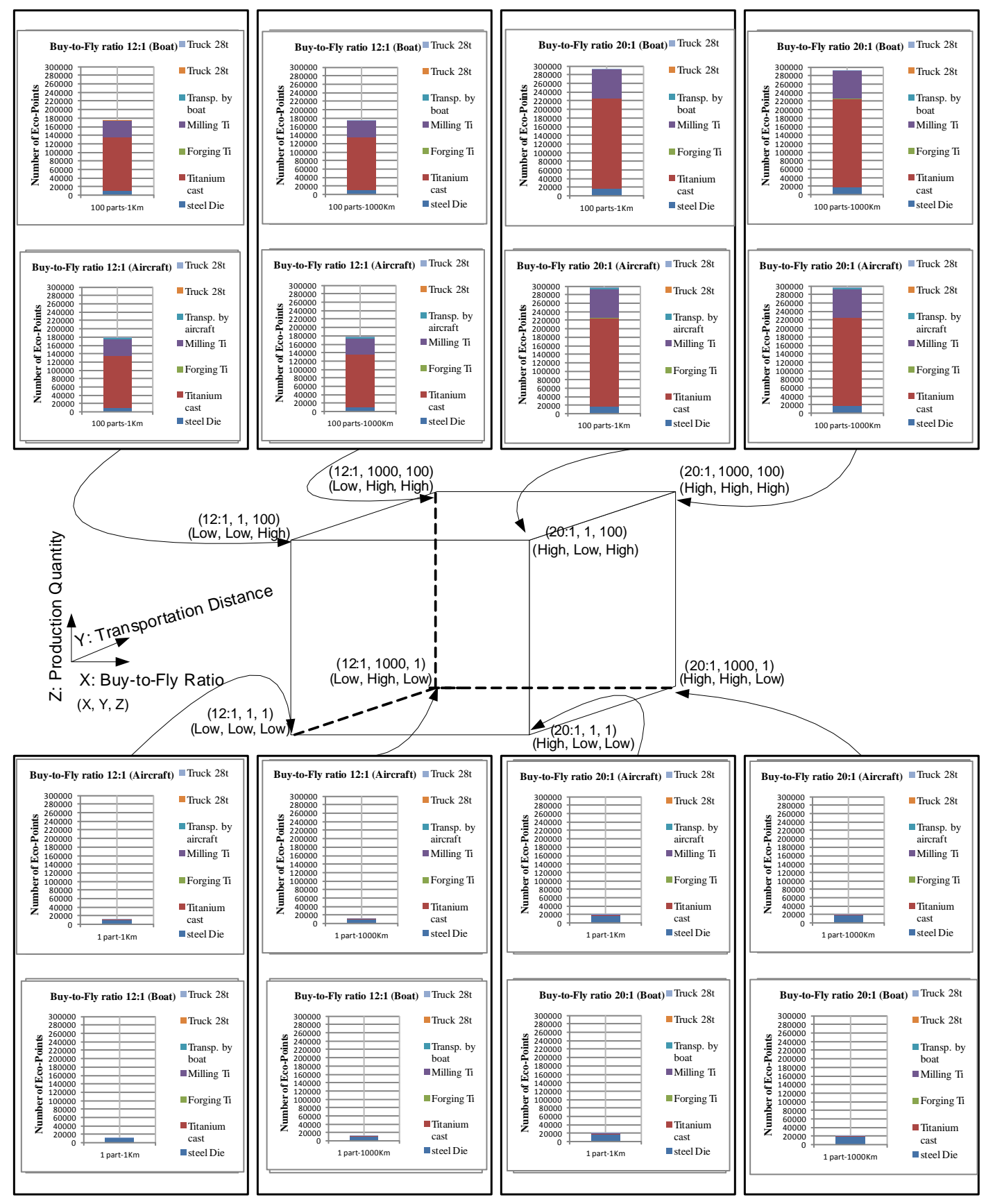

Figure 31 Sensitivity analysis for a large part (46Kg) 


\subsubsection{Environmental Impact of Buy-To-Fly Ratio On Titanium Forgings}

Table 20 shows simulation results for the eight pairwise comparisons in which the only factor being varied is Buy-To-Fly ratio. The process being considered here, forged titanium followed by finish machining, is nearly identical to the process discussed in Chapter 4 . The only difference is the material being processed. Not surprisingly, the results are quite similar. Regardless of the production quantity, transportation distance, or transportation mode, the increase in Eco-Points going from a moderate 12:1 ratio to a larger 20:1 ratio produces an extremely large increase in Eco-Points.

Table 20 Buy-to-Fly Comparison for a Small Titanium Forging and a Large Titanium Forging

\begin{tabular}{|c|c|c|c|c|c|c|}
\hline \multirow[b]{2}{*}{$\begin{array}{c}\text { Lot size, Trans. } \\
\text { Dist., Mode of } \\
\text { Trans. }\end{array}$} & \multicolumn{3}{|c|}{ Small Part (Total Eco-Pts) } & \multicolumn{3}{|c|}{ Large Part (Total Eco-Pts) } \\
\hline & $\begin{array}{c}\text { 12:1 } \\
\text { Buy-To- } \\
\text { Fly }\end{array}$ & $\begin{array}{c}\text { 20:1 } \\
\text { Buy-To- } \\
\text { Fly }\end{array}$ & $\%$ Increase & $\begin{array}{c}\text { 12:1 } \\
\text { Buy-To- } \\
\text { Fly }\end{array}$ & $\begin{array}{c}\text { 20:1 } \\
\text { Buy-To- } \\
\text { Fly }\end{array}$ & \% Increase \\
\hline $100,1 \mathrm{Km}$, boat & 3790 & 6359 & $68 \%$ & 173729 & 291919 & $68 \%$ \\
\hline $100,1 \mathrm{Km}$, air & 3857 & 6426 & $67 \%$ & 176827 & 295017 & $67 \%$ \\
\hline $100,1000 \mathrm{Km}$, boat & 3805 & 6385 & $68 \%$ & 174354 & 293028 & $68 \%$ \\
\hline $100,1000 \mathrm{Km}$, air & 3872 & 6452 & $67 \%$ & 177452 & 296126 & $67 \%$ \\
\hline $1,1 \mathrm{Km}$, boat & 255 & 425 & $67 \%$ & 11736 & 19551 & $67 \%$ \\
\hline $1,1 \mathrm{Km}$, air & 255 & 426 & $67 \%$ & 11767 & 19582 & $66 \%$ \\
\hline $1,1000 \mathrm{Km}$, boat & 269 & 451 & $68 \%$ & 12361 & 20660 & $67 \%$ \\
\hline \multirow[t]{2}{*}{$1,1000 \mathrm{Km}$, air } & 270 & 451 & $67 \%$ & 12392 & 20691 & $67 \%$ \\
\hline & & Avg: & $67 \%$ & & Avg: & $67 \%$ \\
\hline
\end{tabular}

Table 20 shows the total number of EcoPoints produced for each scenario in which only the buy-to-fly ratio is varied. In order to isolate only those EcoPoints directly affected by the buy-to-fly ratio, Table 21 shows the number of Eco-Points for the amount of material needed and the amount of machining done. The buy-to-fly ratio directly influences a significant proportion of the overall Eco-Points generated. 
Table 21 Buy-to-Fly Comparison for Machining Stage for Small and Large Parts

\begin{tabular}{|c|c|c|c|c|}
\hline \multirow{2}{*}{$\begin{array}{c}\text { Lot size, Trans. } \\
\text { Dist., Mode of } \\
\text { Trans. }\end{array}$} & \multicolumn{2}{|c|}{$\begin{array}{c}\text { Small Part (Machining } \\
\text { Eco-Pts) }\end{array}$} & \multicolumn{2}{|c|}{$\begin{array}{c}\text { Large Part (Machining } \\
\text { Eco-Pts) }\end{array}$} \\
\hline & $\begin{array}{c}\text { 12:1 } \\
\text { Buy-To- } \\
\text { Fly }\end{array}$ & $\begin{array}{c}\text { 20:1 } \\
\text { Buy-To- } \\
\text { Fly }\end{array}$ & $\begin{array}{c}\text { 12:1 } \\
\text { Buy-To- } \\
\text { Fly }\end{array}$ & $\begin{array}{c}\text { 20:1 } \\
\text { Buy-To- } \\
\text { Fly }\end{array}$ \\
\hline $100,1 \mathrm{Km}$, boat & 3542 & 5950 & 162300 & 273100 \\
\hline $100,1 \mathrm{Km}$, air & 3542 & 5950 & 162300 & 273100 \\
\hline $100,1000 \mathrm{Km}$, boat & 3542 & 5950 & 162300 & 273100 \\
\hline $100,1000 \mathrm{Kn}$ & 3542 & 5950 & 162300 & 273100 \\
\hline $1,1 \mathrm{Km}$, boat & 35 & 59 & 1623 & 2731 \\
\hline $1,1 \mathrm{Km}$, air & 35 & 59 & 1623 & 2731 \\
\hline $1,1000 \mathrm{Km}, \mathrm{b}$ & 35 & 59 & 1623 & 2731 \\
\hline $1,1000 \mathrm{Km}$, air & 35 & 59 & 1623 & 2731 \\
\hline
\end{tabular}

\subsubsection{Environmental Impact of Transportation Distance On Titanium Forgings}

This is an analysis of centralized manufacturing in which the product is shipped overseas to the end user. The model compares short and long transportation distances for the die and raw materials to the factory where forging takes place.

From the results shown in Table 22, it is apparent that varying the transportation distance has relatively little impact on the number of Eco-Points generated. The transportation distance is significant only to steel die shipment and low alloy steel shipment to the forging factory. The percentage increase is $6 \%$ for production of 1 part and $0 \%$ for production of 100 parts. The difference is understood by keeping in mind that as the production quantity increases, the number of Eco-Points attributed to transportation of the die gets distributed to a larger number of parts produced. Only one die is needed regardless of the number of parts produced. 
Table 22 Transportation Distance Comparison for a Small Titanium Forging and a Large Titanium Forging

Die/Raw Material Transportation

\begin{tabular}{|c|c|c|c|c|c|c|}
\hline \multirow{2}{*}{$\begin{array}{c}\text { Lot size, Buy to } \\
\text { Fly Ratio, Mode of } \\
\text { Trans. }\end{array}$} & \multicolumn{3}{|c|}{ Small Part (Total Eco-Pts) } & \multicolumn{3}{|c|}{ Large Part (Total Eco-Pts) } \\
\hline & $1 \mathrm{Km}$ & $1000 \mathrm{Km}$ & \% Increase & $1 \mathrm{Km}$ & $1000 \mathrm{Km}$ & $\%$ Increase \\
\hline 100, 12:1BTF, boat & 3790 & 3805 & $0 \%$ & 173729 & 174354 & $0 \%$ \\
\hline 100, 12:1BTF, air & 3857 & 3872 & $0 \%$ & 176827 & 177452 & $0 \%$ \\
\hline 100, 20:1BTF, boat & 6359 & 6385 & $0 \%$ & 291919 & 293028 & $0 \%$ \\
\hline 100, 20:1BTF, air & 6426 & 6452 & $0 \%$ & 295017 & 296126 & $0 \%$ \\
\hline 1, 12:1BTF, boat & 255 & 269 & $6 \%$ & 11736 & 12361 & $5 \%$ \\
\hline 1, 12:1BTF, air & 255 & 270 & $6 \%$ & 11767 & 12392 & $5 \%$ \\
\hline 1, 20:1BTF, boat & 425 & 451 & $6 \%$ & 19551 & 20660 & $6 \%$ \\
\hline \multirow[t]{2}{*}{ 1, 20:1BTF, air } & 426 & 451 & $6 \%$ & 19582 & 20691 & $6 \%$ \\
\hline & & Avg: & $3 \%$ & & Avg: & $3 \%$ \\
\hline
\end{tabular}

Table 22 shows the total number of EcoPoints produced for each scenario in which only the transportation distance is varied. In order to isolate only those EcoPoints directly affected by the transportation distance, Table 23 shows the number of Eco-Points for transportation distance only. 
Table 23 Transportation Distance Comparison for Transportation Stage for Small and Large Parts

Die/Raw Material Transportation

\begin{tabular}{|c|c|c|c|c|}
\hline $\begin{array}{c}\text { Lot size, Buy to } \\
\text { Fly Ratio, Mode of } \\
\text { Trans. }\end{array}$ & $\begin{array}{c}\text { Small Part } \\
\text { (Transportation Eco- } \\
\text { Pts) }\end{array}$ & \multicolumn{2}{c|}{$\begin{array}{c}\text { Large Part } \\
\text { (Transportation Eco- } \\
\text { Pts) }\end{array}$} \\
\cline { 2 - 5 } & $\mathbf{1 K m}$ & $\mathbf{1 0 0 0 K m}$ & $\mathbf{1 K m}$ & $\mathbf{1 0 0 0 K m}$ \\
\hline $\mathbf{1 0 0 , 1 2 : 1 B T F , ~ b o a t ~}$ & 0.00273 & 2.73 & 0.125 & 125 \\
\hline $\mathbf{1 0 0 , 1 2 : 1 B T F , ~ a i r ~}$ & 0.00273 & 2.73 & 0.125 & 125 \\
\hline $\mathbf{1 0 0 , 2 0 : 1 B T F , ~ b o a t ~}$ & 0.00455 & 4.55 & 0.209 & 209 \\
\hline $\mathbf{1 0 0 , 2 0 : 1 B T F , ~ a i r ~}$ & 0.00455 & 4.55 & 0.209 & 209 \\
\hline $\mathbf{1 , 1 2 : 1 B T F , ~ b o a t ~}$ & 0.00273 & 2.73 & 0.125 & 125 \\
\hline $\mathbf{1 , 1 2 : 1 B T F , ~ a i r ~}$ & 0.00273 & 2.73 & 0.125 & 125 \\
\hline $\mathbf{1 , 2 0 : 1 B T F , ~ b o a t ~}$ & 0.00455 & 4.55 & 0.209 & 209 \\
\hline $\mathbf{1 , 2 0 : 1 B T F , ~ a i r ~}$ & 0.00455 & 4.55 & 0.209 & 209 \\
\hline
\end{tabular}

\subsubsection{Environmental Impact of Mode of Transportation On Titanium Forgings}

This is an analysis of centralized manufacturing in which the product is shipped either by boat or by aircraft to the end user. The model compares environmental impact output in case of shipping via boat and the case of shipping via aircraft.

For small production quantities (e.g. 1 part) there is effectively no difference in the number of Eco-Points based on the mode of transportation. Although the number of Eco-Points associated with air transportation increases as the production quantity goes up, the percent increase is still modest ( 1 to $2 \%$ increase) for a production quantity of 100 parts. The difference in percentage for production quantities of 1 and 100 is that the total number of Eco-Points gets larger as the number of parts produced increase. Based on the average percentage value of percentage increases for the eight scenarios of a small part in Table $24(1 \%)$, one can conclude that the mode of transportation is relatively insignificant compared with other factors. 
Table 24 Transportation Mode Comparison for a Small Titanium Forging and a Large Titanium Forging

\begin{tabular}{|c|c|c|c|c|c|c|}
\hline \multirow{2}{*}{$\begin{array}{l}\text { Lot size, Trans. } \\
\text { Dist., Buy-to-Fly } \\
\text { Ratio }\end{array}$} & \multicolumn{3}{|c|}{ Small Part (Total Eco-Pts) } & \multicolumn{3}{|c|}{ Large Part (Total Eco-Pts) } \\
\hline & Boat & Air & \% Increase & Boat & Air & \% Increase \\
\hline 100, 1Km, 12:1 & 3790 & 3857 & $2 \%$ & 173729 & 176827 & $2 \%$ \\
\hline $100,1 \mathrm{Km}, 20: 1$ & 6359 & 6426 & $1 \%$ & 291919 & 295017 & $1 \%$ \\
\hline $100,10^{3} \mathrm{Km}, 12: 1$ & 3805 & 3872 & $2 \%$ & 174354 & 177452 & $2 \%$ \\
\hline $100,10^{3} \mathrm{Km}, 20: 1$ & 6385 & 6452 & $1 \%$ & 293028 & 296126 & $1 \%$ \\
\hline $1,1 \mathrm{Km}, 12: 1$ & 255 & 255 & $0 \%$ & 11736 & 11767 & $0 \%$ \\
\hline 1, 1Km, 20:1 & 425 & 426 & $0 \%$ & 19551 & 19582 & $0 \%$ \\
\hline $1,10^{3} \mathrm{Km}, 12: 1$ & 269 & 270 & $0 \%$ & 12361 & 12392 & $0 \%$ \\
\hline \multirow[t]{2}{*}{$1,10^{3} \mathrm{Km}, 20: 1$} & 451 & 451 & $0 \%$ & 20660 & 20691 & $0 \%$ \\
\hline & & $\mathrm{Av}$ & $1 \%$ & & Avg & $1 \%$ \\
\hline
\end{tabular}

Table 24 shows the total number of EcoPoints produced for each scenario in which only the mode of transportation is varied. In order to isolate only those EcoPoints directly affected by the mode of transportation, Table 25 shows the number of Eco-Points for mode of transportation only.

Table 25 Transportation Mode Comparison for Modes of Transportation for Small and Large Parts

\begin{tabular}{|c|c|c|c|c|}
\hline \multirow{2}{*}{$\begin{array}{l}\text { Lot size, Trans. } \\
\text { Dist., Buy-to-Fly } \\
\text { Ratio }\end{array}$} & \multicolumn{2}{|c|}{$\begin{array}{c}\text { Small Part } \\
\text { (Transportation Eco- } \\
\text { Pts) }\end{array}$} & \multicolumn{2}{|c|}{$\begin{array}{c}\text { Large Part } \\
\text { (Transportation Eco- } \\
\text { Pts) }\end{array}$} \\
\hline & Boat & Air & Boat & Air \\
\hline 100, 1Km, 12:1 & 1 & 71 & 31 & 3260 \\
\hline $100,1 \mathrm{Km}, 20: 1$ & 1 & 71 & 31 & 3260 \\
\hline $100,10^{3} \mathrm{Km}, 12: 1$ & 1 & 71 & 31 & 3260 \\
\hline $100,10^{3} \mathrm{Km}, 20: 1$ & 1 & 71 & 31 & 3260 \\
\hline 1, 1Km, 12:1 & 0.01 & 0.71 & 0.307 & 33 \\
\hline 1, 1Km, 20:1 & 0.01 & 0.71 & 0.307 & 33 \\
\hline $1,10^{3} \mathrm{Km}, 12: 1$ & 0.01 & 0.71 & 0.307 & 33 \\
\hline $1,10^{3} \mathrm{Km}, 20: 1$ & 0.01 & 0.71 & 0.307 & 33 \\
\hline
\end{tabular}




\subsubsection{Environmental Impact of Production Quantity On Titanium Forgings}

As was done in Chapter 4, this section examines the Eco-Points per part as a function of transportation distance and buy-to-fly ratio for producing 1, 10, 100, and 1000 parts. Figure 31 is plotted using the same Y-axis maximum Eco-Points value of 700 for analysis of small parts and Figure 32 is plotted using the same Y-axis maximum Eco-Points value of 20700 for analysis of large parts. Tables 26 and 27 show the number of Eco-Points for 1, 10, 100, and 1000 production quantities as well as the percentage decrease.

Although the absolute values are considerably higher for this large part scenario than they are for the small part scenario in this section, the trends are identical. There is a substantial drop in Eco-Points between 1 part and 10 parts, which indicates that tooling is the primary contributor of Eco-Points for very small production quantities.

Table 26 Production Quantity Comparison for a Small Titanium Forging

Production Quantity

\begin{tabular}{|c|c|c|c|c|c|}
\hline $\begin{array}{l}\text { Transportation } \\
\text { Dist., Buy-To-Fly, } \\
\text { Mode } \\
\text { Transportation }\end{array}$ & $\begin{array}{c}1 \text { Part } \\
\text { (Pts per } \\
\text { part) }\end{array}$ & $\begin{array}{c}\text { 10 Parts } \\
\text { (Pts per } \\
\text { part) }\end{array}$ & $\begin{array}{l}100 \text { Parts } \\
\text { (Pts per } \\
\text { part) }\end{array}$ & $\begin{array}{l}\text { 1000 Parts } \\
\text { (Pts per } \\
\text { part) }\end{array}$ & $\begin{array}{c}\text { \% Decrease } \\
\text { from 1Part to } \\
10^{3} \text { Parts }\end{array}$ \\
\hline 1Km, 12:1, Boat & 255 & 58 & 38 & 36 & $86 \%$ \\
\hline 1Km, 12:1, Air & 255 & $\overline{58}$ & 39 & 37 & $85 \%$ \\
\hline 1Km, 20:1, Boat & 425 & 96 & 64 & 60 & $86 \%$ \\
\hline 1Km, 20:1, Air & 426 & 97 & 64 & 61 & $86 \%$ \\
\hline $10^{3} \mathrm{Km}, 12: 1$, Boat & 269 & 59 & 38 & 36 & $87 \%$ \\
\hline $10^{3} \mathrm{Km}, 12: 1$, Air & 270 & $\overline{59}$ & 39 & 37 & $86 \%$ \\
\hline $10^{3} \mathrm{Km}, 20: 1$, Boat & $\overline{451}$ & 99 & 64 & 60 & $87 \%$ \\
\hline $10^{3} \mathrm{Km}, 20: 1$, Air & 451 & 100 & 65 & 61 & $86 \%$ \\
\hline & & & & Avg. & $86 \%$ \\
\hline
\end{tabular}


Table 27 Production Quantity Comparison for a Large Titanium Forging

Production Quantity

\begin{tabular}{|c|c|c|c|c|c|}
\hline $\begin{array}{l}\text { Transportation } \\
\text { Dist., Buy-To-Fly, } \\
\text { Mode of } \\
\text { Transportation } \\
\end{array}$ & $\begin{array}{c}1 \text { Part } \\
\text { (Pts per } \\
\text { part) }\end{array}$ & $\begin{array}{c}10 \text { Parts } \\
\text { (Pts per } \\
\text { part) }\end{array}$ & $\begin{array}{c}\text { 100 Parts } \\
\text { (Pts per } \\
\text { part) }\end{array}$ & $\begin{array}{l}\text { 1000 Parts } \\
\text { (Pts per } \\
\text { part) }\end{array}$ & $\begin{array}{c}\% \text { Decrease } \\
\text { from 1Part to } \\
10^{3} \text { Parts }\end{array}$ \\
\hline 1Km, 12:1, Boat & 11736 & 2646 & 1737 & 1646 & $86 \%$ \\
\hline 1Km, 12:1, Air & 11767 & 2677 & 1768 & 1677 & $86 \%$ \\
\hline 1Km, 20:1, Boat & 19551 & 4431 & 2919 & 2768 & $86 \%$ \\
\hline 1Km, 20:1, Air & 19582 & 4462 & 2950 & 2799 & $86 \%$ \\
\hline $10^{3} \mathrm{Km}, 12: 1$, Boat & 12361 & 2709 & 1744 & 1647 & $87 \%$ \\
\hline $10^{3} \mathrm{Km}, 12: 1$, Air & 12392 & 2740 & 1775 & 1678 & $87 \%$ \\
\hline $10^{3} \mathrm{Km}, 20: 1$, Boat & 20660 & 4542 & 2930 & 2769 & $87 \%$ \\
\hline $10^{3} \mathrm{Km}, 20: 1$, Air & 20691 & 4573 & 2961 & 2800 & $87 \%$ \\
\hline & & & & Avg. & $87 \%$ \\
\hline
\end{tabular}



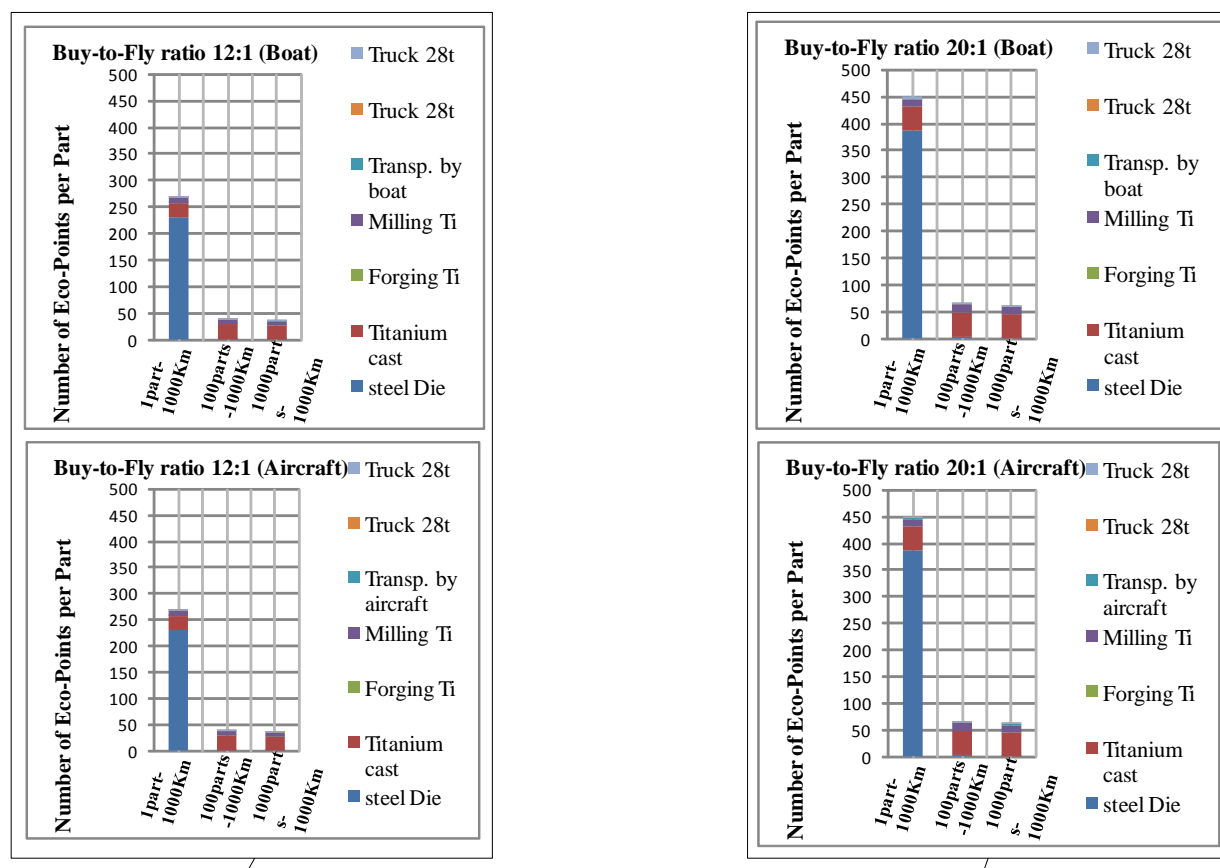

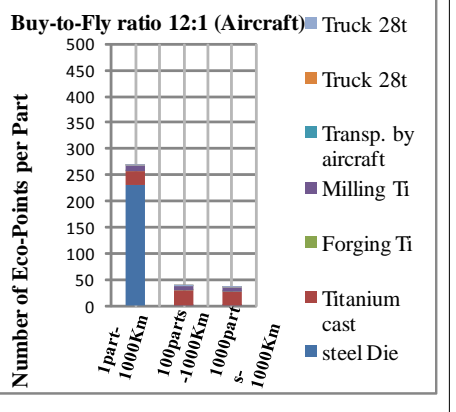

Buy-to-Fly ratio 20:1 (Aircraft) $₫$ Truck 28t
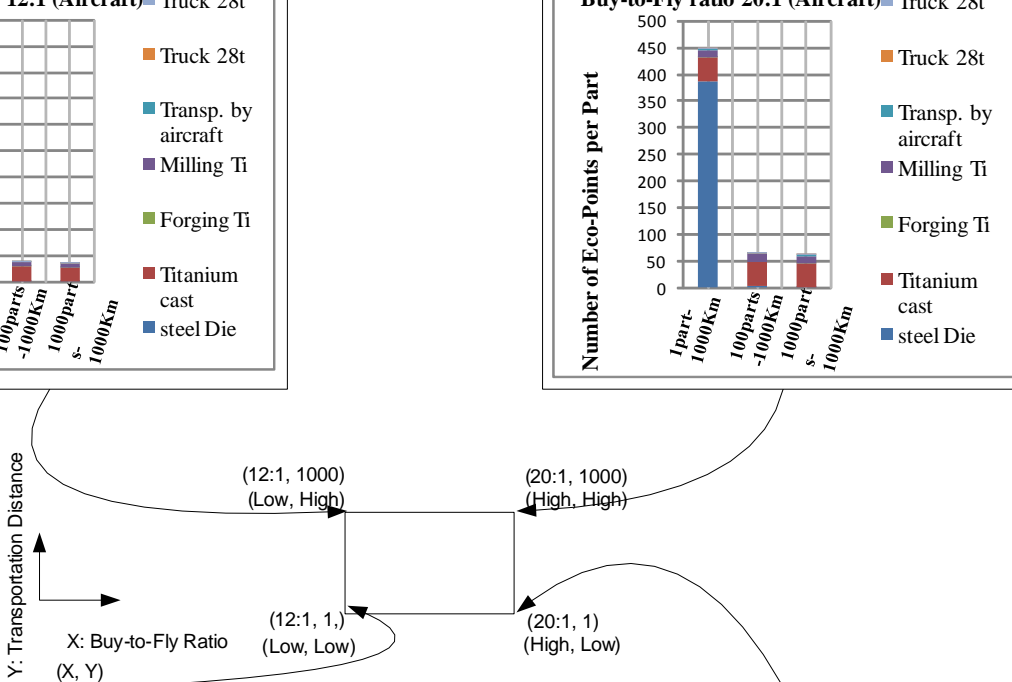

$(12: 1,1000)$

(Low, High)

(High, High)

$(X, Y)$

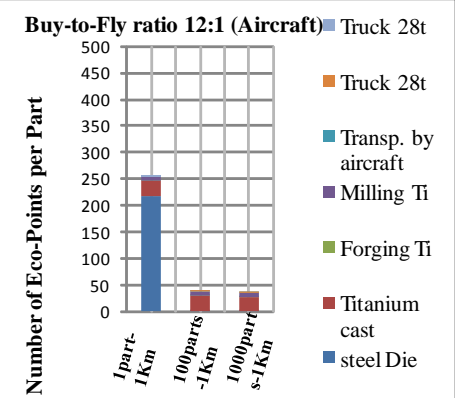

Buy-to-Fly ratio 12:1 (Boat) $\quad$ Truck $28 \mathrm{t}$
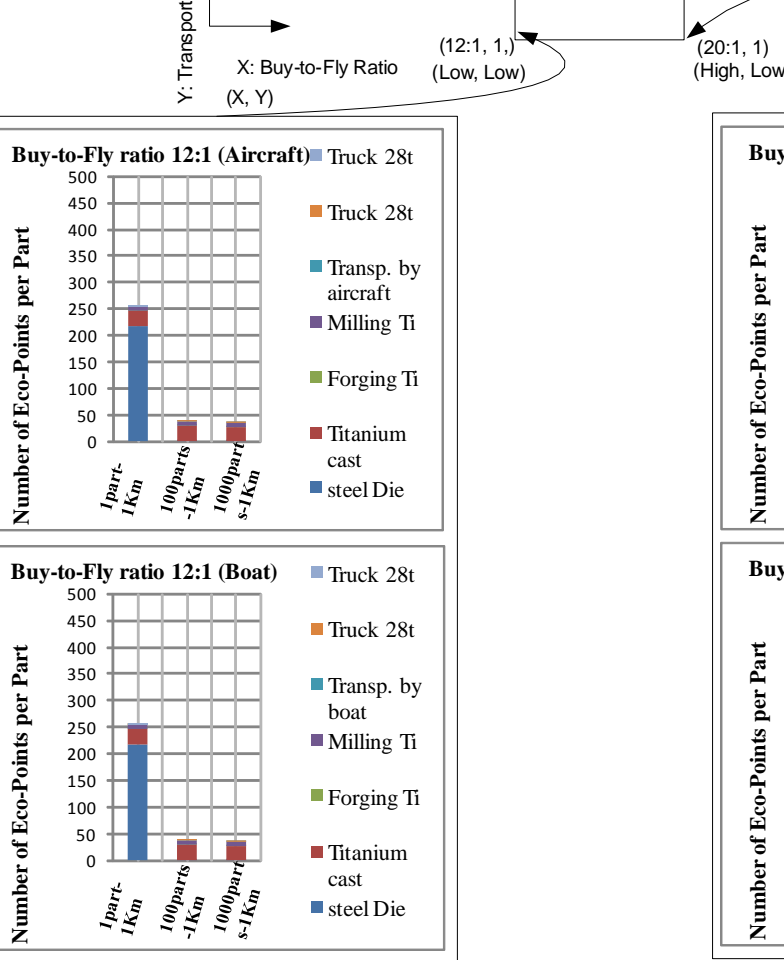

$\begin{array}{ll}(\text { Low, Low) } & (20: 1,1) \\ \text { (High, Low) }\end{array}$

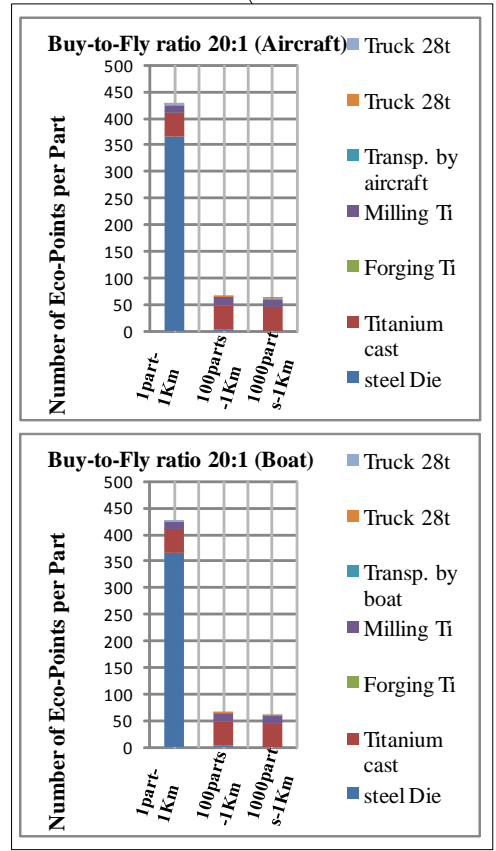

Figure 32 Number of Ecopoints per Part for a Small Part 


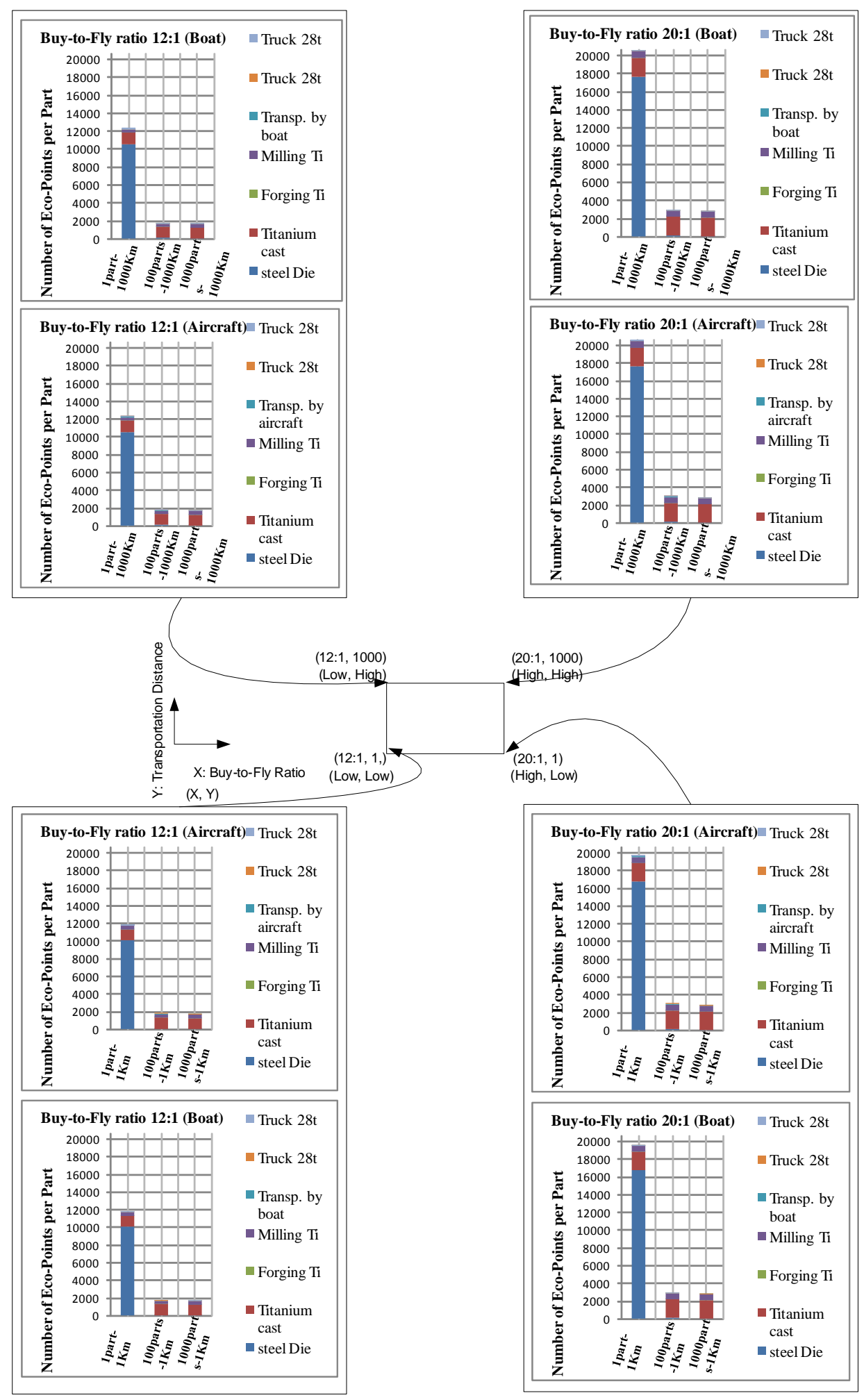

Figure 33 Number of Ecopoints per Part for a large Part (b) 


\subsubsection{Comparison of Part Size In Titanium Forging}

As was done in Chapter 4, this section presents an analysis of simulation results between small $(1 \mathrm{~kg})$ and large (46 kg) forged titanium parts. For every scenario, as shown in Table 28, the number of Eco-Points for a large part is 46 times greater than the number of Eco-Points for a small part. This is logical, as the large part considered has 46 times more material to process and transport. This reveals a major difference in producing a small part over producing a large part.

One could state that the part size is dictated by the mechanical designer and is not influenced by whether the part is made under a centralized or distributed manufacturing scenario. However, component design is dictated not just by mechanical function, but also by whether or not the part can be manufactured. Parts often have more mass than is needed simply because removing unneeded material in certain regions of the part would violate manufacturability guidelines. Additive manufacturing processes, such as Electron Beam Melting, therefore make it possible to produce components in which mass is reduced. This thesis does not deal with design or analysis of a specific mechanical component, but the significant potential for reduction in environmental impact associated with component redesign must be recognized. 
Table 28 Part Size Comparison for a Small and a Large Titanium Forging

Part Size

\begin{tabular}{|c|c|c|c|}
\hline $\begin{array}{l}\text { Number of Parts, } \\
\text { Transportation Dist., } \\
\text { Buy-To-Fly, Mode of } \\
\text { Transportation }\end{array}$ & A small part (Total Pts) & A large part (Total Pts) & \% Increase \\
\hline $100,1 \mathrm{Km}, 12: 1$, Boat & 3790 & 173729 & $4500 \%$ \\
\hline 100,1Km, 12:1, Air & 3857 & 176827 & $4500 \%$ \\
\hline $100,10^{3} \mathrm{Km}, 12: 1$, Boat & 3805 & 174354 & $4500 \%$ \\
\hline $100,10^{3} \mathrm{Km}, 12: 1$, Air & 3872 & 177452 & $4500 \%$ \\
\hline 100, 1Km, 20:1, Boat & 6359 & 291919 & $4500 \%$ \\
\hline 100, 1Km, 20:1, Air & 6426 & 295017 & $4500 \%$ \\
\hline $100,10^{3} \mathrm{Km}, 20: 1$, Boat & 6385 & 293028 & $4500 \%$ \\
\hline $100,10^{3} \mathrm{Km}, 20: 1$, Air & 6452 & 296126 & $4500 \%$ \\
\hline 1, 1Km, 12:1, Boat & 255 & 11736 & $4500 \%$ \\
\hline 1, 1Km, 12:1, Air & 255 & 11767 & $4500 \%$ \\
\hline 1, 1Km, 20:1, Boat & 425 & 19551 & $4500 \%$ \\
\hline 1, 1Km, 20:1, Air & 426 & 19582 & $4500 \%$ \\
\hline $1,10^{3} \mathrm{Km}, 12: 1$, Boat & 269 & 12361 & $4500 \%$ \\
\hline $1,10^{3} \mathrm{Km}, 12: 1$, Air & 270 & 12392 & $4500 \%$ \\
\hline 1,10 ${ }^{3} \mathrm{Km}, 20: 1$, Boat & 451 & 20660 & $4500 \%$ \\
\hline 1, 10 ${ }^{3} \mathrm{Km}, 20: 1$, Air & 451 & 20691 & $4500 \%$ \\
\hline
\end{tabular}




\subsection{Simulation Results for Distributed Manufacturing of Titanium Parts}

Referring to the environmental analysis design space illustrated in Figure 27, distributed manufacturing simulations for small $(1 \mathrm{~kg})$ and large $(46 \mathrm{~kg})$ parts were conducted in SimaPro corresponding to the four extreme points in the design space. Figure 33 provides specific input values for each simulation condition. The output variable being measured in each simulation for comparison purposes was the number of Eco-Points $(\mathrm{Pt})$. The maximum number of Eco-points recorded over those $2 \times 2=4$ simulations was 149 Eco-Points $(\mathrm{Pt})$ for large parts and 3.25 EcoPoints (Pt) for small parts. In Chapter 3, the buy to fly ratio of 1.03:1 was explained for distributed manufacturing. The mass of titanium required at each process step $(1.133,1.03$, 52.12 , and $47.38 \mathrm{~kg}$ ) are obtained by assuming a 10\% scrap rate and then having either $1 \mathrm{~kg}$ or 46 $\mathrm{kg}$ as the mass of the final product. Since this section is for distributed manufacturing where transportation is very small, a nominal $1 \mathrm{~km}$ transportation distance of the finished part to the end user by truck was assumed.

Distributed Manufacturing: - Ti-6Al-4V Final Part at Customer Location

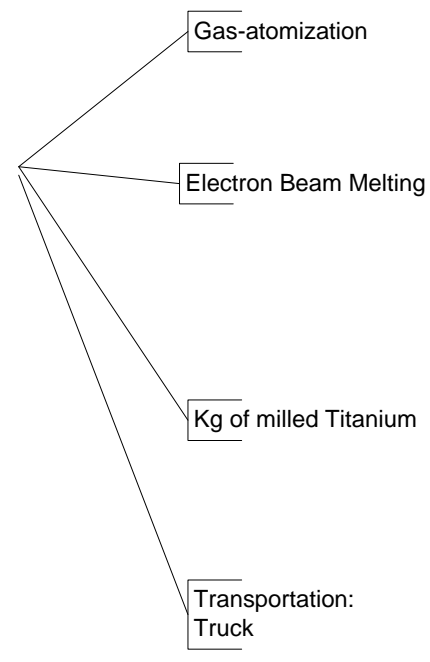

\begin{tabular}{|c|c|c|c|}
\hline In $1 \mathrm{~km}$ for $1.03: 1$ & For small parts & In $1 \mathrm{~km}$ for $1.03: 1$ & For large parts \\
\hline \multicolumn{2}{|c|}{$1.133 \mathrm{Kg}$} & \multicolumn{2}{|c|}{$52.12 \mathrm{Kg}$} \\
\hline \multicolumn{2}{|c|}{$1.03 \mathrm{Kg}$} & \multicolumn{2}{|c|}{$47.38 \mathrm{Kg}$} \\
\hline \multicolumn{2}{|c|}{$0.03 \mathrm{Kg}$} & \multicolumn{2}{|c|}{$1.38 \mathrm{Kg}$} \\
\hline \multicolumn{2}{|c|}{$1 \mathrm{KgKm}$} & \multicolumn{2}{|c|}{$46 \mathrm{KgKm}$} \\
\hline
\end{tabular}

Figure 34 Inputs for Distributed Manufacturing 
As discussed in Chapter 3, the user specifies inputs to the distributed manufacturing model in SimaPro. Once the user has specified inputs and runs the model, SimaPro calculates the environmental outputs for each process and assembly. The following legend maps colors to each source of environmental impact in Chapter 5 section 5.2.

- : Gas-Atomization

- : Electron Beam Melting

๓: Milling Titanium

๓: Truck 28t (Transportation of the final product to the customer by truck)

Simulation results analyzed in this section are plotted with a pie chart representation to more clearly communicate the relative contributions of each model element. Results for a small size $1 \mathrm{~kg}$ and a large size $46 \mathrm{~kg}$ part are shown. For small parts $(1 \mathrm{~kg})$, the maximum number of Eco-Points per part obtained over all experimental conditions was 3.25. For large parts (46kg) the maximum number of Eco-points per part obtained over all experimental conditions was 149. Gas atomization for production of the powder feedstock has the most significant impact on the environment and accounts for approximately $93 \%$ of the total Eco-Points. All other factors combined accounted for only $\sim 7 \%$ of the Eco-Points generated. Given that EBM is a near net shape process with a very low buy-to-fly ratio, it is expected that the Eco-Points associated with milling will be relatively small (2-3\% according to the SimaPro results). Likewise, the model assumes very short transportation distances in which the parts are located close to the point of use. Hence it is expected that the Eco-Points associated with transportation will be close to zero. The Electron Beam Melting process contributes approximately 4-5\% of the total Eco-Points associated with distributed manufacturing of a titanium part.

Chapter 3 detailed how input values associated with powder production were obtained. Two important factors, atomization energy and gas/metal flow ratio, were provided in terms of a $\mathrm{min} / \mathrm{max}$ range of reasonable values. In order to assess whether or not the model output (EcoPoints) is sensitive to values for either/both parameter within their min/max range, simulations were run at the extreme values for both parameters. For small parts $(1 \mathrm{~kg})$, the number of EcoPoints generated at the extreme values for atomization energy and gas/metal flow ratio ranged from a low of 2.93 to a high of 3.05. For large parts, the number of Eco-Points generated at the 
extreme values for atomization energy and gas/metal flow ratio ranged from a low of 135 to a high of 140. The relative small differences in values suggests that the model is not particularly sensitive to the value of atomization energy or gas/metal flow ratio provided the values are selected within the reasonable ranges computed in Chapter 3.

Helium is the gas used in gas atomization, and transportation of it to the atomization facility is counted in SimaPro. The SimaPro process for helium production includes: a) extraction of helium from natural gas including materials, b) energy used, c) facility infrastructure and d) factory emissions. SimaPro's existing multi-output process entitled "natural gas, helium extraction" accounts for the co-products helium, natural gas liquids and sales gas. The Eco-Point allocation for helium production is based on mass calculations and global helium supply sources. 


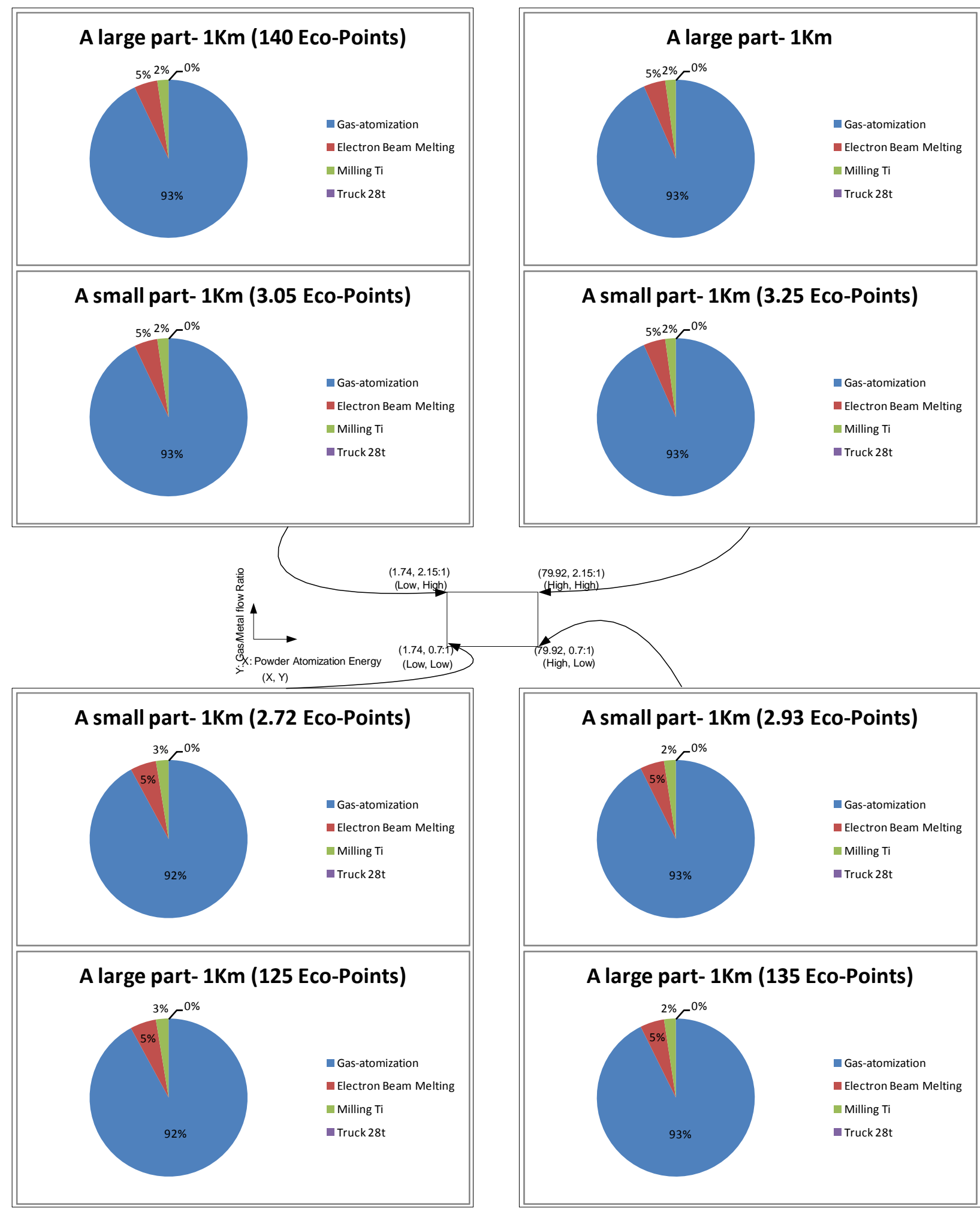

Figure 35 Sensitivity data analysis: Distributed manufacturing 


\subsection{Discussion}

This study describes a model that assesses the potential environmental impact of tooling fabrication, raw materials, processes, and transportation. The primary differences can be summarized as follows:

- Centralized manufacturing requires a forging die whereas distributed manufacturing does not require fixed tooling.

- Centralized manufacturing uses ingot/casting as the raw material whereas distributed manufacturing uses titanium powder as the raw material.

- Centralized manufacturing requires forging followed by a large amount of machining (i.e. high buy-to-fly ratio). For distributed manufacturing, the EBM process is followed by a small amount of finish machining (i.e. low buy-to-fly ratio).

- Lastly, transportation distance is large for centralized manufacturing, but is small for distributed manufacturing.

Based on the analysis done in Chapters 4 and 5, the difference between centralized manufacturing and distributed manufacturing can be summarized by showing curves comparing total Eco-Points as a function of the number and size of parts produced. Figure 36 (a) shows the number of Eco-Points per part for small parts, and Figure 36 (b) shows the number of Eco-Points per part for large parts. The red and blue curves show minimum and maximum Eco-Points per part achieved under the centralized manufacturing scenario. The green curve shows Eco-Points per part for distributed manufacturing. Both small and large part results show that there is a sudden drop of the number of Eco-Points per part under the centralized manufacturing model because the number of Eco-Points generated by production of the dies is distributed over the number of parts produced. However, the graphs for centralized manufacturing at 100 and 1000 levels out because the tooling cost per part becomes small as the number of parts grows beyond 100. At large production quantities, the contribution of die production to the Eco-Points per part is negligible and the Eco-Point per part is almost entirely contributed by forging, finish machining, and transportation. It is interesting to note that the centralized manufacturing curves do not intersect with the distributed manufacturing curve. The distributed manufacturing curve is 
constant because there are no fixed tooling costs. The conclusion is that regardless of part size, the number of Eco-Points per part generated under the centralized manufacturing scenario is always greater than the Eco-Points per part generated under the distributed manufacturing scenario.

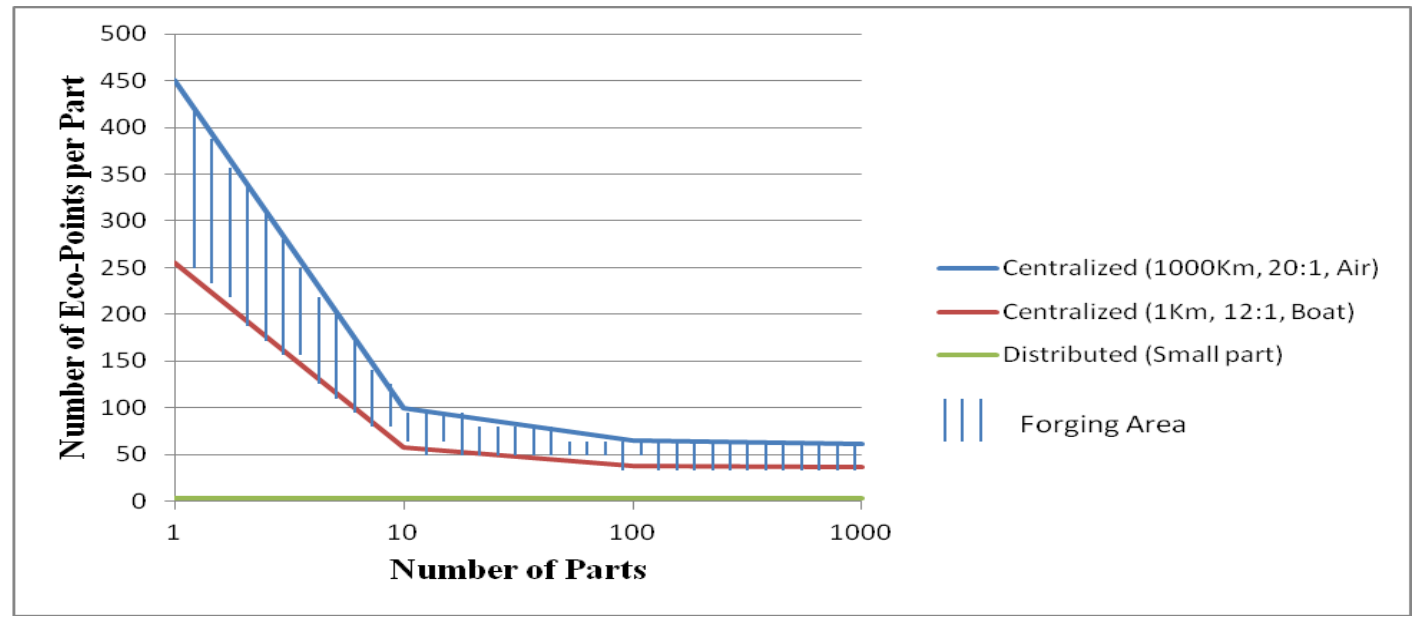

(a)

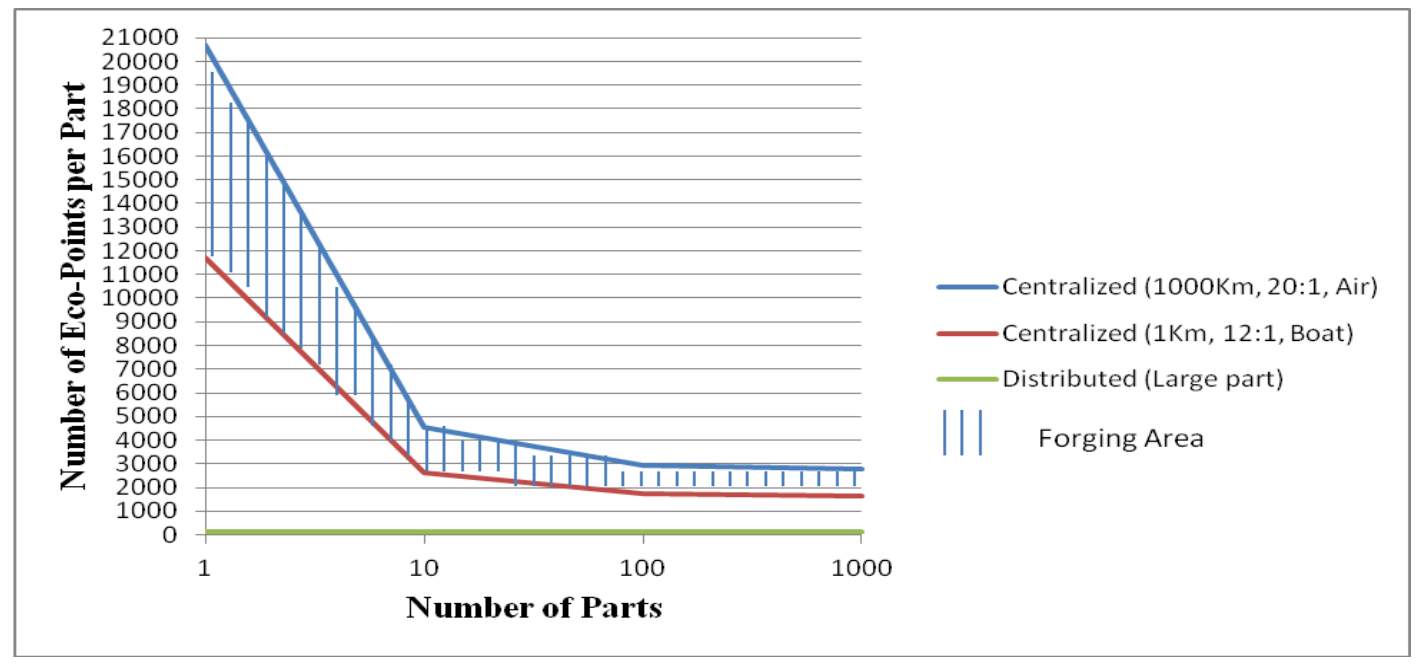

(b)

Figure 36 Eco-Points per part for (a) a small part and (b) a large part

Figure 37 shows the difference between centralized manufacturing and distributed manufacturing in terms of the total number of Eco-Points. The graphs show worst-case scenarios of centralized and distributed manufacturing for small and large parts. 


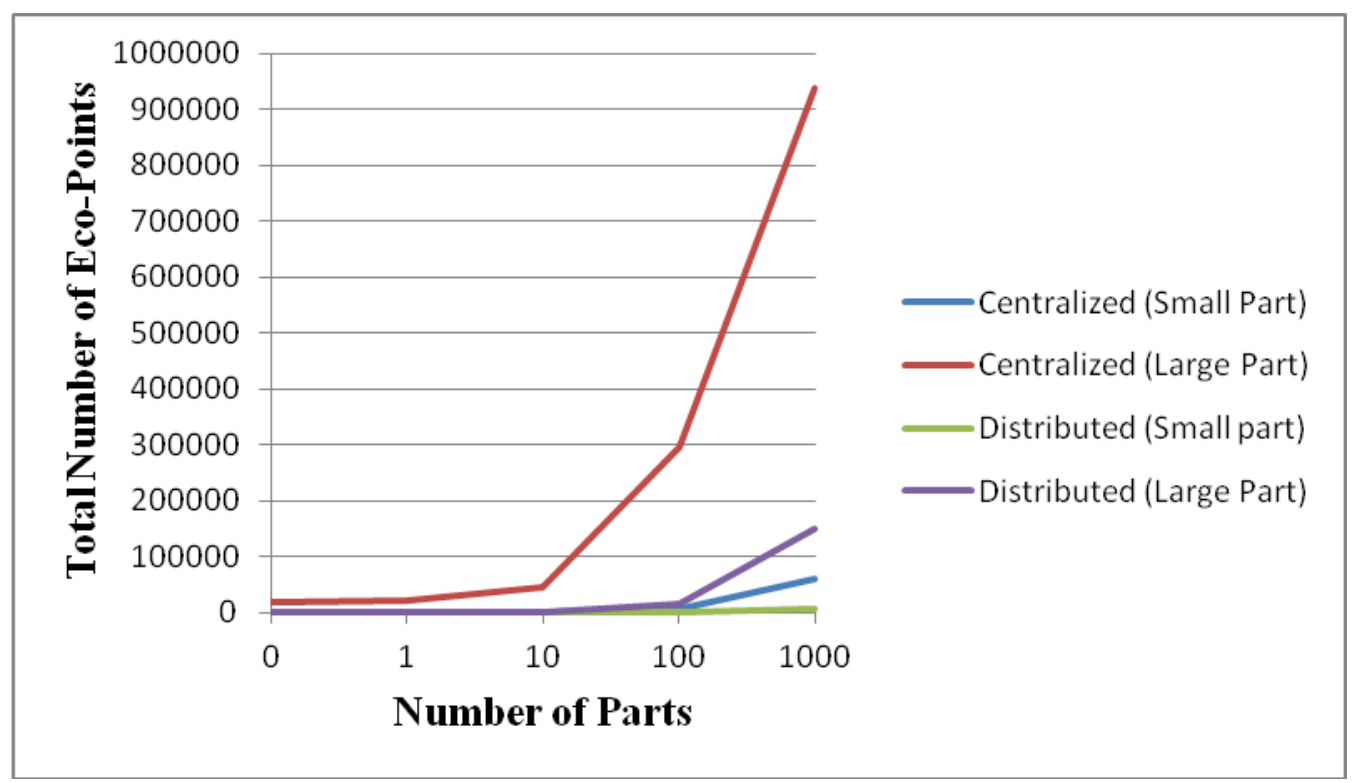

\section{Figure 37 Total Number of Eco-Points for both Centralized and Distributed Manufacturing}

One of the major differences between the centralized and distributed manufacturing models is the amount of transportation. If a SimaPro model is created that consists solely of transportation of a given mass of material a given distance via a given transportation method, then following Eco-Point rates for aircraft, boat, truck28t, and rail are obtained:

- Transportation by aircraft in the database of Eco-Invent: $6.47 \times 10^{-5} \mathrm{Pts} / \mathrm{KgKm}$

- Transportation by sea ship B250 in the database of BUWAL 250: $6.74 \times 10^{-7} \mathrm{Pts} / \mathrm{KgKm}$

- Transportation by truck 28t B250 in the database of BUWAL 250: $1.48 \times 10^{-5} \mathrm{Pts} / \mathrm{KgKm}$

- Transportation by train I in the database of IDEMAT 2001: $5.94 \times 10^{-6} \mathrm{Pts} / \mathrm{KgKm}$

Using transportation distances shown in Chapter 3 along with the values above, one can calculate the number of Eco-Points it takes to ship a final product overseas by air or boat and then over land by truck (i.e. a model in which a product is produced overseas). The maximum percentage of the number of Eco-Points of different modes of transportation in the centralized model is $3 \%$ for aircraft, $0.1 \%$ for truck (in case transportation by truck is done after the product was shipped by airplane), $0.03 \%$ for ship, and $0.2 \%$ for truck (in case transportation by truck is 
done after the product was shipped by boat). However, it is possible for a part made via centralized manufacturing to be located close to the end user. In this case, one could assume a minimal transportation distance of $1 \mathrm{~km}$ which effectively contributes nothing to the overall number of Eco-Points. In the case of distributed manufacturing, transportation by truck a short distance $(1 \mathrm{~km})$ is effectively $0 \%$ of the Eco-Points for small parts $(1 \mathrm{~kg})$ and large parts $(46 \mathrm{~kg})$. Regardless of which extreme point is considered, transportation actually does not account for the majority of difference in Eco-Points generated by the two methods. 


\section{Chapter 6 Summary and Conclusions}

\subsection{Summary}

The objective of this study was to compare the environmental impact of a traditional manufacturing approach with a new distributed manufacturing approach for titanium part production. Specific objectives were to:

(1) Conduct an environmental impact assessment for fabrication of a titanium part via forging. The forging model includes production of forging dies, production of raw ingot, conventional forging, finish machining, and transportation over relatively large distances that are typical of a centralized manufacturing model.

(2) Conduct an environmental impact assessment for fabrication of a titanium part via Electron Beam Melting. The EBM model includes production of titanium powder, energy consumed in the EBM process, light finish machining, and transportation of a very short distance that would be typical of a distributed manufacturing model.

(3) Vary inputs to the models in order to evaluate the two models under differing conditions involving part size, buy-to-fly ratio, production quantities, and transportation distances.

(4) Analyze the results.

\subsection{Conclusions}

This study has supported the statement made by conventional and additive manufacturing publishers concerning the fact that additive manufacturing involves less material requirement, known as buy-to-fly ratio for aerospace companies, which can be translated in energy savings through the production. A detailed outline of most Centralized manufacturing and Additive manufacturing already published has been presented in Chapter 2. Among them includes electron beam melting in which a feedstock is used. The experiment included in this work is for electron beam melting in case powder is used. The experimentation had three major factors to look at: Production Quantity, Transportation Distance, and Buy-to-Fly ratio. However, not limited to forging energy factor and size of parts. 


\subsubsection{Centralized Manufacturing}

This thesis has been laid out to provide preliminary centralized manufacturing results for aluminum using an environmental impact model developed in SimaPro. The system model has been adapted for a titanium forging and finish machining process. For centralized manufacturing, production of the steel die dominates environmental impact for small production quantities. As production quantity increases, the Eco-Points generated by production the steel die are distributed over the number of parts produced. For example, there is an $86 \%$ decrease in EcoPoints per part generated as the lot size goes from 1 part to 1,000 parts. As production quantity rises, the dominant contributors to environmental impact are production of the titanium ingot as well as the finish machining operation. At a production quantity of 100 parts, titanium ingot production and machining accounts for $93-94 \%$ of the total Eco-Points generated depending on the buy-to-fly ratio. It logically follows that environmental impact increases significantly as buyto-fly ratio increases, since higher buy-to-fly ratio corresponds to the need for more raw material and more finish machining. One interesting result of the study was that the large transportation distances incurred as part of the centralized manufacturing model did not account for a significant percentage of the overall total environmental impact (less than $1 \%$ of the total EcoPoints). Likewise, the mode of overseas transportation, boat or airplane, only had a minor influence on the total number of Eco-Points generated. In short, production of the die was found to be the most important factor for very low production quantities of just a few parts, and ingot production and finish machining was found to be the most important factor for production quantities greater than a few parts.

\subsubsection{Distributed Manufacturing}

For distributed manufacturing, a completely new model was created, as no such model was available in SimaPro. In this model, parts are produced to near net shape via the Electron Beam Melting process. No molds or dies are needed, and the amount of finish machining and waste is small (i.e. low buy-to-fly ratio). Production is assumed to take place very close to the end customer. 
Simulation results indicated that production of titanium powder contributed the majority of Eco-Points (>90\%) under each of the distributed manufacturing scenarios. Two important factors for production of titanium powder, atomization energy and gas/metal flow ratio, were input to the model in terms of a min/max range of reasonable values. In order to assess whether or not the model output (Eco-Points) was sensitive to values for either/both parameter within their $\mathrm{min} / \mathrm{max}$ range, simulations were run at the extreme values for both parameters. For small parts $(1 \mathrm{~kg})$, the number of Eco-Points generated at the extreme values for atomization energy and gas/metal flow ratio ranged from a low of 2.93 to a high of 3.05. For large parts, the number of Eco-Points generated at the extreme values for atomization energy and gas/metal flow ratio ranged from a low of 135 to a high of 140 . The relatively small differences in values suggest that the model is not particularly sensitive to the value of atomization energy or gas/metal flow ratio.

Based on the Centralized Manufacturing model simulation results, it was seen that production of the steel die dominated at low production volumes. Since tooling is eliminated in the distributed manufacturing scenario, it is reasonable to expect that environmental impact will be lower for very small production volumes when distributed manufacturing is chosen. The data supports this assumption. Because there are no fixed tooling costs to amortize, the Eco-Points associated with production under distributed manufacturing are linearly related to the number of parts produced. For small $(1 \mathrm{~kg})$ parts, approximately 3 Eco-Points per part were generated under distributed manufacturing. By comparison, small forged and machined parts produced in large quantities (i.e. a "best case" scenario) produced approximately 36-61 Eco-Points per part depending on specifics such as low or high buy-to-fly ratio. Large parts produced via distributed manufacturing produced 135-140 Eco-Points per part versus 1646-2800 Eco-Points per part for large quantities of parts produced under centralized manufacturing. In summary, the distributed manufacturing scenario's that were examined produced approximately one order of magnitude fewer Eco-Points than the centralized manufacturing alternative at high production volumes. The disparity is even greater at small production volumes where the Eco-Points associated with tooling production are spread over fewer parts. 
Another interesting conclusion that can be drawn from the analysis is that the forging process itself contributes very little to the overall Eco-Points under the centralized manufacturing model. The titanium ingot production and subsequent machining are the dominant factors. At small production volumes where the cost of forging dies cannot be justified, it is typical to machine parts from solid bar or plate stock. In this case, the buy-to-fly ratio would be even higher. Based on the fact that ingot production and machining represent the majority of EcoPoints, it is a reasonable conclusion that production of parts via distributed manufacturing is favored over machining of bar or plate stock from an environmental perspective.

It is very important to stress the fact that this analysis did not consider the cost of producing parts. While it may be the case that environmental impact analysis favors distributed manufacturing, it is well understood that production rates of additive processes are very low. For that reason, additive processes such as EBM and laser deposition are not economically feasible for large production (tens of thousands or more per year) at this time unless the parts are extremely small.

\subsection{Future Work}

There are several areas of opportunity for future work. One opportunity for major improvements and further research would involve doing a full Life Cycle Analysis (LCA) case study for one or more specific parts. There are two specific areas that would provide interesting material for investigation.

The first area has to do with potential environmental impact improvements from redesign of parts to reduce weight. Because parts produced via additive manufacturing do not require molds or dies, nearly any geometric shape can be produced including internal channels. The literature includes several "design for additive manufacturing" case studies in which parts have been redesigned to reduce weight while still satisfying the original functional design requirements (i.e. strength, stiffness, etc). From an LCA perspective, weight reduction in aerospace or automotive components can dramatically reduce energy consumption and carbon emissions over the life of the vehicle. These sorts of savings are not reflected in the analysis done in this research. 
A second area for future work involves a study of logistics/supply chain opportunities associated with the distributed manufacturing model. When parts can be produced "on demand" close to the end user, the need fill warehouses with spare or replacement parts diminishes. Companies have millions of dollars tied up in finished goods inventories that they often don't recoup for years after production of the parts. Along with the cost of producing those parts, additional inventory carrying costs are incurred for heating of buildings, salaries, product obsolescence, etc. A valuable topic for study would entail analyzing the relative costs and cost savings associated with distributed "build on demand" versus "build to inventory" of spare/replacement parts.

One additional topic for future consideration would involve a more in-depth analysis of the effect of transportation modes and distances on environmental impact. For example, the model presented here considered transportation distances of $1 \mathrm{~km}$ and $1,000 \mathrm{~km}$ for the steel dies and forging ingots. A more comprehensive model could evaluate additional distance and mode of transportation scenarios. 


\section{References}

1. Ashby, M. F. (2009). Materials and the Environment: Eco-informed Material Choice, Elsevier, Burlington, MA.

2. Baumers, M., Tuck, C., Hague, R., Ashcroft, I., \& Wildman, R. (2010). A Comparative Study of Metallic Additive Manufacturing Power Consumption. Proceedings of the 2010 Solid Free Form Fabrication Symposium, Austin TX, pp. 278-288.

3. Dalquist, S., \& Gutowski, T. (2004). Life Cycle Analysis of Conventional Manufacturing Techniques: Sand Casting. The ASME International Mechanical Engineering Congress and RD\&D Exposition, Nov. 13-19, 2004, Anaheim, CA.

4. Dalquist, S., \& Gutowski, T. (2004). Life Cycle Analysis of Conventional Manufacturing Techniques: Die Casting. LMP-MIT-TGG-03-12-09-2004.

5. Desai, P.D. (1987). Thermodynamic Properties of Aluminum. International Journal of Thermophysics, 8(5), pp. 270-275.

6. Desmira, N., Narita, H., \& Fujimoto, H. (2009). A Minimization of Environmental Burden of High-Speed Milling. Service Robotics and Mechatronics, Part 19, pp. 367-372.

7. Groover, M. P. (2010). Fundamentals of Modern Manufacturing: Materials, Processes, and Systems, Wiley \& Sons, Danverse, MA.

8. Guo, Y.B., Wen, Q., \& Horstemeyer, M.F. (2005). An Internal State Variable PlasticityBased Approach to Determine Dynamic Loading History Effects on Material Property in Manufacturing Processes. International Journal of Mechanical Sciences, 47, 1423-1441.

9. Gutowski, T., \& Thiriez, A. (2006). An Environmental Analysis of Injection Molding. IEEE International Symposium on Electronics and the Environment, Scottsdale, AZ, May 8-11, 2006, pp. 195-200.

10. Hafley, R. A., Taminger, K. M. B., \& Bird, K. R. (2007). Electron Beam Freeform Fabrication in the Space Environment. American Institute of Aeronautics and Astronautics. Vol (AIAA 2007-1154). Reno, Nevada.

11. Hague, R., Campbell, I., \& Dickens, P. (2003). Implications on Design of Rapid Manufacturing. Mechanical Engineering Science, 217(1), pp. 25-30. 
12. He, J1, Li, D., Lu, B., Wang, Z., and Zhang, T. (2006) "Custom fabrication of a composite hemi-knee joint based on rapid prototyping". Emerald Group Publishing Limited. Rapid Prototyping Journal, 12(4), pp. 198-205.

13. Helms, H., \& Lambrecht, U. (2007). The Potential Contribution of Light-Weighting to Reduce Transport Energy Consumption. International Journal of Life-Cycle Assessment. 12(1), pp. 58-64.

14.Hieu, L.C. , Zlatov, N., Vander Sloten, J., Bohez, E., Khanh, L., Binh, P.H., Oris, P., and Toshev, Y. (2005) "Medical rapid prototyping applications and methods", Assembly Automation, Vol. 25 Iss: 4, pp.284-292.

15. Hopkinson, N., \& Dickens, P. (2003). “Analysis of Rapid Manufacturing-Using Layer Manufacturing Processes for Production", Proceedings of the Institute of Mechanical Engineers, Part C : Journal of Mechanical Engineering Science, 217 (C1), pp. 31-39.

16. Kaschnitz, E., Reiter, P., \& McClure, J. L. (2002) “Thermophysical Properties of Solid and Liquid 90Ti-6Al-4V in the Temperature Range from 1400 to $2300 \mathrm{~K}$ Measured by Millisecond and Microsecond Pulse-Heating Techniques", Int. J. Thermophys, 23(1), pp. 267-275.

17. Kuchi, S. C. (2009). Effect of Finite Geometry on Solidification Microstructure in BeamBased Fabrication of Thin Wall Structures (Master's thesis, Wright State University).

18. Loughborough University. (2007). ATKINS: Manufacturing a Low Carbon Footprint. ZEEFSReportN0012J.

19. Luo, Y., Ji, Z., Leu, M. C., \& Caudill, R. (1999) "Environmental Performance Analysis of Solid Freeform Fabrication Processes" IEEE International Symposium on Electronics and the Environment, Danvers, MA, USA, May 11, 1999, pp. 1-6.

20. Morrow, W., Qi, H., Kim, I., Mazumder, J., \& Skerlos, S. (2007) "Environmental aspects of laser-based and conventional tool and die manufacturing" Journal of Cleaner Production, 15, Issue 10, pp. 932-943.

21. Narita, H., Desmira, N., \& Fujimoto, H. (2008) "Environmental Burden Analysis for Machining Operation Using LCA Method" The 41st CIRP Conference on Manufacturing Systems. Part 2, pp. 65-68. 
22. Narita, H., \& Fujimoto, H. (2007) "Environmental Burden Analysis Due to High Speed Milling" 19th International Conference on Production Research. Japan, pp. 65-68.

23. Neto, B., Kroeze, C., Hordijk, L., \& Costa, C. (2008) "Modeling the environmental impact of an aluminium pressure die casting plant and options for control" Environmental Modelling \& Software, 23(2), pp. 147-168.

24. Ruffo, M., \& Hague, R. (2007) "Cost estimation for rapid manufacturing-simultaneous production of mixed components using laser sintering" Proceedings of the Institution of Mechanical Engineers, Part B: Journal of Engineering Manufacture, 221(11), pp. 15851591.

25. Ruffo, M., Tuck, C., \& Hague, R. (2006) "Cost estimation for rapid manufacturing - laser sintering production for low to medium volumes" Proceedings of the Institution of Mechanical Engineers, Part B: Journal of Engineering Manufacture, 220(9), pp. 1417-1427.

26. Sokovic, M., \& Mijanovic, K. (2001) "Ecological aspects of the cutting fluids and its infuence on quantifiable parameters of the cutting processes" Journal of Materials Processing Technology, 109(1-2), pp. 181-189.

27. Tang, X., Prakash, V., \& Lewandowski, J. (2006) "Dynamic Tensile Deformation of Aluminum Alloy 6061-T6 and 6061-OA" Proceedings of the 2006 SEM Annual Conference.

28. Traini, T., Mangano, C., Sammons, R.L., Mangano, F., Macchi, A., and Piatteli, A. (2008) "Direct laser metal sintering as a new approach to fabrication of an isoelastic functionally graded material for manufacture of porous titanium dental implants" Dental Materials, 24(11), pp. 1525-1533.

29. Treverton, J. A., \& Margrave, J. L. (1971) "Thermadynamic Properties by Levitation Calorimetry" J.Chem. Thermodynamics, 3(4), pp. 473-481.

30. Unal, A. (1987) "Effect of Processing Variables on Particle Size in Gas-Atomization of Rapidly Solidified Aluminum Powders" Materials Science and Technology, 3(11), pp. 10291039.

31. U.S. Environmental Protection Agency (1995) "Fabricated Metal Products Industry" EPA Office of Compliance Sector Notebook Project EPA/310-R-95-007. 
32. Walter, M., Holmstrom, J., \& Yrjola, H. (2004) "Rapid manufacturing and its impact on supply chain management" Logistics Research Network Annual Conference. Sept. 9-10, 2004, Dublin, Ireland.

33. Wehmoller, M., Warnke, P.H., Zilian, C. and Eufinger, H. (2005) "Implant design and production - a new approach by selective laser melting", Computer Assisted Radiology and Surgery, V 1281, pp. 690-695.

34. Xue, Q., Meyers, M. A., \& Nestenenko, V. F. (2002) "Self-organization of Shear Bands in Titanium and Ti-6Al-4V alloy" Acta Materialia, 50(3), pp. 575-596. 


\section{Appendices}

\section{Table 29 Sensitivity data analysis results: In case of a small part}

\begin{tabular}{|c|c|c|c|c|c|c|c|c|c|}
\hline & & & & \multicolumn{3}{|c|}{ Sensitivity data analysis results: In case of a small part } & & & \\
\hline SimaPro 7.2 & \multicolumn{2}{|c|}{ Process contribution } & & & SimaPro 7.2 & \multicolumn{2}{|c|}{ Process contribution } & & \\
\hline Project & \multicolumn{3}{|c|}{ Centralized manufacturing for an aluminum part } & & Project & \multicolumn{3}{|c|}{ Centralized manufacturing for an aluminum part } & \\
\hline Title & Analysis $1 \mathrm{p}^{\prime}$ & 'Final Part at Cust & tomer Location' & & Title & \multirow{2}{*}{\multicolumn{4}{|c|}{\begin{tabular}{|l} 
Analysis 1 p 'Final Part at Customer Location' \\
Eco-indicator 99 (E) V2.03 / Europe EI 99 E/A
\end{tabular}}} \\
\hline Method & \multicolumn{4}{|c|}{ Eco-indicator 99 (E) V2.03 / Europe EI $99 \mathrm{E} / \mathrm{A}$} & Method & & & & \\
\hline Indicator & Single score & & & & Indicator & Single score & & & \\
\hline Cutt-off & $0 \%$ & & & & Cutt-off & $0 \%$ & & & \\
\hline \multirow[t]{4}{*}{ Unit } & Pt & & & & Unit & $\mathrm{Pt}$ & & & \\
\hline & & \multicolumn{2}{|c|}{ Buy-to-Fly ratio: $12: 1$} & & & & \multicolumn{2}{|c|}{ Buy-to-Fly ratio: $20: 1$} & \\
\hline & Quadrant I & Quadrant I & Quadrant IV & Quadrant IV & & Quadrant II & Quadrant II & Quadrant III & Quadrant III \\
\hline & 1 part- $1 \mathrm{~km}$ & 1 part- $1000 \mathrm{Km}$ & 100 parts- $1 \mathrm{Km}$ & 100 parts $-1000 \mathrm{Km}$ & & 1 part- $1 \mathrm{Km}$ & 1 part- $1000 \mathrm{Km}$ & 100 parts- $1 \mathrm{Km}$ & 100 parts $-1000 \mathrm{Km}$ \\
\hline Total & 391.983 & 417.455 & 2208.336 & 2233.808 & Total & 653.29 & 695.409 & 3681.898 & 3724.017 \\
\hline steel Die & 373.631 & 394.108 & 373.631 & 394.108 & steel Die & 622.69 & 656.817 & 622.69 & 656.817 \\
\hline Al Ingots & 9.063 & 9.063 & 906.3 & 906.3 & Al Ingots & 15.105 & 15.105 & 1510.5 & 1510.5 \\
\hline Forging al I & 0.226 & 0.226 & 22.6 & 22.6 & Forging al I & 0.377 & 0.377 & 37.7 & 37.7 \\
\hline Milling al & 8.322 & 8.322 & 832.2 & 832.2 & Milling al & 14.374 & 14.374 & 1437.4 & 1437.4 \\
\hline Transp. by aircraft & 0.708 & 0.708 & 70.8 & 70.8 & Transp. by aircraft & 0.708 & 0.708 & 70.8 & 70.8 \\
\hline Truck 28t & 0.028 & 0.028 & 2.8 & 2.8 & Truck 28t & 0.028 & 0.028 & 2.8 & 2.8 \\
\hline \multirow[t]{3}{*}{ Truck $28 \mathrm{t}$} & 0.005 & 5 & 0.005 & 5 & Truck 28t & 0.008 & 8 & 0.008 & 8 \\
\hline & & & & & & & & & \\
\hline & 1 part- $1 \mathrm{~km}$ & 1 part- $1000 \mathrm{Km}$ & 100 parts- $1 \mathrm{Km}$ & 100 parts- $1000 \mathrm{Km}$ & & 1 part- $1 \mathrm{Km}$ & 1 part-1000Km & 100 parts- $1 \mathrm{Km}$ & 100 parts- $1000 \mathrm{Km}$ \\
\hline Total & 391.31 & 416.782 & 2141.036 & 2166.508 & Total & 652.617 & $\begin{array}{r}694.736 \\
\end{array}$ & 3614.598 & 3656.717 \\
\hline steel Die & 373.631 & 394.108 & 373.631 & 394.108 & steel Die & 622.69 & 656.817 & 622.69 & 656.817 \\
\hline Al Ingots & 9.063 & 9.063 & 906.3 & 906.3 & Al Ingots & 15.105 & 15.105 & 1510.5 & 1510.5 \\
\hline Forging al I & 0.226 & 0.226 & 22.6 & 22.6 & Forging al I & 0.377 & 0.377 & 37.7 & 37.7 \\
\hline Milling al & 8.322 & 8.322 & 832.2 & 832.2 & Milling al & 14.374 & 14.374 & 1437.4 & 1437.4 \\
\hline Transp. by boat & 0.007 & 0.007 & 0.7 & 0.7 & Transp. by boat & 0.007 & 0.007 & 0.7 & 0.7 \\
\hline Truck 28t & 0.056 & 0.056 & 5.6 & 5.6 & Truck 28t & 0.056 & 0.056 & 5.6 & 5.6 \\
\hline Truck $28 \mathrm{t}$ & 0.005 & 5 & 0.005 & 5 & Truck 28t & 0.008 & 8 & 0.008 & 8 \\
\hline
\end{tabular}




\section{Table 30 Sensitivity data analysis results: In case of a large part}

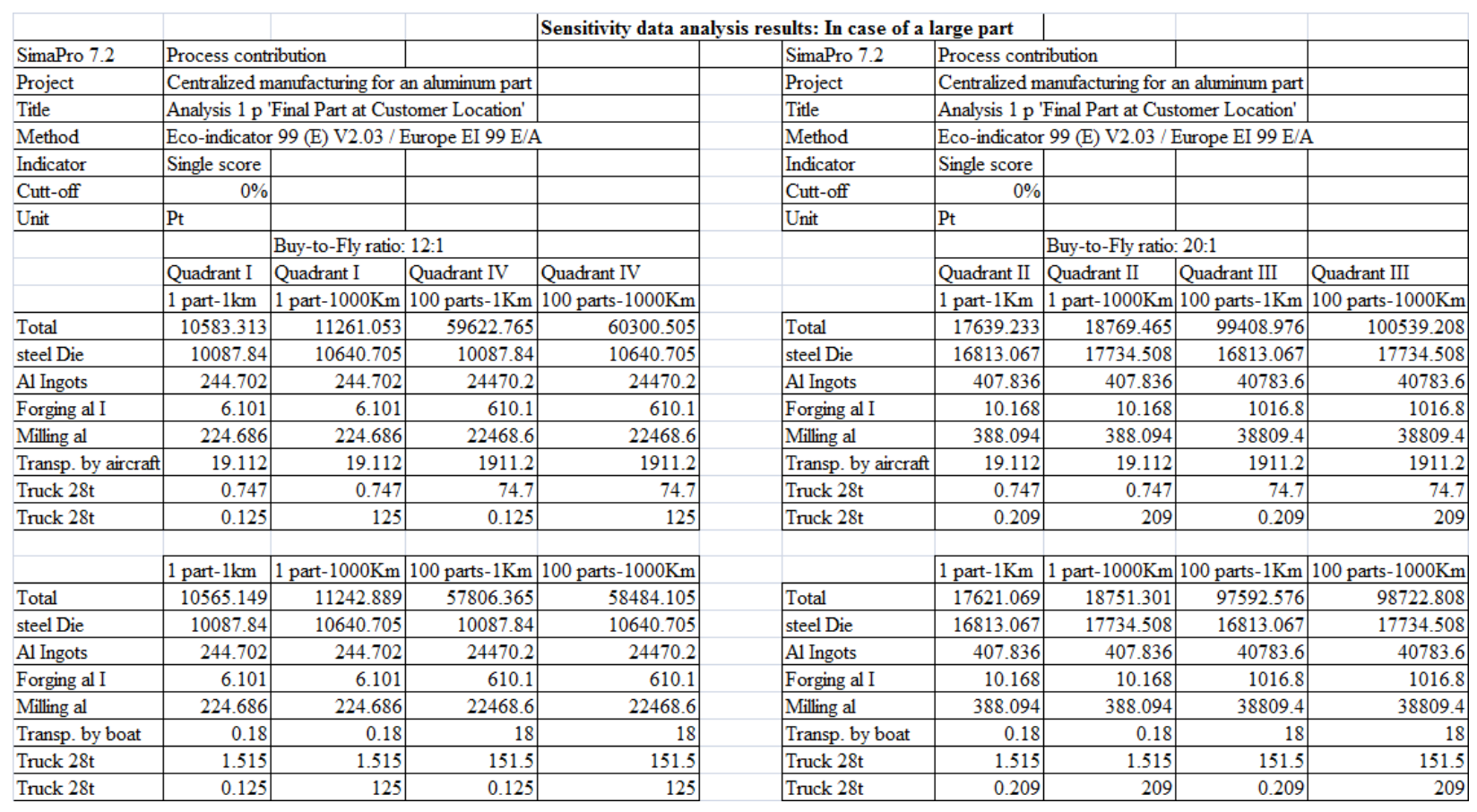

\section{Table 31 Sensitivity data analysis results: In case of a small part}

\begin{tabular}{|c|c|c|c|c|c|c|c|c|c|}
\hline & & & & \multicolumn{3}{|c|}{ Sensitivity data analysis results: In case of a small part } & & & \\
\hline SimaPro 7.2 & \multicolumn{2}{|c|}{ Process contribution } & & & SimaPro 7.2 & \multicolumn{2}{|c|}{ Process contribution } & & \\
\hline Project & \multicolumn{3}{|c|}{ Centralized manufacturing for a Ti-6Al-4V part } & & Project & \multicolumn{3}{|c|}{ Centralized manufacturing for a Ti-6Al-4V part } & \\
\hline Title & \multicolumn{3}{|c|}{ Analysis $1 \mathrm{p}$ 'Final Part at Customer Location' } & & Title & \multicolumn{3}{|c|}{ Analysis $1 \mathrm{p}$ 'Final Part at Customer Location' } & \\
\hline Method & \multicolumn{4}{|c|}{ Eco-indicator 99 (E) V2.03 / Europe EI 99 E/A } & Method & \multicolumn{4}{|c|}{ Eco-indicator 99 (E) V2.03 / Europe EI 99 E/A } \\
\hline Indicator & Single score & & & & Indicator & Single score & & & \\
\hline Cutt-off & $0 \%$ & & & & Cutt-off & $0 \%$ & & & \\
\hline \multirow[t]{4}{*}{ Unit } & $\mathrm{Pt}$ & & & & Unit & $\mathrm{Pt}$ & & & \\
\hline & & \multicolumn{2}{|c|}{ Buy-to-Fly ratio: $12: 1$} & & & & \multicolumn{2}{|c|}{ Buy-to-Fly ratio: $20: 1$} & \\
\hline & Quadrant I & Quadrant I & Quadrant IV & Quadrant IV & & Quadrant II & Quadrant II & Quadrant III & Quadrant III \\
\hline & 1 part- $1 \mathrm{~km}$ & 1 part- $1000 \mathrm{Km}$ & 100 parts $-1 \mathrm{Km}$ & 100 parts- $1000 \mathrm{Km}$ & & 1 part- $1 \mathrm{Km}$ & 1 part- $1000 \mathrm{Km}$ & 100 parts $-1 \mathrm{Km}$ & 100 parts- $1000 \mathrm{Km}$ \\
\hline Total & 255.38443 & 270.1117 & 3857.17273 & 3871.9 & Total & 425.61725 & 451.1627 & 6426.27455 & 6451.82 \\
\hline steel Die & 219 & 231 & 219 & 231 & steel Die & 365 & 386 & 365 & 386 \\
\hline Titanium cast & 27.1 & 27.1 & 2710 & 2710 & \begin{tabular}{|l|} 
Titanium cast \\
\end{tabular} & 45.1 & 45.1 & 4510 & 4510 \\
\hline Forging $\mathrm{Ti}$ & 0.226 & 0.226 & 22.6 & 22.6 & Forging $\mathrm{Ti}$ & 0.377 & 0.377 & 37.7 & 37.7 \\
\hline Milling $\mathrm{Ti}$ & 8.32 & 8.32 & 832 & 832 & Milling Ti & 14.4 & 14.4 & 1440 & 1440 \\
\hline Transp. by aircraft & 0.708 & 0.708 & 70.8 & 70.8 & Transp. by aircraft & 0.708 & 0.708 & 70.8 & 70.8 \\
\hline Truck $28 \mathrm{t}$ & 0.0277 & 0.0277 & 2.77 & 2.77 & Truck 28t & 0.0277 & 0.0277 & 2.77 & 2.77 \\
\hline \multirow[t]{3}{*}{ Truck 28t } & 0.00273 & 2.73 & 0.00273 & 2.73 & Truck 28t & 0.00455 & 4.55 & 0.00455 & 4.55 \\
\hline & & & & & & & & & \\
\hline & 1 part- $1 \mathrm{~km}$ & 1 part- $1000 \mathrm{Km}$ & 100 parts- $1 \mathrm{Km}$ & 100 parts- $1000 \mathrm{Km}$ & & 1 part- $1 \mathrm{Km}$ & 1 part- $1000 \mathrm{Km}$ & 100 parts- $1 \mathrm{Km}$ & 100 parts $-1000 \mathrm{Km}$ \\
\hline Total & 254.7115 & 269.43877 & 3789.87973 & 3804.607 & Total & 424.94432 & 450.48977 & 6358.98155 & 6384.527 \\
\hline steel Die & 219 & 231 & 219 & 231 & steel Die & 365 & 386 & 365 & 386 \\
\hline Titanium cast & 27.1 & 27.1 & 2710 & 2710 & Titanium cast & 45.1 & 45.1 & 4510 & 4510 \\
\hline Forging $\mathrm{Ti}$ & 0.226 & 0.226 & 22.6 & 22.6 & Forging $\mathrm{Ti}$ & 0.377 & 0.377 & 37.7 & 37.7 \\
\hline Milling $\mathrm{Ti}$ & 8.32 & 8.32 & 832 & 832 & Milling $\mathrm{Ti}$ & 14.4 & 14.4 & 1440 & 1440 \\
\hline Transp. by boat & 0.00667 & 0.00667 & 0.667 & 0.667 & Transp. by boat & 0.00667 & 0.00667 & 0.667 & 0.667 \\
\hline Truck $28 \mathrm{t}$ & 0.0561 & 0.0561 & 5.61 & 5.61 & Truck 28t & 0.0561 & 0.0561 & 5.61 & 5.61 \\
\hline Truck $28 \mathrm{t}$ & 0.00273 & 2.73 & 0.00273 & 2.73 & Truck 28t & 0.00455 & 4.55 & 0.00455 & 4.55 \\
\hline
\end{tabular}


Table 32 Sensitivity data analysis results: In case of a large part

\begin{tabular}{|c|c|c|c|c|c|c|c|c|c|}
\hline & & & & \multicolumn{3}{|c|}{ Sensitivity data analysis results: In case of a large part } & & & \\
\hline SimaPro 7.2 & \multicolumn{2}{|c|}{ Process contribution } & & & SimaPro 7.2 & \multicolumn{2}{|c|}{ Process contribution } & & \\
\hline Project & \multicolumn{3}{|c|}{ Centralized manufacturing for a Ti-6Al-4V part } & & Project & \multicolumn{3}{|c|}{ Centralized manufacturing for a Ti- $6 \mathrm{Al}-4 \mathrm{~V}$ part } & \\
\hline Title & \multicolumn{3}{|c|}{ Analysis 1 p 'Final Part at Customer Location' } & & Title & \multicolumn{3}{|c|}{ Analysis $1 \mathrm{p}$ 'Final Part at Customer Location' } & \\
\hline Method & \multicolumn{4}{|c|}{ Eco-indicator 99 (E) V2.03 / Europe EI 99 E/A } & Method & \multicolumn{4}{|c|}{ Eco-indicator 99 (E) V2.03 / Europe EI 99 E/A } \\
\hline Indicator & Single score & & & & Indicator & Single score & & & \\
\hline Cutt-off & $0 \%$ & & & & Cutt-off & $0 \%$ & & & \\
\hline \multirow[t]{4}{*}{ Unit } & Pt & & & & Unit & $\mathrm{Pt}$ & & & \\
\hline & & \multicolumn{2}{|c|}{ Buy-to-Fly ratio: $12: 1$} & & & & \multicolumn{2}{|c|}{ Buy-to-Fly ratio: $20: 1$} & \\
\hline & Quadrant I & Quadrant I & Quadrant IV & Quadrant IV & & Quadrant II & Quadrant II & Quadrant III & Quadrant III \\
\hline & 1 part- $1 \mathrm{~km}$ & 1 part- $1000 \mathrm{Km}$ & 100 parts $-1 \mathrm{Km}$ & 100 parts- $1000 \mathrm{Km}$ & & 1 part- $1 \mathrm{Km}$ & 1 part- $1000 \mathrm{Km}$ & 100 parts $-1 \mathrm{Km}$ & 100 parts- $1000 \mathrm{Km}$ \\
\hline Total & 11767.395 & 12392.27 & 176827.125 & 177452 & Total & 19582.379 & 20691.17 & 295017.209 & 296126 \\
\hline steel Die & 10100 & 10600 & 10100 & 10600 & steel Die & 16800 & 17700 & 16800 & 17700 \\
\hline Titanium cast & 1240 & 1240 & 124000 & 124000 & \begin{tabular}{|l|} 
Titanium cast \\
\end{tabular} & 2070 & 2070 & 207000 & 207000 \\
\hline Forging $\mathrm{Ti}$ & 10.4 & 10.4 & 1040 & 1040 & Forging $\mathrm{Ti}$ & 17.3 & 17.3 & 1730 & 1730 \\
\hline Milling $\mathrm{Ti}$ & 383 & 383 & 38300 & 38300 & Milling $\mathrm{Ti}$ & 661 & 661 & 66100 & 66100 \\
\hline Transp. by aircraft & 32.6 & 32.6 & 3260 & 3260 & Transp. by aircraft & 32.6 & 32.6 & 3260 & 3260 \\
\hline \begin{tabular}{|l|l} 
Truck 28t \\
\end{tabular} & 1.27 & 1.27 & 127 & 127 & Truck 28t & 1.27 & 1.27 & 127 & 127 \\
\hline \multirow[t]{3}{*}{ Truck $28 \mathrm{t}$} & 0.125 & 125 & 0.125 & 125 & Truck 28t & 0.209 & 209 & 0.209 & 209 \\
\hline & & & & & & & & & \\
\hline & 1 part- $1 \mathrm{~km}$ & 1 part- $1000 \mathrm{Km}$ & 100 parts $-1 \mathrm{Km}$ & 100 parts $-1000 \mathrm{Km}$ & & 1 part- $1 \mathrm{Km}$ & 1 part- $1000 \mathrm{Km}$ & 100 parts- $1 \mathrm{Km}$ & 100 parts- $1000 \mathrm{Km}$ \\
\hline Total & 11736.412 & 12361.287 & 173728.825 & 174353.7 & Total & 19551.396 & 20660.187 & 291918.909 & 293027.7 \\
\hline steel Die & 10100 & 10600 & 10100 & 10600 & steel Die & 16800 & 17700 & 16800 & 17700 \\
\hline Titanium cast & 1240 & 1240 & 124000 & 124000 & \begin{tabular}{|l|} 
Titanium cast \\
\end{tabular} & 2070 & 2070 & 207000 & 207000 \\
\hline Forging $\mathrm{Ti}$ & 10.4 & 10.4 & 1040 & 1040 & Forging $\mathrm{Ti}$ & 17.3 & 17.3 & 1730 & 1730 \\
\hline Milling $\mathrm{Ti}$ & 383 & 383 & 38300 & 38300 & Milling $\mathrm{Ti}$ & 661 & 661 & 66100 & 66100 \\
\hline Transp. by boat & 0.307 & 0.307 & 30.7 & 30.7 & Transp. by boat & 0.307 & 0.307 & 30.7 & 30.7 \\
\hline Truck $28 \mathrm{t}$ & 2.58 & 2.58 & 258 & 258 & Truck 28t & 2.58 & 2.58 & 258 & 258 \\
\hline Truck 28t & 0.125 & 125 & 0.125 & 125 & Truck 28t & 0.209 & 209 & 0.209 & 209 \\
\hline
\end{tabular}

\section{Table 33 Sensitivity data analysis results: Distributed manufacturing}

\begin{tabular}{|c|c|c|c|c|c|c|c|c|c|}
\hline & & & & \multicolumn{4}{|c|}{ Sensitivity data analysis results: In case of a small part and a large part } & & \\
\hline SimaPro 7.2 & \multicolumn{2}{|c|}{ Process contribution } & & & SimaPro 7.2 & \multicolumn{2}{|c|}{ Process contribution } & & \\
\hline Project & \multicolumn{4}{|c|}{ Distributed manufacturing for a Ti-6Al-4V part (Small part) } & Project & \multicolumn{4}{|c|}{ Distributed manufacturing for a Ti-6Al-4V part (Large part) } \\
\hline Title & \multicolumn{3}{|c|}{ Analysis $1 \mathrm{p}$ 'Final Part at Customer Location' } & & Title & \multicolumn{3}{|c|}{ Analysis 1 p 'Final Part at Customer Location' } & \\
\hline Method & \multicolumn{3}{|c|}{ Eco-indicator 99 (E) V2.03 / Europe EI 99 E/A } & & Method & \multicolumn{4}{|c|}{ Eco-indicator 99 (E) V2.03 / Europe EI 99 E/A } \\
\hline Indicator & Single score & & & & Indicator & Single score & & & \\
\hline Cutt-off & $0 \%$ & & & & Cutt-off & $0 \%$ & & & \\
\hline \multirow[t]{4}{*}{ Unit } & $\mathrm{Pt}$ & & & & Unit & $\mathrm{Pt}$ & & & \\
\hline & & \multicolumn{3}{|c|}{ Buy-to-Fly ratio: $1.03: 1$ - Travel distance $1 \mathrm{~km}$} & & & \multicolumn{3}{|c|}{ Buy-to-Fly ratio: $1.03: 1$ - Travel distance $1 \mathrm{~km}$} \\
\hline & Low flow rate & Low flow rate & High flow rate & High flow rate & & Low flow rate $\mathrm{I}$ & Low flow rate & High flow rate & High flow rate \\
\hline & Low energy & High energy & low energy & High energy & & Low energy 1 & High energy & low energy & High energy \\
\hline Total & 2.72 & 2.93 & 3.05 & 3.25 & Total & 125 & 135 & 140 & 149 \\
\hline Gas-atomization & 2.51 & 2.71 & 2.83 & 3.03 & Gas-atomization & 115 & 125 & 130 & 140 \\
\hline Electron Beam Melting & 0.145 & 0.145 & 0.145 & 0.145 & Electron Beam Melting & 6.67 & 6.67 & 6.67 & 6.67 \\
\hline Milling Ti average & 0.0702 & 0.0702 & 0.0702 & 0.0702 & Milling $\mathrm{Ti}$ average & 3.23 & 3.23 & 3.23 & 3.23 \\
\hline Truck 28t & 0.0000148 & 0.0000148 & 0.0000148 & 0.0000148 & Truck 28t & 0.000681 & 0.000681 & 0.000681 & 0.000681 \\
\hline
\end{tabular}

